\title{
Physicochemical properties of Alaska Pollock (Theragra chalcogramma) surimi seafood nutrified with powdered cellulose fiber and omega-3 polyunsaturated fatty acidS
}

\author{
Alicia Debusca \\ West Virginia University
}

Follow this and additional works at: https://researchrepository.wvu.edu/etd

\section{Recommended Citation \\ Debusca, Alicia, "Physicochemical properties of Alaska Pollock (Theragra chalcogramma) surimi seafood nutrified with powdered cellulose fiber and omega-3 polyunsaturated fatty acidS" (2012). Graduate Theses, Dissertations, and Problem Reports. 3537. \\ https://researchrepository.wvu.edu/etd/3537}

This Thesis is protected by copyright and/or related rights. It has been brought to you by the The Research Repository @WVU with permission from the rights-holder(s). You are free to use this Thesis in any way that is permitted by the copyright and related rights legislation that applies to your use. For other uses you must obtain permission from the rights-holder(s) directly, unless additional rights are indicated by a Creative Commons license in the record and/ or on the work itself. This Thesis has been accepted for inclusion in WVU Graduate Theses, Dissertations, and Problem Reports collection by an authorized administrator of The Research Repository @ WVU. For more information, please contact researchrepository@mail.wvu.edu. 


\title{
PHYSICOCHEMICAL PROPERTIES OF ALASKA POLLOCK (THERAGRA CHALCOGRAMMA) SURIMI SEAFOOD NUTRIFIED WITH POWDERED CELLULOSE FIBER AND OMEGA-3 POLYUNSATURATED FATTY ACIDS
}

\author{
Alicia Debusca \\ Thesis submitted to the \\ Davis College of Agriculture, Natural Resources and Design \\ at West Virginia University \\ in partial fulfillment of the requirements \\ for the degree of \\ Master of Science \\ in \\ Animal and Nutritional Sciences \\ Jacek Jaczynski, Ph.D., Chair \\ Kristen E. Matak, Ph.D. \\ Susan Partington, Ph.D., R.D. \\ Department of Animal and Nutritional Sciences
}

Morgantown, West Virginia

2012

Keywords: Surimi seafood, functional food, nutraceutical food, dietary fiber, powdered cellulose, omega-3 polyunsaturated fatty acids, menhaden oil, algae oil, flaxseed oil, potassium chloride, salt substitute 


\title{
ABSTRACT \\ Physicochemical properties of Alaska Pollock (Theragra chalcogramma) surimi seafood nutrified with powdered cellulose fiber and omega-3 polyunsaturated fatty acids
}

\begin{abstract}
Alicia Debusca
Surimi is minced deboned fish meat that has been washed of lipids, sarcoplasmic proteins, and other impurities. Surimi seafood, also known as "imitation crabmeat", is widely enjoyed in the United States; however, it is not currently nutrified with fiber, omega-3 polyunsaturated fatty acids, and salt substitute. In the present study, preliminary experimentation was done to determine the optimal level of fiber addition. Powdered cellulose was added to Alaska Pollock surimi gels at levels of $0 \%$ (control), $2 \%, 4 \%, 6 \%$, and $8 \%$ fiber. The objectives of this initial study were to determine effect of dietary fiber on 1) color and textural properties and 2) endothermic transitions and gelation properties of surimi gels. Increased fiber up to $6 \%$ resulted in higher gel strength; however, detrimental effects were seen with $8 \%$ fiber, thus $6 \%$ fiber was chosen for use. After determining optimal fiber concentration, Alaska Pollock surimi gels were formulated containing 6\% powdered cellulose fiber, 10\% omega-3-rich oil (flax seed oil, algae oil, and menhaden oil in a 8:1:1 ratio), and potassium chloride $(\mathrm{KCl})$ as a salt substitute.

Treatments included a control (with no fiber or oil), $6 \%$ fiber, $10 \%$ oil, and fiber/oil (6\% fiber + $10 \%$ oil). The objective of this study was to analyze the effects of added dietary fiber and $\omega-3$ oil and their interactions with surimi. Surimi gel whiteness decreased $(\mathrm{P}<0.05)$ with fiber, oil, and fiber/oil treatments due to increased $(\mathrm{P}<0.05) \mathrm{b}^{*}$ with oil addition and decreased $(\mathrm{P}<0.05) \mathrm{a}^{*}$ with fiber addition and oil addition. Total TPA and Kramer shear force increased $(\mathrm{P}<0.05)$ with the fiber/oil treatment indicating increased gel strength. Torsion shear stress and strain increased $(\mathrm{P}<0.05)$ with the fiber treatment and oil treatment. Viscoelasticity $\left(\mathrm{G}^{\prime}\right)$ increased with the fiber/oil treatment. Addition of both fiber and oil to surimi (fiber/oil treatment) increased the gel strength and resulted in a quality product that could be useful for manufacturers in developing a nutraceutical surimi product.
\end{abstract}




\section{ACKNOWLEDGEMENTS}

I would first and foremost like to acknowledge and thank Dr. Jacek Jaczynski for his guidance during this journey toward earning a Master's degree. I appreciate all of his support, encouragement, and answers to questions as I completed my research. I am also grateful for his patience and prodding during the writing process. Without his guidance, I would still be at square one.

I would also like to extend my gratitude to my committee members, Dr. Kristen Matak and Dr. Susan Partington. I appreciate their expertise and support in this process and for the privilege of being their student. Thank you to Dr. P. Brett Kenney for making his laboratory and equipment available for use with my research. Thank you to Susan Slider for the use of her laboratory equipment. I would also like to extend a big thank you to Reza Tahergorabi for taking me under his wing in the lab, teaching me how to use the equipment, and helping me understand the research process. Thank you to Sarah Beamer for helping me feel comfortable in the lab and for being there whenever I had a question or concern.

Last, but not least, I would like to thank my family and friends. I would like to thank my husband, David Debusca, for his endless support and patience during my bouts of frustration and anxiety. I am so grateful for his loving encouragement and also for his technical assistance in the formatting of this paper. I would like to thank my fellow interns (Jordan Bryan, Maria Dalzot, and Christin Sell) for listening to my complaints and concerns. They have been a great support throughout this process. Finally, I would like to thank my family for their endless support and faith in me. Thank you! 


\section{TABLE OF CONTENTS}

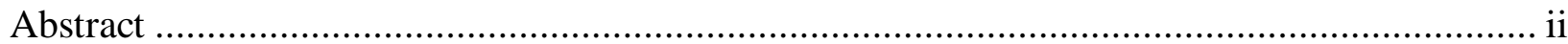

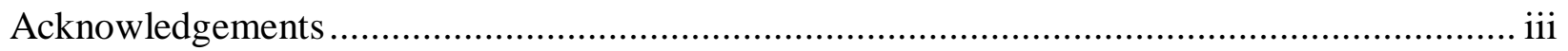

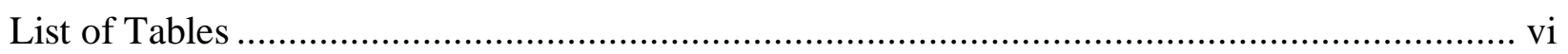

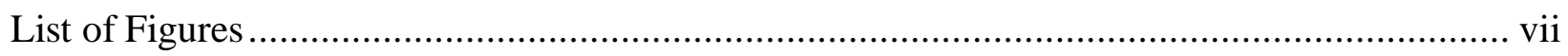

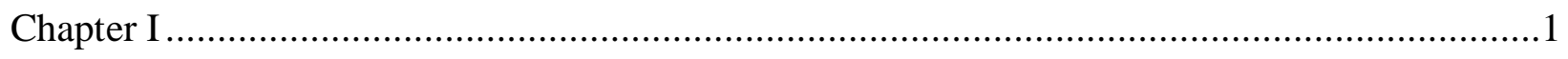

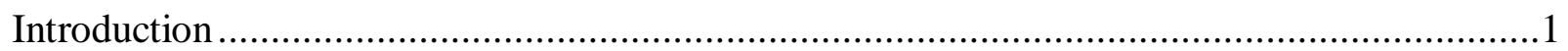

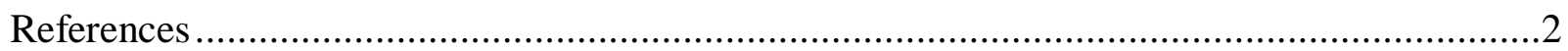

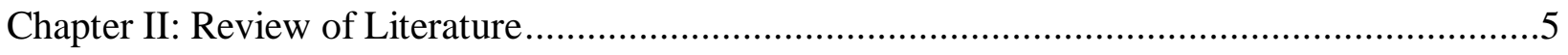

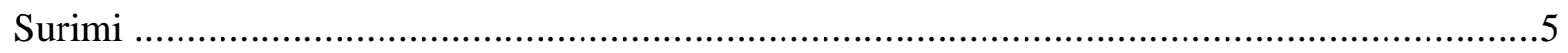

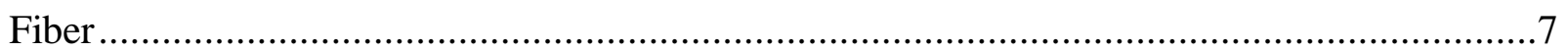

Omega-3 Polyunsaturated Fatty Acids .............................................................. 12

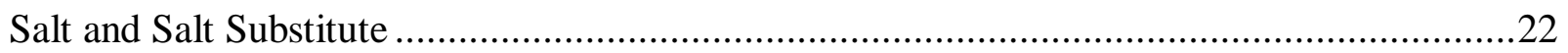

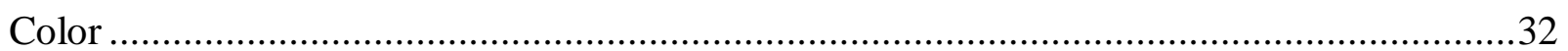

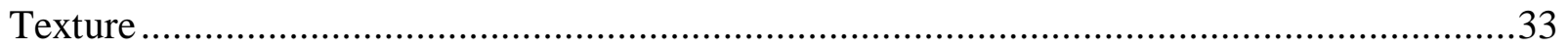

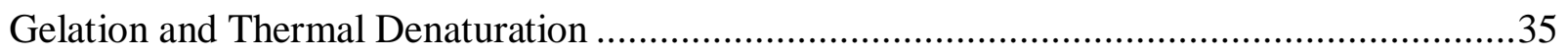

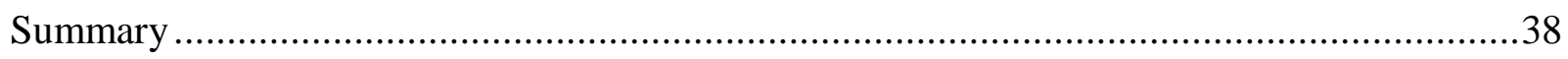

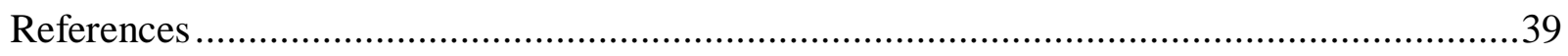

Chapter III: Pysicochemical Properties of Surimi Nutrified with Dietary Fiber .......................49

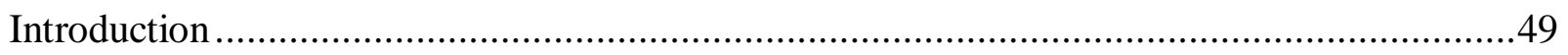

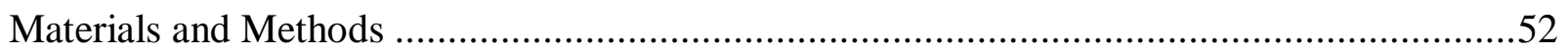

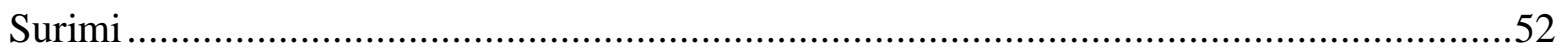

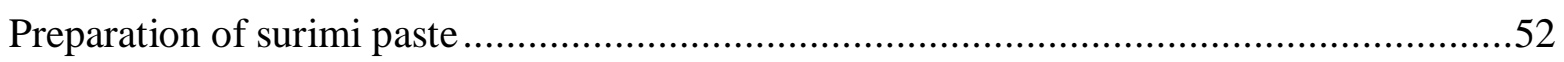

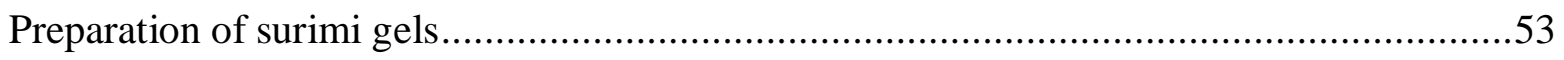

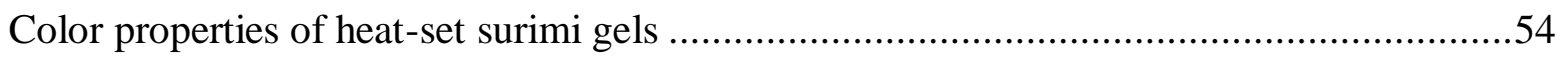

Texture properties of heat-set surimi gels .............................................................54

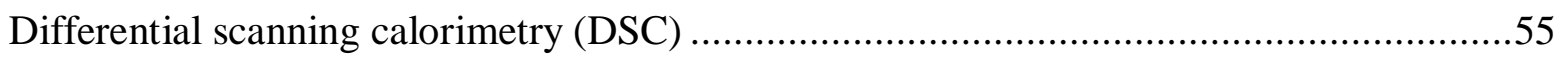

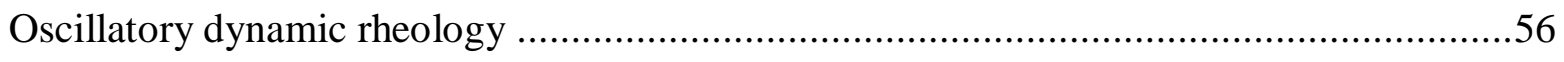

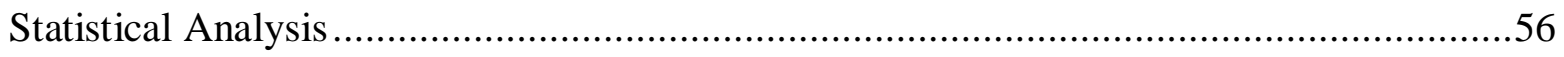

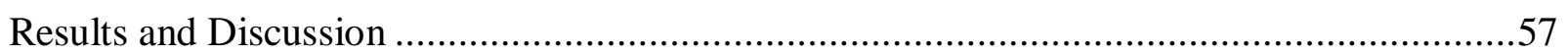

Color properties of heat-set surimi gels .............................................................57

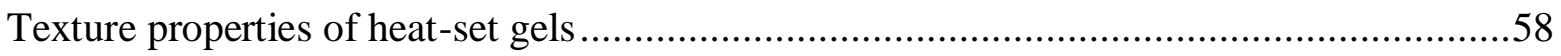

Differential scanning calorimetry (DSC) .............................................................6 61

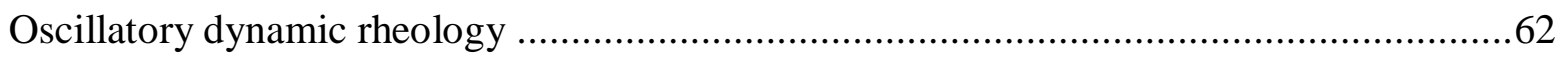




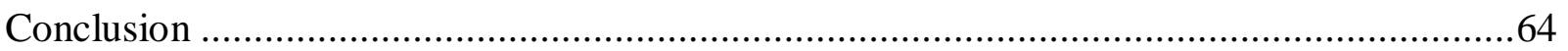

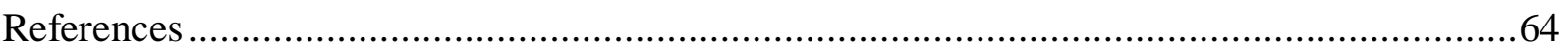

Chapter IV: Interactions of Dietary Fiber and Omega-3-Rich Oils with Protein in Surimi Gels .69

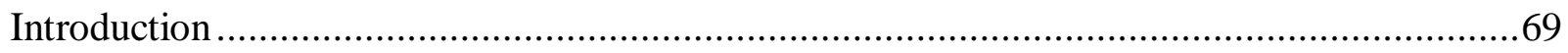

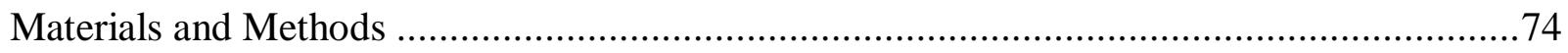

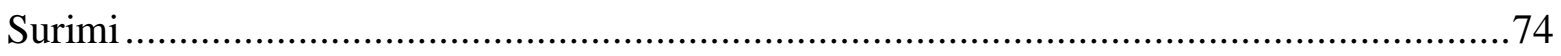

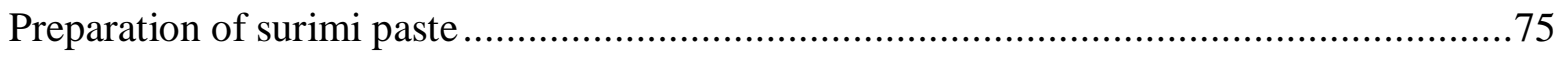

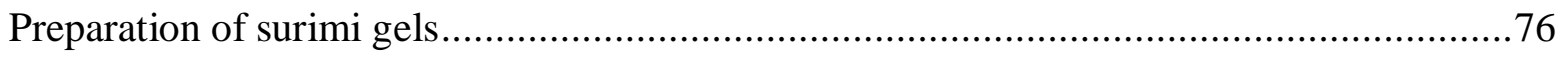

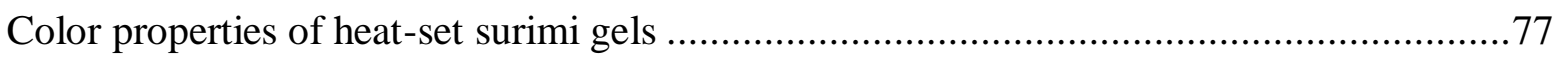

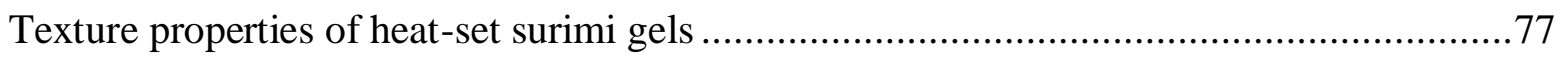

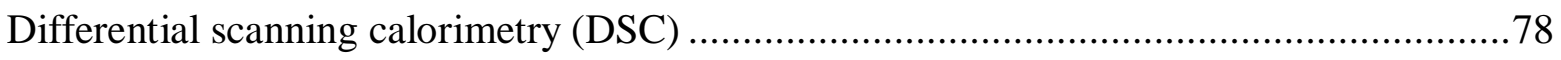

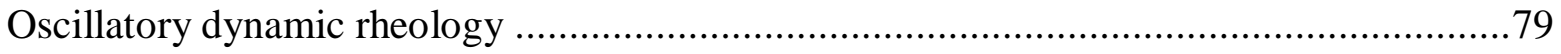

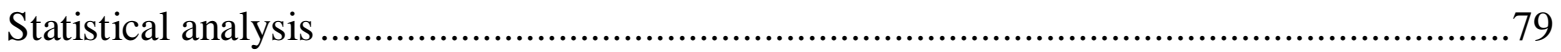

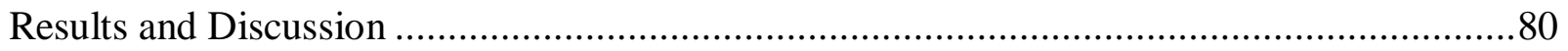

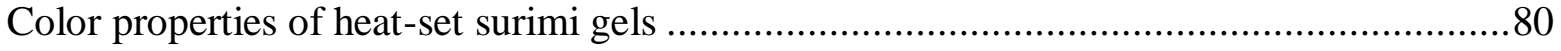

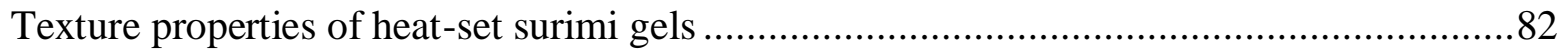

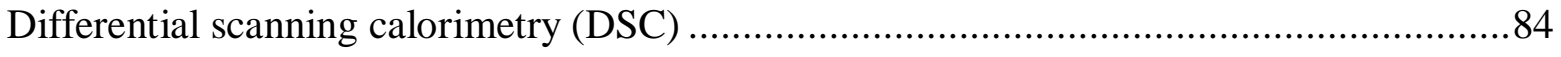

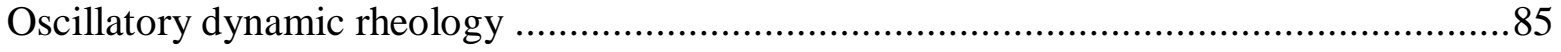

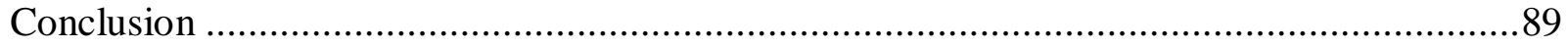

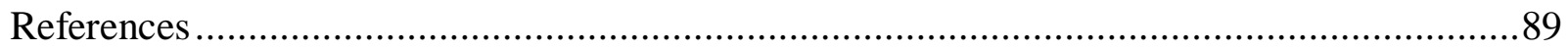

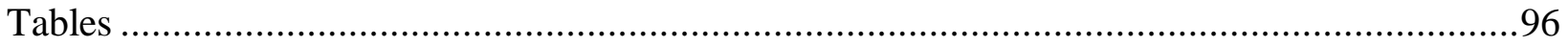

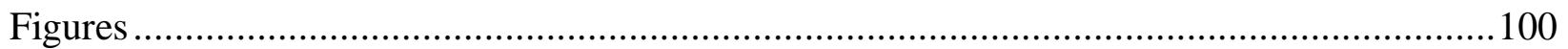




\section{LIST OF TABLES}

Table 1. Final surimi batter formulations. Batters with different levels of fiber were formulated to contain $78 \%$ moisture and equal amount of protein, water, salt, and water-based crab flavor by using inert filler, silicon dioxide $\left(\mathrm{SiO}_{2}\right)$. Batch size was $1000 \mathrm{~g}$ .96

Table 2. Effect of fiber on texture profile analysis* (TPA) of surimi gels.

Table 3. Final surimi batter formulations. Batters were formulated to contain equal amount of protein (i.e., surimi) and salt substitute. Silicon dioxide $\left(\mathrm{SiO}_{2}\right)$ was used as inert filler in place of

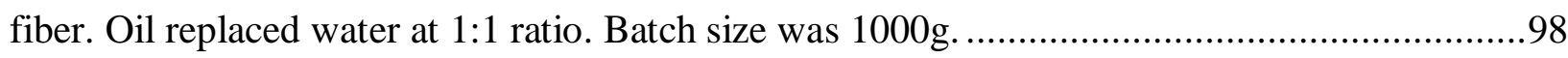

Table 4. Effect of nutraceutical additives on texture profile analysis* (TPA) of surimi gels. .....99 


\section{LIST OF FIGURES}

Figure 1. Effect of fiber on whiteness values* (top) and color properties* (bottom) of surimi gels.

Figure 2. Effect of fiber on torsion shear stress and strain* at mechanical fracture of surimi gels

(• - shear stress; ○ - shear strain).

Figure 3. Effect of fiber on Kramer shear force* (top) and hardness* (bottom) of surimi gels. 102

Figure 4. Average $(n=3)$ elastic moduli $\left(G^{\prime}\right.$, top graph) and differential scanning calorimetry (DSC) thermograms (bottom graph) of surimi pastes with different levels of added fiber. 103

Figure 5. Effect of nutraceutical additives on whiteness values* (top) and color properties* (bottom) of surimi gels. 104

Figure 6. Effect of nutraceutical additives on torsion shear stress and strain* at mechanical fracture of surimi gels $(\bullet-$ shear stress; $\bigcirc-$ shear strain $)$. 105

Figure 7. Effect of nutraceutical additives on Kramer shear force* (top) and hardness* (bottom) of surimi gels. .106

Figure 8. Average $(n=3)$ differential scanning calorimetry (DSC) thermograms of surimi pastes with added nutraceutical additives.

Figure 9. Average $(n=3)$ elastic moduli $\left(G^{\prime}\right)$ of surimi pastes with added nutraceutical additives. .108 


\section{CHAPTER I}

\section{Introduction}

Surimi is defined as an intermediate product used in the production of seafood analogues and consists of myofibrillar fish protein that has been deboned and washed of lipids, sarcoplasmic proteins, and other impurities (Hall, 2011). Surimi was traditionally a Japanese product until the 1970s, after which both production and consumption expanded (Mansfield, 2003). Around that time, surimi was first introduced to North America where it is known as "imitation crabmeat" (Park, 2005). Consumption in the United States has continued to steadily increase over the years (Park, 2005). The popularity remains high and continues to grow possibly due to the low-cholesterol, low-fat, and high nutrient content of surimi seafood (Campo \& Tovar, 2008).

Due to its low fat content, nutritional quality, and highly functional myofibrillar proteins, surimi is a logical vehicle for functional additives. The market for functional foods is becoming increasingly popular worldwide. Functional foods are those that contain added, technologically developed ingredients with specific health benefits (Siró, Kápolna, Kápolna, \& Lugasi, 2008). Both fiber and omega-3 polyunsaturated fatty acids (PUFAs) are accepted to be physiologically beneficial. Studies have shown that a high intake of dietary fiber is protective against coronary heart disease, diabetes, obesity, and intestinal disorders (Anderson et al., 2009). Omega-3 PUFAs, especially eicosapentaenoic acid (EPA, 20:5n3) and docosahexaenoic acid (DHA, 22:6n3), are associated with improvement of cardiovascular measures, including decreased triglycerides, total cholesterol, and low density lipoprotein (LDL) cholesterol, and increased high density lipoprotein (HDL) cholesterol (Juturu, 2008; Nair, Leitch, Falconer, \& Garg, 1997; 
Narayan, Miyashita, \& Hosakawa, 2006). In addition to fiber and omega-3 polyunsaturated fatty acids, salt substitute in the form of potassium chloride $(\mathrm{KCl})$ has been shown to reduce hypertension by replacing sodium chloride $(\mathrm{NaCl})$ in the diet and by the physiologically beneficial effects of increased potassium intake itself (Houston, 2011; Matsui et al., 2006; Van Mierlo, Greyling, Zock, Kok, \& Geleijnse, 2010). Furthermore, the Food and Drug Administration (FDA) encourages the production and use of foods that have low sodium and high potassium (Karppanen \& Marvaala, 2006). Incorporating fiber, omega-3 PUFAs, and potassium chloride (as a salt substitute) into food would create a super-nutraceutical product with the potential for cardiovascular and other health benefits.

Fiber, omega-3 PUFAs, and salt substitute have, individually, been successfully incorporated into protein gels (Cardoso, Mendes, Vaz-Pires, \& Nunes, 2009; Gimeno, Astiasarán, \& Bello, 1999; Horita, Morgano, Celeghini, \& Pollonio, 2011; Pérez-Mateos, Boyd, \& Lanier, 2004; Sánchez-Alonso, Haji-Maleki, \& Borderías, 2007). However, a combined incorporation of fiber, omega-3 rich oils, and salt substitute has not been studied in surimi seafood. The purpose of this study was to investigate the effects of these ingredients on physicochemical properties, including texture, color, and gelation.

\section{References}

Anderson, J. W., Baird, P., Davis, R. H., Ferreri, S., Knudtson, M., Koraym, A., Waters, V., \& Williams, C. L. (2009). Health benefits of dietary fiber. Nutrition Reviews, 67(4), 188205. doi:10.1111/J.1753-4887.2009.00189.x

Campo, L., \& Tovar, C. (2008). Influence of the starch content in the viscoelastic properties of surimi gels. Journal of Food Engineering, 84, 140-147.

Cardoso, C., Mendes, R., Vaz-Pires, P., \& Nunes, M. L. (2009). Effect of dietary fibre and MTGase on the quality of mackerel surimi gels. Journal of the Science of Food and Agriculture, 89, 1648-1658. doi:10.1002/jsfa.3636 
Gimeno, O., Astiasarán, I., \& Bello, J. (1999). Influence of partial replacement of NaCl with $\mathrm{KCl}$ and $\mathrm{CaCl}_{2}$ on texture and color of dry fermented sausages. Journal of Agricultural and Food Chemistry, 47, 873-877.

Hall, G. M. (2011). Surimi and fish mince products. In G. M. Hall (Ed.), Fish processing sustainability and new opportunities (pp. 98-111). Oxford: Wiley-Blackwell.

Horita, C. N., Morgano, M. A., Celeghini, R. M. S., \& Pollonio, M. A. R. (2011). Physicochemical and sensory properties of reduced-fat mortadella prepared with blends of calcium, magnesium and potassium chloride as partial substitutes for sodium chloride. Meat Science, 89, 426-433.

Houston, M. C. (2011). The importance of potassium in managing hypertension. Current Hypertension Reports, 13, 309-317.

Juturu, V. (2008). Omega-3 fatty acids and the cardiometabolic syndrome. Journal of the Cardiometabolic Syndrome, 3, 244-253.

Karppanen, H., \& Mervaala, E. (2006). Sodium intake and hypertension. Progress in Cardiovascular diseases, 49(2), 59-75.

Mansfield, B. (2003). Spatial globalization: A "geography of quality" in the seafood industry. Economic Geography, 79(1), 1-16.

Matsui, H., Shimosawa, T., Uetake, Y., Wang, H., Ogura, S., Kaneko, T., Liu, J., Ando, K., \& Fujita, T. (2006). Protective effect of potassium against hypertensive cardiac dysfunction: Association with reactive oxygen species reduction. Hypertension, 48, 225-231.

Nair, S. S. D., Leitch, J. W., Falconder, J., \& Garg, M. L. (1997). Prevention of cardiac arrhythmia by dietary (n-3) polyunsaturated fatty acids and their mechanism of action. Journal of Nutrition, 127, 383-393.

Narayan, B., Miyashita, K., \& Hosakawa, M. (2006). Physiological effects of eicosapentaenoic acid (EPA) and docosahexaenoic acid (DHA) - a review. Food Reviews International, 22, 291-307.

Park, J. W., \& Lin, T. M. J. (2005). Surimi: Manufacturing and evaluation. In J. W. Park (Ed.), Surimi and surimi seafood, $2^{\text {nd }}$ ed (pp. 33-106), Boca Raton, FL: Taylor and Francis Group.

Pérez-Mateos, M., Boyd, L. C., \& Lanier, T. C. (2004). Stability of omega-3 fatty acids in fortified surimi seafoods during chilled storage. Journal of Agricultural and Food Chemistry, 55, 7944-7949. 
Sánchez-Alonso, I., Haji-Maleki, R., \& Borderias, A. J. (2007). Wheat fiber as a functional ingredient in restructured fish products. Food Chemistry, 100, 1037-1043. doi:10.1016/j.foodchem.2005.09.090

Siró, I., Kápolna, E., Kápolna, B., \& Lugasi, A. (2008). Functional food. Product development, marketing and consumer acceptance - a review. Appetite, 51, 456-467.

Van Mierlo, L. A. J., Greyling, A., Zock, P. L., Kok, F. J., \& Geleijnse, J. M. (2010). Suboptimal potassium intake and potential impact on population blood pressure. Archives of Internal Medicine, 170(16), 1501-1502. 


\section{CHAPTER II: REVIEW OF LITERATURE}

\section{Surimi}

Surimi is defined as an intermediate product used in the production of seafood analogues (Hall, 2011). The process used to create surimi involves washing debonded, minced fish meat to isolate protein (Park \& Lin, 2005). Mechanical deboners and mincers were developed in the 1970s, making surimi processing much easier and contributing to the boom in surimi production seen in the 1980s (Hall \& Ahmad, 1997). After the surimi is minced and deboned, it is washed to remove sarcoplasmic proteins, enzymes, pigments, lipids, and heme compounds. The removal of these impurities results in whiter color values, which indicate a higher quality surimi product (Hastings, Keay, \& Young, 1990). It also increases the concentration of actin and myosin in the final product resulting in a surimi product with better gelation qualities (Hall \& Ahmad, 1997; Park, Lin, \& Yongsawatdigul, 1997). The excess water is pressed out of the surimi and cryoprotectants are added to prevent protein denaturation during freezing (Hall \& Ahmad, 1997). The surimi can then be stored at very low temperatures for later use (Park \& Lin, 2005).

Every year, more than six million metric tons of whitefish are harvested (Guenneugues \& Morrissey, 2005). In 1999, Alaska Pollock (Theragra charcogramma) was the third most abundantly harvested species in the world, and was the main source for surimi production (Larkin \& Sylvia, 1999; Mansfield, 2003). Although many other species are now being used for surimi production, Alaska Pollock is still predominately favored, being used in about 50-70\% of surimi production (Park et al., 1997; Park \& Lin, 2005). In fact, many manufacturers still consider Alaska Pollock to the be the "premium" fish species for surimi production likely because of its high whiteness values and lack of protease activity which contribute to a higher 
quality product (Klesk, Yongsawatdigul, Park, Viratchakul, \& Virulhakul, 2000; Reed \& Park, 2008). In general, white fish like Alaska Pollock are favored in the production of surimi because they contain fewer color pigments and fewer lipids (Hall, 2011). Other factors that are taken into account when commercially producing surimi are the cost of the fish used and the properties of the surimi produced (Hastings et al., 1990).

Surimi popularity has broadened over the years. Surimi was traditionally a Japanese product until the 1970s, after which both production and consumption expanded (Mansfield, 2003). Around that time, surimi was first introduced to North America in the form of crabmeat leg (Park, 2005). Surimi seafood in the United States is mainly found in the form of sticks, flakes, or chunks and is known as "imitation crabmeat" (Park, 2005). The popularity of surimi seafood in the United States dramatically increased in the 1980s when the United States began catching Alaska Pollock and producing surimi (Mansfield, 2003). Although popularity declined somewhat in the early 1990s, consumption in the United States has continued to steadily increase over the years (Park, 2005). The consumption of surimi seafood in the United States reached 200 million pounds by 2008 (Reed \& Park, 2008). The popularity remains high and continues to grow possibly due to the low-cholesterol, low-fat, and high nutrient content of surimi seafood (Campo \& Tovar, 2008). Currently, the United States is one of the major producers of surimi followed closely by Japan and Thailand (Hall, 2011). With consumption and popularity becoming more widespread, surimi exports are becoming more globalized to areas such as Southeast Asia, Western Europe, and North America (Mansfield, 2003). With this growing popularity and globalization of surimi seafood, "the only limit to the use of surimi lies in the imagination of the product developers" (Hall \& Ahmad, 1997). 


\section{Fiber}

Dietary fiber has become more popular in research and supplementation after observations that populations consuming diets high in dietary fiber have lower incidence of the chronic diseases that are commonly seen in Western populations with diets low in fiber (Raninen, Lappi, Mykkänen, \& Poutanen, 2011). Dietary fiber is defined as "remnants of the edible part of the plant and analogous carbohydrate that are resistant to digestion and absorption in the human small intestine with complete or partial fermentation in the human large intestine. It includes polysaccharides, oligosaccharides, lignin and associated plant substances...that promote beneficial physiological effects" (Bodner \& Sieg, 2009; Prosky, 2000). There are two basic types of dietary fiber: soluble and insoluble (Raninen et al., 2011). Insoluble fibers are mainly composed of cellulose, hemicelluloses, and lignin whereas soluble fibers consist of gums, polyfructoses, pectins, and mucilages (Bodner \& Sieg, 2009).

It has been shown that a high intake of dietary fiber is protective against intestinal disorders, heart disease, obesity, and diabetes (Anderson et al., 2009; Smith \& Tucker, 2011). Most Americans, however, consume less than half of the recommended daily fiber, or about 15 grams on average each day (Anderson et al., 2009; Dietary Guidelines Advisory Committee, 2010). The Institute of Medicine recommends an intake of 25 to 38 grams of fiber each day, depending on age and gender (Dietary Guidelines Advisory Committee, 2010). This recommendation includes both soluble and insoluble fiber, yet these two types of fiber have different physiological effects (Brownlee, Dettmar, Strugala, \& Pearson, 2006; Raninen et al., 2011).

Fiber is well-known for its beneficial effects on cardiovascular risk factors. A high intake of dietary fiber is associated with reduced risk of cardiovascular disease (Raninen et al., 
2011). The Nurses' Health Study followed 75,521 women for 10 years and found that a dietary fiber intake of 14 to 20 grams per day, although below the recommended intake for women, was associated with greater protection from fatal and non-fatal cardiovascular disease (Smith \& Tucker, 2011). Soluble fiber has been implicated in reducing total and low density lipoprotein (LDL) cholesterol, most likely due to its ability to bind bile acids, thus impeding micelle formation and increasing cholesterol and bile acids excreted in the feces (Anderson et al., 2009; Smith \& Tucker, 2011).

Dietary fiber intake is related to intestinal health. Dietary fiber has been theorized to reduce colorectal cancer via various mechanisms such as the dilution of fecal carcinogens by fiber, decreased transit time that decreases the amount of time the colonocytes are exposed to these compounds, and the production of short chain fatty acids that contribute to colonocyte health (Anderson et al., 2009; Brownlee et al., 2006). Some of these mechanisms are related to the effects of soluble fiber and others to insoluble fiber. Soluble fiber also can act to form a sort of gel in the intestines, slowing transit time, whereas insoluble fiber creates "intestinal hurry," reducing the transit time (Anderson et al., 2009). Insoluble fiber, specifically, has been implicated in easing defecation and reducing gut and stomach intolerance by increasing fecal volume and weight and therefore adding bulk, improving stool consistency, decreasing transit time, and increasing stool frequency (Raninen et al., 2011). Insoluble fiber is also associated with hypertrophy of colonic smooth muscle due to its bulking effect (Brownlee et al., 2006).

There is a strong negative association between fiber intake and obesity (Anderson et al., 2009; Smith \& Tucker, 2011). This association can be explained by various mechanisms related to fiber intake, including the feeling of fullness, delayed gastric emptying, and increased release of satiating gut hormones (Anderson et al., 2009). Soluble fibers seem to contribute to slowing 
the rate of gastric emptying and thereby delaying hunger and increasing satiety (Smith \& Tucker, 2011). A similar reduction in gastric emptying rate is also seen after insoluble fiber consumption; however, in terms of satiety, insoluble fiber seems to have more beneficial effects on increasing short-term satiety as opposed to long-term satiety (Smith \& Tucker, 2011).

There is a similar inverse relationship between fiber intake and diabetes risk via mechanisms related to reduced obesity, improved lipid profile, and improved glucose metabolism as seen in the Nurses' Health Study, the Black Women's Health Study, and the Framingham Offspring Study (Smith \& Tucker, 2011). In previous studies, individuals with the highest fiber intake had a $62 \%$ reduction in the progression of prediabetes to diabetes over a four-year period (Anderson et al., 2009). The mechanisms of this response were initially attributed to soluble viscous fibers; however, recent research has shown insoluble cereal dietary fiber, mainly comprised of cellulose and hemicelluloses, to be more significantly associated with reducing the risk factors for diabetes (Weickert \& Pfeiffer, 2008). Whereas soluble fibers may reduce or slow down glucose absorption after a meal, insoluble fiber has been shown to increase insulin sensitivity and the body's glycemic response (Raninen et al., 2011; Smith \& Tucker, 2011). In one study, consumption of 31 grams per day of highly purified insoluble oat fiber for three days resulted in a $13 \%$ improvement in whole body insulin sensitivity in overweight and obese women (Smith \& Tucker, 2011). The distinct mechanisms of insoluble fiber may be attributed to the beneficial effects of insoluble fiber on factors of obesity, such as increasing satiety and gut transit time postmeal and reducing weight gain; however, no obvious mechanisms exist (Weickert \& Pfeiffer, 2008).

Although fiber has been proven to be physiologically beneficial, it was not until the 1980s that consumers became aware of dietary fiber (Bodner \& Sieg, 2009). Generally, whole 
foods are promoted and recommended as sources of fiber; however, the low intake of dietary fiber seen in the current U.S. diet is evidence that Americans are not meeting their needs with whole food sources, and supplementation or fortification with isolated food components may be necessary (Smith \& Tucker, 2011). In addition, observations from the Women's Health Initiative and observations by the Food and Drug Admnistration (FDA) indicate that consumers are not as effective in modifying dietary habits as they intend to be (Anderson et al., 2009).

When adding dietary fiber to foods as a supplemented or fortified ingredient, it is important that the original taste and other sensory characteristics are maintained as consumers are unlikely to change traditional quality expectations for health benefits (Bodner \& Sieg, 2009). Fiber-containing ingredients such as whole grains, flours, and bread crumbs are currently used in a variety of products (Bodner \& Sieg, 2009). Processed meats may also be a vehicle for fiber supplementation (Bodner \& Sieg, 2009). Germany has already come out with meat products marketed as "enriched with fibers" and "rich in fibers" (Bodner \& Sieg, 2009).

Researchers have studied fiber incorporation in surimi; however, fiber is not currently used as an additive in surimi production (Cardoso, Vas-Pires, \& Nunes., 2009; Sánchez-Alonso, Haji-Maleki, \& Borderías, 2007). Fibers commonly used in research include carrageenans, garrofin, guar, and xanthan, which are soluble fibers (Montero, Hurtado, \& Pérez-Mateos, 2000; Sánchez-Alonso et al., 2007). Soluble fibers often have the effect of softening surimi gel products and are thus detrimental to textural properties, whereas insoluble fibers were seen to improve hardness and springiness in a study by Cardoso et al. (2009). Sanchez-Alonso et al. (2007) found that wheat dietary fiber improved the hardness and the whiteness of surimi made from hake and horse mackerel, demonstrating the potential for fiber incorporation in surimi seafood. 
Research supports the use of highly-extracted, long-chain cellulosic fibers in increasing the functionality of processed meats (Bodner \& Sieg, 2009). Powdered cellulose is a food-grade refined fiber that is formed by cooking organic plant material in a caustic solution at high temperatures and pressure to dissolve the lignin structure and remove impurities by filtering and washing (Bodner \& Sieg, 2009). The remaining material is bleached, dried and ground, resulting in powdered cellulose fiber (Bodner \& Sieg, 2009). The organic material used to make powdered cellulose typically comes from wood, cotton, or bamboo sources (Bodner \& Sieg, 2009). Powdered cellulose is typically used as a noncaloric bulking agent in calorie-reduced foods (Ang \& Miller, 1991). In addition to being noncaloric, powdered cellulose fiber is insoluble, neutral in taste and odor, white in color, and inert toward other ingredients (Ang, 1991; Bodner \& Sieg, 2009; Sánchez-González, Rodríguez-Casado, Careche, \& Carmona, 2009). Cellulose is a porous fiber and can absorb water and oil; however, these physical properties are dependent on fiber length, with longer fibers having a higher water and oil holding capacity than shorter fibers (Ang, 1991; Bodner \& Sieg, 2009). Water holding capacity is significantly higher in fiber around 100 microns in length compared to 35 microns in length, but fiber lengths more than 110 microns only had slightly increased water holding capacity compared to lengthsaround 100 microns. Oil retention capacity follows the same trend; however, oil retention capacity is not as great as water retention capacity in powdered cellulose fiber of all lengths (Ang, 1991). Fiber length also seems to be important in textural properties of surimi gels as powdered cellulose fiber of 11 to 55 microns in length resulted in significantly decreased firmness, chewiness, and rubberiness at the $2 \%$ level compared to incorporation of longer fibers (Yoon, Lee, \& Chung, 1987). Powdered cellulose with a fiber length of 110 microns also showed some thickening properties, but this observation was not seen with other fiber lengths, and the fiber 
will settle out of solution upon sitting (Ang, 1991). Yoon and Lee (1990) found cellulose to have some cryoprotectant properties, but these properties were not seen in other studies.

\section{Omega-3 Polyunsaturated Fatty Acids}

In populations where total fat constitutes more than $30 \%$ of total energy, mortality from cardiovascular disease is seen to be low, contrary to the belief that high-fat diets contribute to cardiovascular disease; however in these populations, fish and plant oils are the primary sources of fat consumed (Psota, Gebauer, \& Kris-Etherton, 2006). One population specifically, the Greenland Eskimos, consumed a diet very high in fat from seal, whale, and fish, but had a very low incidence in coronary heart disease (Narayan, Miyashita, \& Hosakawa, 2006). The lower rates of cardiovascular disease seen in these fish eating communities prompted investigations into the nutritional benefits of fish consumption (Ruxton, Reed, Simpson, \& Millington, 2007). Since this discovery, the global market for omega-3 polyunsaturated fatty acid (PUFA) supplements has grown to over US\$700 million, with an annual growth rate of $8 \%$ (Clough, 2008).

Omega-3 PUFAs include $\alpha$-linolenic acid (ALA, 18:3n3), eicosapentaenoic acid (EPA, 20:5n3), and docosahexaenoic acid (DHA, 22:6n3). ALA is the "parent" fatty acid of the omega-3 family and is primarily found among plant sources, including nuts (like English walnuts), seeds (such as sesame), and flaxseed, soybean, canola, and olive oils (Calder \& Yaqoob, 2009; Gogus \& Smith, 2010; Psota et al., 2006; Ratnayake \& Galli, 2009). Humans do not possess the enzymes necessary to synthesize ALA, thus ALA is considered an essential fatty acid that must be consumed in the diet (McManus, Merga, \& Newton, 2011). EPA and DHA can be synthesized from ALA in the body, but the conversion rates are low (McManus et al., 
2011). In the diet, EPA and DHA are major components of marine lipids and are especially high in cold-water fish species (Gogus \& Smith, 2010; Ratnayake \& Galli, 2009). Unicellular phytoplankton, including algae, and seaweeds appear to be an exception in that they are able to synthesize EPA and DHA and thus are a major source of long-chain omega-3 PUFAs for both fish and for humans (Narayan et al., 2006; Ratnayake \& Galli, 2009).

In the typical Western diet, the current ratio of omega- 6 to omega-3 intake is close to 16:1 whereas the recommended ratio is 4:1 (n-6:n-3) (Simopoulos, 2003). In North America, Europe, and Australia, lineleic acid (an omega-6 fatty acid) is consumed in quantities of 8.3 to 19.0 grams per day in men and 6.8 to 13.2 grams per day in women, which is approximately ten times as high as ALA intake (Ratnayake \& Galli, 2009). Psota et al. (2006) report ALA intake to be 1.7 grams/day for men and 1.3 grams/day for women. EPA and DHA intake is reported to be on average 0.1 to 0.2 grams/day in North America (Anderson \& Ma, 2009).

Studies have shown that reducing the omega- 6 to omega- 3 ratio to $4: 1$ by increasing omega-3 PUFA intake and/or decreasing omega-6 PUFA intake results in decreased total mortality by 70\% via secondary prevention of cardiovascular disease (McManus et al., 2011). The Institute of Medicine (2005) has recommended that ALA intake should be 1.6 grams per day for men and 1.1 grams per day for women. In addition, the Dietary Guidelines for Americans recommends consuming 8 ounces of a variety of seafood each week to provide $250 \mathrm{mg}$ per day of EPA and DHA (Dietary Guidelines Advisory Committee, 2010). The American Heart Association (AHA) similarly recommends two servings of fish per week, but recommends a total intake of one gram of EPA and DHA per day with cardiovascular disease (Kris-Etherton, Harris, Appel, \& AHA Nutrition Committee, 2002). To expound, at least $500 \mathrm{mg}$ per day is recommended for cardiovascular disease risk reduction and one gram per day is recommended 
with existing cardiovascular disease (Domingo, 2007). Another source recommends 200 to 650 milligrams per day for general good health, one gram per day for secondary prevention of myocardial infarction, and two to four grams per day to lower blood triglycerides (Calder \& Yaqoob, 2009). The minimum effective doses of omega-3 PUFAs has not yet been determined; however, the Food and Drug Administration (FDA) has determined that an intake of three grams per day is generally regarded as safe (Gogus \& Smith, 2010).

After ingestion, omega-3 PUFAs are digested the same as other long-chain fatty acids (Ratnayake \& Galli, 2009). Digestion begins by the action of the enzyme lipase that hydrolyzes fatty acids from triglycerides (Ratnayake \& Galli, 2009). Although lipase is found in the mouth (lingual lipase), stomach (gastric lipase), and small intestines (pancreatic juices), the small intestine is the major site of fat digestion (Ratnayake \& Galli, 2009). The presence of fat in the duodenum signals the gall bladder to release bile and pancreatic juices (Ratnayake \& Galli, 2009). Bile assists in emulsifying fats while pancreatic juices contain sn-1(3) lipase that yields 2-monoacylglycerol and free fatty acids as final products (Ratnayake \& Galli, 2009). The remaining 2-monoacylclycerol and free fatty acids as well as cholesterol and phospholipids are stabilized with bile salts to form micelles that are able to diffuse between microvilli of enterocytes and enter the intestinal cells (Ratnayake \& Galli, 2009). Inside the intestinal cells, free fatty acids and 2-monoacylglycerols are then re-esterified to form triglycerides which are transported out of the cell via chylomicrons (Ratnayake \& Galli, 2009). These chylomicrons travel through the lymph system into the blood stream and eventually reach the liver where the triglycerides are repackaged into very low density lipoproteins (VLDLs) that which travel throughout the body as a source of free fatty acids for cellular uptake (Ratnayake \& Galli, 2009). 
In the cells of the body, ALA can be converted to EPA and DHA, although this process is very inefficient, as previously mentioned (McManus et al., 2011). ALA is converted to EPA and DHA via a series of enzymes that are shared with the omega- 6 fatty acids, with the rate limiting step being the first enzyme in the process, $\Delta-6$ desaturase (Ratnayake \& Galli, 2009). Although $\Delta-6$ desaturase has a greater affinity for ALA than linolenic acid (LA, of the omega-6 fatty acid series), this advantage is offset by the high concentration of LA found in the typical Western diet in comparison to ALA (Ratnayake \& Galli, 2009). In addition, study has shown that the conversion rate of ALA to EPA is $0.2 \%$ and the subsequent conversion to DHA is only $0.05 \%$, although other sources report the conversion rates to be 5 to $10 \%$ and 2 to 5\% for EPA and DHA, respectively (Psota, Bebauer, \& Kris-Etherton, 2006; Ratnayake \& Galli, 2009). Because of these low conversion rates, individuals who do not eat seafood will not achieve recommended DHA intake without supplementation (McManus et al., 2011).

EPA and arachidonic acid (AA) are more biologically active than their respective parent fatty acids, ALA and LA, as these 20-carbon molecules can be converted to eicosanoids (Psota et al., 2006). Eicosanoids act as local hormones and include prostaglandins, thromboxanes, prostacyclins, and lipoxins (Ratnayake \& Galli, 2009). As a 22-carbon molecule, DHA is converted to docosanoids (Ratnayake \& Galli, 2009). Upon intracellular stimulation by phospholipase $A_{2}$, these long-chain fatty acids are released from cell membrane phospholipids and are rapidly metabolized to form eicosanoids (Ratnayake \& Galli, 2009). Eicosanoids and docosanoids contribute to blood pressure regulation, platelet aggregation, blood clotting, blood lipid profiles, immune responses, and inflammatory responses (Ratnayake \& Galli, 2009). AA and EPA are metabolized using the same enzymes (e.g. COX II), however EPA produces 3series eicosanoids that are less pro-inflammatory and decrease platelet aggregation compared to 
AA which produces proinflammatory and proaggregatory 2-series eicosanoids (Tou, Altman, Gigliotti, Benedito, \& Cordonier, 2011). With an increased consumption of EPA and DHA, these omega-3 PUFAs are incorporated into cells at the expense of AA, and eicosanoid production shifts from 2-series eicosanoids to 3 -series eicosanoids due to the lower quantity of AA available for use as a substrate (Nair, Leitch, Falconer, \& Garg, 1997).

An imbalance in eicosanoids, in favor of omega-6 metabolites, can lead to development of certain pathological conditions (Ratnayake \& Galli, 2009). Benefits of omega-3 PUFAs have been implicated in various physiological conditions including cardiovascular disease, platelet aggregation, hypertension, hyperlipidemia, inflammation, cancer, dementia, Alzheimer's disease, and depression (McManus et al., 2011). This is perhaps because a chronically upregulated inflammatory state, due in part to the production of pro-inflammatory eicosanoids from omega-6 derivatives, is involved in the etiology of these conditions, including cardiovascular disease, insulin resistance, and cancer (Anderson \& Ma, 2009). The mechanisms of action involved in the progression or prevention of these diseases by omega- 3 fatty acids include the ability of these PUFAs to alter physical properties of cell membranes (including fluidity), affect cell signaling pathways by modifying expression and activity of membrane receptors or modifying intracellular signal transduction mechanisms, and alter patterns of eicosanoids produced (Calder \& Yaqoob, 2009).

Omega-3 PUFAs have been shown to reduce mortality caused by myocardial infarction (MI) and sudden death in patients with coronary heart disease (CHD) and in so doing have been proven useful in the secondary prevention of cardiovascular disease (Ruxton et al., 2007). A meta-analysis of epidemiological studies showed a $7 \%$ and $14 \%$ reduction in coronary artery disease $(\mathrm{CAD})$ with a 20 gram per day increase in fish intake and for any amount of fish intake, 
respectively (Psota et al., 2006). Additional epidemiological studies reported decreases in cardiovascular disease (CVD) with fish oil consumption possibly explained by the role of fish oil in reducing hypertriglyceridemia (Nair et al., 1997). Salmon consumption has been shown to significantly decrease triglyceride levels by $15 \%$ and low density lipoprotein (LDL) cholesterol by $7 \%$ and increase high density lipoprotein (HDL) cholesterol by 5\% (Juturu, 2008). EPA and DHA have been shown to lower blood pressure and prevent hypertension (Narayan et al., 2006). EPA and DHA are inversely associated with CVD mortality, reducing CVD mortality by $30 \%$ to $60 \%$ in some studies (Psota et al., 2006).

Study shows that increased EPA incorporation into cells increases competition with AA resulting in lower production of the eicosanoids thromboxane- $\mathrm{A}_{2}$, leukotriene- $\mathrm{B}_{4}$, and prostaglandin- $\mathrm{E}_{2}$ and increased production of less potent eicosanoids thereby reducing platelet aggregation, vasoconstriction, and leukocyte chemotaxis and adherence (Anderson \& Ma, 2009). The eicosanoids produced from EPA and DHA result in a decrease in platelet aggregation that reduces the development of atherosclerotic plaques by making blood less viscous and decreasing the likelihood of thrombus formation, and also an increase in vasodilation that promotes blood flow with less resistance thereby decreasing the likelihood of endothelial damage and plaque initiation (Anderson \& Ma, 2009).

Although most cardiovascular benefits are seen with EPA and DHA, ALA also has an overall cardio-protective effect that is not explained by modest reductions in cholesterol levels (Anderson \& Ma, 2009). In one study, a high ALA diet (6.5\% of total energy from ALA) resulted in approximately $75 \%$ decrease in C-reactive protein (CRP), which is a marker of inflammation associated with heart disease (Zhao, Etherton, Martin, West, Gillies, \& KrisEtherton, 2004). 
Omega-6 PUFAs have been shown to promote cancer development whereas omega-3 PUFAs may reduce or protect against tumor development (Narayan et al., 2006). A study using menhaden oil at $20 \%$ of total energy found reduced tumor incidence and prolonged tumor latency (Anderson \& Ma, 2009). EPA and DHA inhibit the enzyme cycloxygenase, reducing the amount of the prostaglandin eicosanoids produced, and increasing the activity of the enzyme lipoxygenase which produces the eicosanoids hydroxyeicosatrienoic acid and leukotriene-B4 which may slow the process of cancerous cells overtaking a tissue (Narayan et al., 2006). EPA and DHA act to decrease the activation of oncogene transcription factors, inhibit angiogenesis, and promote apoptosis (Anderson \& Ma, 2009). ALA has also been seen to decrease angiogenesis and metastasis in some studies (Anderson \& Ma, 2009).

Both EPA and DHA had favorable effects on markers of diabetes, resulting in increased insulin sensitivity, decreased inflammatory mediators, and altered lipid metabolism in lean adults (Anderson \& Ma, 2009). When EPA and DHA are incorporated into cell membranes, they increase membrane fluidity which has the effect of increasing the number of insulin receptors on cell membranes and increasing the affinity of the receptors to insulin (Anderson \& Ma, 2009). EPA also increases the ability of erythrocytes to clear glucose when EPA is given to individuals with type 2 diabetes mellitus (Narayan et al., 2006).

Research has shown that DHA supports neural and visual development of infants, improving cognitive performance and visual acuity (Arterburn, Oken, Hall, Hamersley, Kuratko, \& Hoffman, 2008). DHA has also been found to be protective against all-cause dementia (Arterburn et al., 2008). Plasma studies show that low omega-3 levels are associated with dementia (Ruxton et al., 2007). In individuals 55 years of age and older, fish consumption over 20 grams per day reduced the risk of cognitive impairment, cognitive decline, dementia, and 
Alzheimer's disease (Ruxton et al., 2007). Fish consumption is also associated with higher selfreported mental health status, and reduced tissue levels of omega-3 PUFAs were seen in depressed patients (Ruxton et al., 2007). DHA is a major constituent of membrane phospholipids in neural structures including those of the brain and retina (Narayan et al., 2006). By enabling fluidity in neuronal membranes, omega-3 PUFAs help regulate neurotransmitters (Ruxton et al., 2007). Omega-3 PUFAs may also reduce the severity of depression by enhancing the rate of serotonin production (Gogus \& Smith, 2010).

Omega-3 PUFAs have been used in the treatment of inflammatory diseases such as inflammatory bowel disease (IBD), eczema, psoriasis, and rheumatoid arthritis (Gogus \& Smith, 2010). There is good evidence that omega-3 PUFAs are therapeutically beneficial in the case of rheumatoid arthritis by mediating the inflammatory effects of the immune system (Ruxton et al., 2007). Significant improvement has also been seen in active mild-to-moderate ulcerative colitis, an inflammatory bowel disease (Ruxton et al., 2007). EPA and DHA are substrates for antiinflammatory compounds, such as resolvins and protectins, which inhibit activation of nuclear factors (including nuclear factor- $\mathrm{kB}$ and interleukins) that produce inflammation (Gogus \& Smith, 2010). The incorporation of EPA and DHA into cell membranes also increases the fluidity of the membranes, making them more flexible and resistant to extrinsic and intrinsic destructive factors, especially inflammatory agents (Gogus \& Smith, 2010).

The various sources of omega-3 PUFAs have different properties. The most bioavailable sources of omega-3 PUFAs are from fish and seafood (McManus et al., 2011). Menhaden oil is a type of fish oil that contains omega-3 PUFAs primarily in the form of EPA and DHA (Pietrowski, Tahergorabi, Matak, Tou, \& Jaczynski, 2011). Menhaden oil has a ratio of EPA to DHA of 3:1 (Tou et al., 2011). Narcisco-Gaytán et al. (2011) found that EPA and DHA from 
menhaden oil could successfully be incorporated into thigh muscles of broilers. In comparison, algae oil has been found to be a bioavailable source of omega-3 PUFAs when delivered in capsules and fortified in snack bars (Arterburn et al., 2007). In a study by Pietrowski et al. (2011), algae was been found to be high in DHA compared to menhaden, flaxseed, and krill oils. Arterburn et al. (2008) found that equivalent amounts of DHA from algal-oil capsules and salmon oil were incorporated into plasma phospholipids and erythrocytes. Algae oil also contains carotenoids and vitamin $\mathrm{E}$ which may be useful in providing antioxidative properties as well as providing added nutritional benefit (Nitsan, Mokady, \& Sukenik, 1999). Flaxseed oil has the highest omega-3 to omega-6 ratio among plant sources (53.5\% ALA and $12.7 \%$ LA), with the majority of the omega-3 being ALA (Chen, Nguyen, Semmens, Beamer, \& Jaczynski, 2006).

The high cost of fish as well as the potential for contaminants, such as mercury, cadmium, polychlorinated biphenyl (PCB), polycyclic aromatic hydrocarbon (PAH), etc., may contribute to the lack of fish intake in the Western diet (Candela, López, \& Kohen, 2011; Domingo, 2007). However, if individuals do not eat fish or change dietary habits to include fish in their diet, they are not likely to achieve the recommended EPA and DHA intake (Calder \& Yaqoob, 2009). Food enrichment is a potential option for consumers who do not wish to consume oily fish or fish oil supplements (Calder \& Yaqoob, 2009). Because of this, there is a growing need to find ways to enrich or fortify foods with omega-3 PUFAs to create an inexpensive, desirable product that contains significant amounts of omega-3 PUFAs for consumers (Tolasa, Lee, \& Cakli, 2010). Also known as a functional food, these products would contain added, technologically developed ingredients with specific health benefits and would provide a way to achieve health effects without the ingestion of supplements or the original food source (Kassis, Beamer, Matak, Tou, \& Jaczynski, 2010; Siró, Kápolna, Kápolna, \& Lugasi, 
2008). The presence of a food matrix augments the rate of entry of omega-3 PUFAs into the intestinal mucosal cells, supporting the fortification of omega-3 PUFAs in food products (McManus et al., 2011). Levels of fortification should be significant in the serving size consumed; however, the level of enrichment is currently limited by food technology, processing, and storage conditions (Calder \& Yaqoob, 2009; McManus et al., 2011). Incorporation of omega-3 PUFAs may alter taste, but incorporation has been successful in egg-products (Kassis et al., 2010). Enriching other food products such as meat, milk, eggs, spreads, and yogurts would allow consumers to increase intake of EPA and DHA without changing dietary habits (Calder \& Yaqoob, 2009).

Surimi is isolated fish protein that has been washed during manufacturing to remove fats and other substances and thereby create a functional actomyosin concentrate (Park, Lin, \& Yongsawatdigul, 1997). Surimi is a logical vehicle for omega-3 PUFA incorporation because it is a good source of protein and lacks accompanying high quantities of saturated fat found in many other meat sources (Tolasa et al., 2010). Addition of omega-3 PUFAs would "mimic" natural fish products that already contain these nutrients (Park, Kelleher, McClements, \& Decker, 2004). For successful incorporation, it is necessary to have a highly cohesive structure, such as that provided by surimi, to allow for uniform dispersion of oil droplets (Tolasa et al., 2010). It is theorized that oil droplets may be protected by protein membranes or a cohesive protein matrix, thus allowing for complete incorporation into the product (Tolasa et al., 2010). Park et al. (2004) observed that addition of oil as an emulsion did not decrease gel strength of surimi in comparison to a control with no oil added; however, a decrease in gel strength was seen with bulk oil addition. Tolasa et al. (2010) reported that gel-softening occurs when oil has a disrupting effect on the structure of the gel. On the other hand, an increase in gel strength was 
seen when oil was added in place of the same amount of water used in formulation (PérezMateos, Boyd, \& Lanier, 2004). Pérez-Mateos et al. (2004) observed an increase in breaking force and hardness in heat-induced mackerel gels containing $2.5 \%$ omega-3 rich oil compared to a control with no oil added. The same researchers also observed an increase in lightness $\left(\mathrm{L}^{*}\right)$ in the samples with oil. Oil has been found to act as a whitener in surimi due to the ability of oil droplets to scatter light (Benjakul, Visessanguan, \& Kwalumtharn, 2004). These properties show that oil can be successfully incorporated into surimi seafood.

\section{Salt and Salt Substitute}

Hypertension is one of the leading causes of heart disease and death in developed countries (Houston, 2011; Karppanen \& Mervaala, 2006). Hypertension, however, is a modifiable cause of death that resulted in 395,000 preventable deaths in the United States alone in 2005 (Appel et al., 2011). Worldwide, hypertension is responsible for 7.6 million deaths, or 13.5\% or total mortality (Montasser et al., 2010). Hypertension accounts for 54\% of strokes and 47\% of coronary heart disease events worldwide (Appel et al., 2011). Although more than 72 million Americans, or one third of all adults, are estimated to have hypertension, only $34 \%$ achieve blood pressure (BP) control. Hypertension is the most common reason for patient visits to physician offices, and resulted in an estimated $\$ 55$ billion in medical costs in 2001 (Cotugna \& Wolpert, 2011; Houston, 2011). Direct and indirect costs for cardiovascular disease (CVD), for which hypertension is a risk factor, were estimated to be over $\$ 400$ billion in 2009 (Appel et al., 2011).

Hypertension, or blood pressure (BP) more than $140 / 90 \mathrm{~mm} \mathrm{Hg}$, is one of the main risk factors for cardiovascular disease and as such increases the risk for myocardial infarction, 
coronary heart disease, cerebrovascular accident, and end-stage renal disease (Cotugna \& Wolpert, 2011; Karppanen \& Mervaala, 2006). It is estimated that suboptimal BP levels attribute to two-thirds of cerebrovascular disease and half of coronary heart disease worldwide (China Salt Substitute Study Collaborative Group, 2007). A reduction in systolic BP by 2 to 3 mm Hg could result in reductions CVD events (Taylor, Ashton, Moxham, Hooper, \& Ebrahim, 2011). Such a reduction may decrease stroke mortality by $10 \%$ and ischemic heart disease mortality by 7\% (Montasser et al., 2010). If these reductions are maintained long-term, a $1 \mathrm{~mm}$ $\mathrm{Hg}$ reduction and $4 \mathrm{~mm} \mathrm{Hg}$ reduction would result in a 5\% and 20\% decrease in CVD, respectively (Taylor et al., 2011).

Diet has been found to play an important role in BP, indicating the possible role of therapeutic dietary strategies for reducing BP (Houston, 2011). Dietary therapies include decreased sodium intake, increased potassium and magnesium intake, a diet rich in fruits and vegetables, and various antioxidants (Houston, 2011). Other lifestyle interventions also include weight control and exercise (Montasser et al., 2010). Dietary goals of the United States and other countries worldwide include a reduction of sodium as a key factor in lowering BP (Karppanen \& Mervaala, 2006). Increased potassium and the Dietary Approaches to Stop Hypertension (DASH) diet, which focuses on increased fruit and vegetable intake alongside reduced sodium intake, are current dietary recommendations for lowering BP from the European Society of Hypertension (ESH), the World Health Organization (WHO), the International Society of Hypertension (ISH), and the British Hypertension Society (Houston, 2011). Because of the positive relationship of sodium intake to BP, a reduction in sodium intake of $1200 \mathrm{mg}$ per day could save $\$ 10$ to $\$ 24$ billion in health care costs annually (Appel et al., 2011; Taylor et al., 2011). This may be especially true for the elderly population as the strength of association 
between sodium and BP increases with age and BP in cross-sectional studies (Geleijnse, Witteman, Bak, den Breeijen, \& Grobbee, 1994). Studies show that therapeutic diets may be more effective in reducing BP if the intake of several minerals is changed at once, for example reducing sodium intake while increasing potassium intake (Geleijnse et al., 1994; Van Mierlo, Greyling, Zock, Kok, \& Geleijnse, 2010).

The relationship between salt intake, high BP, and CVD is well-established (Wesseling, Koeners, \& Joles, 2011). It has been shown that high salt-loading on salt-sensitive subjects can result in hypertension as well as left ventricular hypertrophy and hypertensive heart failure (Matsui et al., 2006). Although sodium intake is related to increased BP which results in the development of more progressed disease states, sodium also has physiological effects independent of BP including fibrosis in the heart, kidneys, and arteries (Appel et al., 2011). This is because a high sodium intake is associated with increased large elastic artery stiffness with aging (Appel et al., 2011). High sodium intake can also cause direct damage to the kidney, accelerating kidney disease caused by other conditions (Appel et al., 2011). An increased 24hour urinary sodium excretion, which is reflective of sodium intake, correlated significantly with an increased risk of type 2 diabetes mellitus independent of obesity and hypertension (Cotugna \& Wolpert, 2011).

Whereas increased sodium intake contributes to multiple disease states, a reduction in sodium intake has been seen to blunt the rise in BP seen with increasing age (Appel et al., 2011). In a trial of patients with resistant hypertension, a reduction in sodium intake by $4600 \mathrm{mg}$ per day lowered systolic and diastolic BP by $22.9 \mathrm{~mm} \mathrm{Hg}$ and $9.1 \mathrm{~mm} \mathrm{Hg}$, respectively (Appel et al., 2011). In a study by Lennie et al. (2011), it was observed that individuals with New York Heart Association (NYHA) class III and IV heart failure who consumed more than 3 grams of sodium 
per day were more likely to be hospitalized for cardiac problems than those who consumed less than 3 grams per day. Sodium restriction to $40 \%$ of the usual dietary level produced a fall of 6.7 $\mathrm{mm} \mathrm{Hg}$ and $3.5 \mathrm{~mm} \mathrm{Hg}$ in systolic and diastolic BP, respectively, in the DASH study (Karppanen \& Mervaala, 2006). A major trial in the United States also reported that reduced sodium intake can prevent hypertension by about 20\% (Appel et al., 2011).

There are many mechanisms for the impact of sodium on various disease states. In regards to hypertension, the body controls sodium balance via extracellular fluid volume (Karppanen \& Mervaala, 2006). By increasing the BP level, the body is able to rid itself of excess sodium and water through the pressure-natriuresis mechanism (Karppanen \& Mervaala, 2006). High sodium has also been implicated in inducing modifications in the arterial wall, including hypertrophy, that result in arterial stiffening (Buyck et al., 2009). An increase in collagen fibers and decrease in elastin fibers is also implicated in the development of artery stiffening with increased sodium consumption (Buyck et al., 2009). In addition, sodium retention decreases the synthesis of nitric oxide, which acts as an arteriolar vasodilator. High salt consumption has also been seen to induce over-production of reactive oxygen species (ROS), which have a positive correlation with severity of heart failure, by activating NADPH oxidase (Matsui et al., 2006).

The harmful effect of high dietary sodium on BP is mainly observed in individuals with a low potassium intake (Buyck et al., 2009). Increased intakes of potassium, calcium, and magnesium have been found to increase the excretion of excess sodium (Karppanen \& Mervaala, 2006). Whereas dietary sodium intake is positively associated with pulse pressure, a peripheral marker of central arterial stiffness, potassium intake is negatively associated with systolic BP, diastolic BP, and mean arterial pressure after adjusting for demographic and nutritional factors 
that may affect BP (Buyck et al., 2009). The BP-lowering effect of potassium has been observed to be even greater in the presence of a high intake of sodium (Houston, 2011; Lee, Zhekov, Owens, Kim, \& Meullenet, 2012).

Increasing potassium intake has been shown to lower blood pressure (Van Mierlo et al., 2010). Higher sodium to potassium ratio in the diet is associated with a higher BP and risk of CVD; however, the ratio of potassium intake to sodium intake in the United States is less than 1:2 compared to the 5:1 ratio recommended (Houston, 2011). This low potassium intake is considered by some to be a major contributor to the prevalence of hypertension and cardiovascular disease (Houston, 2011). Increasing potassium intake to the recommended amount of 4.7 grams per day would lower systolic BP by 1.7 to $3.2 \mathrm{~mm} \mathrm{Hg}$, similar to the amount seen by reducing sodium intake from 9 grams to 5 grams per day (Van Mierlo et al., 2010). Such an increase in potassium alone could decrease the prevalence of hypertension in the United States by $17 \%$ and increase life expectancy by 5.1 years (Houston, 2011). In addition to attenuating hypertension, potassium has also been implicated in reducing the risk of cerebrovascular accidents and cardiac arrhythmias (Houston, 2011). Increased potassium intake, even in initial stages of cardiac dysfunction, has been shown to be beneficial (Matsui et al., 2006). Potassium has been proven to have physiological effects independent of BP, such as improving the function of the left ventricle of the heart (Matsui et al., 2006). Although potassium supplementation is beneficial in cardiovascular diseases, individuals with renal disease, such as end-stage renal failure, have a reduced secretory ability for potassium and must limit potassium intake (Houston, 2011; Taylor et al., 2011).

In past studies, three meta-analyses showed that increased potassium intake significantly lowered BP in a dose dependent manner in both non-hypertensive and hypertensive individuals 
(Houston, 2011). In one study, increase potassium intake by about 700 to $1000 \mathrm{mg}$ per day lowered systolic BP by 2 to $3 \mathrm{~mm} \mathrm{Hg}$ (Houston, 2011). Similarly, another study found that increasing potassium by 1800 to $1900 \mathrm{mg}$ per day lowered systolic BP by $4 \mathrm{~mm} \mathrm{Hg}$ and diastolic BP by $2.5 \mathrm{~mm} \mathrm{Hg}$ (Karppanen \& Mervaala, 2006). When potassium chloride (KCl) was supplemented an average of $86 \mathrm{mmol}$ per day, reductions of 5.9 and $3.4 \mathrm{~mm} \mathrm{Hg}$ were seen over a period of about 39 days for systolic BP and diastolic BP, respectively (Houston, 2011). In a study including rural citizens in China, the effect of salt substitute increased over time with a maximum systolic BP reduction of about $5.4 \mathrm{~mm} \mathrm{Hg}$ after 12 months (China Salt Substitute Study Collaborative Group, 2007). Along with the effect of decreasing BP, potassium supplementation has also been found to reduce the need for antihypertensive medications by 50\% (Houston, 2011). Similar effects of potassium have also been seen for other physiological states, such as cerebrovascular accidents, which were seen to decrease with high potassium intake (Houston, 2011).

The effects of potassium in lowering BP are explained my mechanisms including improved natriuresis, reduced sympathetic nervous activity, and decreased pressor response to noradrenaline and angiotensin II (Karppanen \& Mervaala, 2006). Specific effects on the endothelial pathways of the vasculature include stimulation of nitric oxide production, which acts as a potent vasodilator and thus maintains normal BP (Montasser et al., 2010). An increase in potassium also causes endothelium-dependent vasodilation by hyperpolarizing the endothelial cell, which in turn decreases the cytosolic calcium of vascular smooth muscle cells and promotes this vasodilatory mechanism (Houston, 2011). Potassium also protects the integrity of the vascular endothelium by reducing the production of free radicals which may initiate damage to the endothelium (Montasser et al., 2010). Potassium has been shown to inhibit ROS formation 
from endothelium and white blood cells (Matsui et al., 2006). Further protecting the vasculature from endothelial injuries, high potassium intake reduces leukocyte adherence to the vascular wall (Montasser et al., 2010).

Despite the risk of high sodium intake and low potassium intake, current consumption of both minerals is suboptimal (Karppanen \& Mervaala, 2006). The human body requires only 180 mg of sodium to maintain physiological functions; however, the current dietary intake in the United States is over $3400 \mathrm{mg}$ each day for individuals ages 2 and older (Dietary Guidelines Advisory Committee, 2010). The Dietary Guidelines Advisory Committee (2010) recommends a sodium intake less than $2300 \mathrm{mg}$ for the general population, and an intake less than $1500 \mathrm{mg}$ for those aged 51 or older, of African American ethnicity, or afflicted with hypertension, diabetes, or chronic kidney disease. Similarly, most developed countries have a dietary goal to reduce sodium intake by half (Taylor et al., 2011). Despite these recommendations, sodium intake has continued to rise, and NHANES data from 1999 to 2004 showed that only about 30\% of the American population consumed less than the recommended sodium intake (Cotugna \& Wolpert, 2011; Karppanen \& Mervaala, 2006). In addition, per capita use of salt increased by about 55\% from 1983 to 1998, remaining high and corresponding to a similar increase in high BP in the population starting in the late 1980s and early 1990s (Karppanen \& Mervaala, 2006). Potassium intake is similarly suboptimal with only $43 \%$ of individuals meeting the current recommended intake of $4700 \mathrm{mg}$ of potassium per day (Dietary Guidelines Advisory Committee, 2010; Karppanen \& Mervaala, 2006). Potassium intake has been observed to be about $2000 \mathrm{mg}$ in a typical 2400 calorie American diet (Karppanen \& Mervaala, 2006).

Although individuals with hypertension generally receive counseling, this counseling has had a minimal impact on population sodium intake, leading researchers to believe that the only 
effective way of decreasing overall sodium intake would be to reduce the level of salt added in industrial manufacturing of foods (Cotugna \& Wolpert, 2011; Karppanen \& Mervaala, 2006). Whereas $12 \%$ of salt intake occurs naturally in foods, $6 \%$ is added to foods at the table, and $5 \%$ is added during the at-home cooking process, more than $75 \%$ of sodium intake comes from salt added to processed foods (Appel et al., 2011; Cotugna \& Wolpert, 2011; Karppanen \& Mervaala, 2006). The consumption of meat has been criticized due to its high sodium and fat levels and lack of fiber and calcium (Horita, Morgano, Celeghini, \& Pollonio, 2011). This criticism of meat may be well-founded as meat products contribute to about $16 \%$ to $25 \%$ of the recommended sodium intake (Horita et al., 2011)

Surimi is isolated fish protein that has been washed during manufacturing to remove fats and other substances and thereby create a functional actomyosin concentrate (Park, Lin, \& Yongsawatdigul, 1997). Surimi seafood is known to be relatively high in sodium content (Kim $\&$ Park, 2008). The typical salt content of manufactured surimi is about $1 \%$ to $3 \%$, with the maximum acceptable concentration for taste being 2\% to 2.5\% (Kim \& Park, 2008; Pigott, 1986; Tahergorabi, Beamer, Matak, \& Jaczynski, submitted for publication). Salt plays an essential role in meat products, such as surimi, due to its contribution to texture, addition to flavor, and ability to control microbial growth by lowering the water activity of the product (Kim \& Park, 2008; Lee et al., 2012). Textural properties are of critical importance for surimi quality and acceptance, thus the addition of salt it also critical because it improves texture (Tahergorabi \& Jaczynski, 2012). Salt acts in meats to solubilize myofibrillar proteins, with more myofibrillar proteins being solubilized at higher salt concentrations (Alvarez, Couso, \& Tehada, 1995). If less salt is used in manufacturing a negative effect is seen on the functional and mechanical properties of the resulting surimi seafood (Tahergorabi \& Jaczynski, 2012). Sodium chloride 
$(\mathrm{NaCl})$ solubilizes protein by causing the myofibrillar proteins to swell and break into actomyosin, myosin, and a variety of protein aggregates and complexes upon chopping and kneading of the salted surimi paste (Lian, Lee, \& Chung, 2002; Pigott, 1986). The dissociated actomyosin participates in forming the protein matrix of the gel and in binding water (Horita et al., 2011; Kim \& Park, 2008; Pigott, 1986). The solubilized proteins form crosslinks with other myofibrils during gelation to make gels more firm, thus a decrease in solubilized proteins caused by reduced sodium addition would result in a product with lower gel strength (Horita et al., 2011; Lian et al., 2002). Salt also strengthens the hydrophobic interactions between proteins in the gel, thus contributing to gel strength (Kim \& Park, 2008).

Tahergorabi and Jaczynski (2012) proposed that it is possible to reduce sodium content in surimi by 1) lowing the concentration of added salt $(\mathrm{NaCl}), 2)$ replacing all or part of the salt ( $\mathrm{NaCl}$ ) with other chloride salts (such as $\mathrm{KCl}, \mathrm{CaCl}_{2}$, or $\mathrm{MgCl}_{2}$ ), flavors, and preservatives, or 3) using a combination of the aforementioned approaches. The type of salt used, however, can influence the salting process to a greater or lesser extent depending upon the characteristics of the salt; for example, divalent metal ions (including calcium, magnesium, and zinc) may cause changes in protein conformation by interacting with the negative charges on polypeptide chains of proteins and decreasing electrostatic interactions between protein molecules (Ding et al., 2011; Martínez-Alvarez, Borderías, \& Gómez-Guillén, 2005). The use of chloride salts is supported by the hypothesis that the chloride ion is the main contributor to the effect of $\mathrm{NaCl}$ on myofibrillar proteins because the chloride ion more strongly reacts with positive charges on muscle protein whereas the cation (such as sodium, in $\mathrm{NaCl}$ ) is only weakly bound, thus the chloride ion may continue to exert its effect regardless of the cation present (Lian et al., 2002). Potassium chloride $(\mathrm{KCl})$ has been the most investigated chloride substitute for $\mathrm{NaCl}$ due to its 
positive health impact in reducing blood pressure in humans (Horita et al., 2011; Lee et al., 2012). In addition, food products that have a low sodium and high potassium content are eligible for health claims on their labels, possibly increasing consumer consumption (Karppanen \& Mervaala, 2006). Possible negative effects reported from the use of $\mathrm{KCl}$ as a salt substitute include complaints of a metallic or bitter aftertaste (Lee et al., 2012). If salt substitute were used in place of $\mathrm{NaCl}$ in the manufacturing of surimi seafood, these products would contribute to $4 \%$ of the recommended sodium intake in a 100 gram serving compared to surimi seafood with $1 \%$ to $3 \% \mathrm{NaCl}$ which would contribute $16 \%$ to $44 \%$ of the recommended intake, respectively (Tahergorabi et al., submitted for publication).

When used as a substitute for $\mathrm{NaCl}$ in Alaska Pollock surimi, $\mathrm{KCl}$ has been found to produce an acceptable product with acceptable color and textural character traits (Tahergorabi et al., submitted for publication). Using $\mathrm{KCl}$ as a salt substitute, however, did result in softer gels with decreased hardness (Gimeno, Astiasarán, \& Bello, 1999; Montero \& Pérez-Mateos, 2001; Tahergorabi et al., submitted for publication). This decrease in hardness and gel strength is most likely due to the increase in moisture that is seen with the use of $\mathrm{KCl}$ (Martínez-Alvarez et al., 2005). In formulations of surimi, dry-cured pork loin, and mortadella that used only partial substitutions of $\mathrm{KCl}$ for $\mathrm{NaCl}$, gel firmness was not affected (Gou, Guerrero, Gelabert, \& Arnau, 1996; Horita et al., 2011; Lian et al., 2002). Although some differences were seen in texture, surimi gelation patterns and viscoelasticity were unchanged when $\mathrm{KCl}$ was used in place of $\mathrm{NaCl}$ (Lian et al., 2002; Tahergorabi \& Jaczynski, 2012). Salt substitution has also been reported to have little effect on the color of resulting gels (Tahergorabi et al., submitted for publication). Sensory evaluations of products using $\mathrm{KCl}$ as a salt substitute confirmed that $\mathrm{KCl}$ may contribute a metallic or bitter taste resulting in sensory rejection by consumers (Gou et al., 1996; Horita et 
al., 2011). $\mathrm{KCl}$ may only have an effect on taste, however, when $\mathrm{KCl}$ fully replaces $\mathrm{NaCl}$ (Lian et al., 2002). Martínez-Alvarez et al. (2005) found that $\mathrm{KCl}$ negatively influenced taste when the level of replacement for $\mathrm{NaCl}$ was more than $50 \%$. Potassium may have additional benefits in protecting against oxidation, as Horita et al. (2011) observed the lowest pro-oxidant action in mortadella after 30 days in samples containing $\mathrm{KCl}$ and $\mathrm{CaCl}_{2}$. These results show $\mathrm{KCl}$ to be a potential salt substitute for surimi.

\section{Color}

The concept of color was initially a difficult concept to express due to the limitations of human vocabulary to adequately describe magnitude and direction of color variations (Lauro, Inami, \& Johnson, 2005). It was soon determined that color could be measured based on measuring wavelengths of energy (Lauro et al., 2005). With this knowledge, instruments were developed that could measure color with adequate reproducibility (Lauro et al., 2005). The Commision Internationale de l'Eclairage (CIE) later established criteria to test and express color mathematically, and developed a model patterned after the color perception of the human eye and known as the tristimulus color scale, which was a tool for measuring the amount of red, green, and blue light in a sample (Lauro et al., 2005). The L*a*b* color space was subsequently developed to more closely correlate with color as perceived by the human eye (Lauro et al., 2005). In the $\mathrm{L}^{*} \mathrm{a}^{*} \mathrm{~b}^{*}$ color space, $\mathrm{L}^{*}$ is a value from 0 to 100 that indicates darkness (closer to 0) or lightness (closer to 100), a* indicates redness (positive value) or greenness (negative value), and $b^{*}$ indicates yellowness (positive value) or blueness (negative value) (Lauro et al., 2005). These $L^{*} a^{*} b^{*}$ values can be combined in the equation $100-\left[\left(100-L^{*}\right)^{2}+a^{* 2}+b^{* 2}\right]^{1 / 2}$ to 
indicate overall whiteness (Lanier, 1992). This $\mathrm{L}^{*} \mathrm{a}^{*} \mathrm{~b}^{*}$ concept of color is widely used in surimi seafood (Lauro et al., 2005).

Color, especially whiteness, is an essential characteristic of surimi seafood (Gehring, Gigliotti, Moritz, Tou, \& Jaczynski, 2011; Pigott, 1986). For this reason, white-fleshed fish such as Alaska pollock, Pacific whiting, and hake, are used for the production of surimi as opposed to darker-fleshed fish such as mackerel or sardine (Benjakul, Visessanguan, \& Kwalumtharn, 2004; Guenneugues \& Morrissey, 2005). Surimi generally has L* (lightness) values well above 50 and $\mathrm{a}^{*}$ and $\mathrm{b}^{*}$ values near zero (Lanier, 1992).

In surimi gels, various additives influence color properties. Park (1995) found that gels with added moisture tended to be lighter with less yellowness, causing them to look whiter then gels with lower moisture. In addition to moisture, various components can be added to surimi pastes to improve the whiteness of the gels, including titanium dioxide, calcium carbonate, and oil (Benjakul et al., 2004; Gehring et al., 2011). Pérez-Mateos et al. (2004) observed that oil increased lightness $\left(\mathrm{L}^{*}\right)$ through the light scattering effect of emulsified oil droplets. Although oil may increase lightness through this light-scattering effect, some oils also contain pigments that increase either $\mathrm{a}^{*}$ or $\mathrm{b}^{*}$. Algae oil, for example, contains carotenoids that are yellow-orange in color and these colors are reflected in surimi gels (Nitsan, Mokady, \& Sukenik, 1999; Park, Kelleher, McClements, \& Decker, 2004; Pietrowski, Tahergorabi, Matak, Tou, \& Jaczynski, 2011).

\section{Texture}

Texture is one of the most important characteristics of surimi seafood (Hamann \& MacDonald, 1992). The measurement of texture is the sum of the properties of individual 
protein fibers and matrix between these fibers that causes them to adhere (Hamann \& MacDonald, 1992). Surimi seafood texture can be affected by various factors, including protein concentration, heating temperature, heating period, and additives (Hamann \& MacDonald, 1992; Luo, Kuwahara, Kaneniwa, Murata, \& Kokoyama, 2001). There are three classes of instrumental analyses: fundamental which is objective in nature, empirical which correlates well with textural properties, and imitative which imitates conditions of the mouth or plate (Kim, Park, \& Yoon, 2005). Instruments can correlate well with the "mechanical" sensory characteristics, or the reaction of food to stress (Hamann \& MacDonald, 19992). However, because texture is a multi-faceted property, using only one of the above instrumental analyses is not adequate for measuring and describing the different aspects of textural characteristics (Hamann \& MacDonald, 1992).

Torsion is a fundamental test that measures shear stress and shear strain of a sample at failure when the sample is subjected to twisting forces (Hamann \& MacDonald, 1992; Kim et al., 2005). Shear stress and shear strain correspond to gel strength and cohesiveness, respectively, of the surimi seafood (Kim et al., 2005). Lanier (1986) identified shear strain as the most important and sensitive parameter to describe the functional ability of myofibrillar protein in surimi gel. Higher values of shear stress and shear strain indicate premium products (Shie \& Park, 1999).

Kramer shear is considered to be an empirical test and imitates mastication (Kim et al., 2005). As opposed to a puncture test, Kramer shear test uses a multiple slot-and-blade fixture that has the advantage of testing a sample over a broader area, thus reducing the effect of local irregularities (Hamann \& MacDonald, 1992; Kim et al., 2005). The Kramer shear test measures gel strength or stiffness of surimi seafood (Kim et al., 2005). 
Texture profile analysis (TPA) is an empirical measure that involves compressing a sample twice between two parallel surfaces to imitate the action of the human jaw (Hamann \& MacDonald, 1992; Kim et al., 2005). TPA uses data measured to report multiple parameters, including hardness, the peak height on the first compression (food's resistance during the first bite); springiness, the ratio of product height on the second compression to the original compression distance (ability of the product to retain its shape and size after one bite); cohesiveness, the ratio of the second compression area to the first compression area (resistance of the product during chewing); gumminess, the product of hardness and chewiness (strength required in chewing); chewiness, the product of gumminess and springiness (energy used in chewing); and resilience, a measure of how well a product regains its original position, (Cardoso, Mendes, Pedro, \& Nunes, 2008). TPA characteristics have been found to correlate well with sensory ratings (Bourne, 1978).

\section{Gelation and Thermal Denaturation}

Gelation consists of the conversion of a viscous sol to the formation of a three dimensional elastic network with cross-linked protein (Karthikeyan, Dileep, \& Shamasundar, 2006; Niwa, 1992). Myofibrillar proteins, that are solubilized by the addition of salt during processing, form bonds with each other when heat is applied, thus changing the viscosity and mechanical properties of the surimi gel (Hamann \& MacDonald, 1992). Heat-induced gelation consists of two steps. First is the initiation (or denaturation) step during which protein molecules are unfolded (Yoon, Gunasekaran, \& Park, 2004). Proteins are naturally in a highly folded state; however, the addition of heat enhances structural changes such as the unfolding of protein molecules (Yoon et al., 2004). Second is the aggregation step which occurs at higher 
temperatures (above $55^{\circ} \mathrm{C}$ ) and triggers chemical reactions among exposed surfaces of neighboring protein molecules, including the formation of covalent bonds, electrostatic bonds, hydrogen bonds, and hydrophobic bonds that result in three-dimensional network formation (Yoon et al., 2004). Because these bonds are heat-induced, rheological and thermal properties of surimi gels are methods of assessing the quality of surimi gels (Yoon et al., 2004).

The chemical reactions occur at different temperatures during gelation and act on different components of the protein molecules. During the heating of surimi paste, hydrophobic interactions and disulfide covalent bonds form (Hamann \& MacDonald, 1992; Niwa, 1992). Hydrophobic interactions are strengthened with increased temperature and play a role in stabilizing the molecular structure of proteins (Niwa, 1992). Disulfide bonds usually form at higher temperatures in the later stages of the cooking process by the oxidation of two cysteine residues (Hamann \& MacDonald, 1992). The heating process also degrades the natural $\alpha$-helix structure of surimi paste and $\beta$-sheets are formed (Niwa, 1992). Because a higher percentage of $\beta$-sheet structure is found in more elastic products, this contributes to protein network formation (Niwa \& Nakajima, 1975; Sánchez-González et al., 2008). Intermolecular hydrogen bonds are formed among amino acid groups and help to stabilize the gel network within cooled surimi gels (Niwa, 1992).

Dynamic oscillatory rheology is a small strain test widely used in studying the heatinduced gelation of myofibrillar proteins (Karthikeyan et al., 2006). Because such small strains are used in these tests, it is possible to measure physical and molecular changes during gelation without disrupting network structure development of the gels (Hamann \& MacDonald, 1992; Yoon et al., 2004). These gelation experiments are performed by heating a sample of surimi paste at a constant rate (Yoon et al., 2004). The instrument then measures viscous and elastic 
properties that lend insight into chemical changes taking place, including mechanical, thermal, and chemical reactions (Kim, Park, \& Yoon, 2005). The storage modulus $\left(\mathrm{G}^{\prime}\right)$ is used for assessing viscoelasticity, or gel-forming ability, of the proteins (Karthikeyan et al., 2006). A perfectly viscous sample is indicated by $\mathrm{G}^{\prime}$ equal to zero, whereas $\mathrm{G}^{\prime}$ increases as the elasticity of the sample increases (Hamann \& MacDonald, 1992). This change in elasticity relates to protein unfolding and bond formation during protein gelation (Hamann \& MacDonald, 1992). The temperature at which $\mathrm{G}^{\prime}$ initially begins to increase is associated with the beginning of covalent bonding and hydrophobic interactions, while the maximum temperature of $\mathrm{G}^{\prime}$ indicates the completion of most covalent bonding (Karthikeyan et al., 2006; Yoon et al., 2004).

Additives in surimi pastes may contribute to or inhibit the gelation of surimi protein. Xiong (1992) discussed three different types of multi-component gelling systems to explain interactions between protein and additives: filled, which involves active filler within a matrix; complex, involving copolymerization with protein; and mixed gels. Previous studies have found a positive association between pre-emulsified lipids and gel network formation (Dickinson \& Chen, 1999; Pietrowski, Tahergorabi, \& Jaczynski, 2012; Wu et al., 2009). Wu and others (2009) observed that fat molecules coated with protein may crosslink with the protein matrix. Dickinson and Chen (1999) concluded that these protein-coated fat droplets acted as active fillers in heat-set whey protein-stabilized emulsions and thereby increased the elastic modulus of the resulting gels. In a study investigating the effect of fiber on surimi gelation, Sánchez-González and others (2009) observed an increase in $\beta$-sheet formation, possibly due to the dehydrating effect of fiber on protein molecules, contributing to the elasticity of surimi gels.

Differential scanning calorimetry (DSC) is used to monitor physicochemical changes that occur during heating (Wu, Akahane, Lanier, \& Hamann, 1985). It provides information on the 
temperature of protein denaturation and the enthalpy change $(\Delta \mathrm{H})$ associated with these denaturation transitions (Murray, Arntfield, \& Ismond, 1985). $\Delta \mathrm{H}$ values represent the sum of exothermic reactions (disruption of hydrophobic interactions) and endothermic reactions (disruption of hydrogen bonds) and are determined by measuring the area under the DSC transition curve (Murray et al., 1985; Wright, Leach \& Wilding, 1977). Protein denaturation is indicated by peaks in the DSC thermograms (Koshiyama, Hamano, \& Fukushima, 1980-1981; Wu et al., 1985). Wright and others attributed the first peak to the denaturation of myosin and the second peak to the denaturation of actin, signifying that myosin denatures at a lower temperature than actin (Park, Lin, Yongsawatdigul, 1997; Wright et al., 1977). Broad peaks in DSC thermograms show that the protein denaturation does not occur at a single temperature point, but instead can occur over a range of temperatures (Park \& Lanier, 1989). Because protein denaturation results in changes in rheological properties, DSC thermograms can be compared with rheological properties (Wu et al., 1985).

\section{Summary}

The current American diet is low in both fiber and omega-3 polyunsaturated fatty acids (Anderson et al., 2009; Dietary Guidelines Advisory Committee, 2010; Ratnayake \& Galli, 2009). Fiber and omega-3 rich oils have been incorporated independently into surimi seafood gels resulting in gels with acceptable textural and rheological characteristics (Benjakul, Visessanguan, \& Kwalumtharn, 2004; Cardoso, Mendes, Vaz-Pires, \& Nunes, 2009; Park, Kelleher, McClements, \& Decker, 2004; Pérez-Mateos, Boyd, \& Lanier, 2004; Sánchez-Alonso, Haji-Maleki, \& Borderías, 2007). The use of salt substitute in the form of potassium chloride (KCl) in surimi gels also results in acceptable products (Gimeno, Astiasarán, \& Bello, 1999; 
Gou, Guerrero, Gelabert, \& Arnau, 1996; Horita, Morgano, Celeghini, \& Pollonio, 2011;

Montero \& Pérez-Mateos, 2001). No research has studied the combined incorporation of fiber, omega-3 rich oils, and salt substitute in surimi seafood. The incorporation of these ingredients would create a heart-healthy, nutraceutical product. The goal of this study was to investigate the effects of a combination of fiber, omega-3 rich oil, and salt substitute on the physicochemical properties of surimi seafood.

\section{References}

Alvarez, C., Couso, L., \& Tehada, M. (1995). Sardine surimi as affected by salt concentration, blending, heat treatment and moisture. Journal of Food Science, 60(3), 622-625.

Anderson, B. M., \& Ma, D. W. L. (2009). Are all n-3 polyunsaturated fatty acids created equal? Lipids in Health and Disease, $8,33$.

Anderson, J. W., Baird, P., Davis, R. H., Ferreri, S., Knudtson, M., Koraym, A., Waters, V., \& Williams, C. L. (2009). Health benefits of dietary fiber. Nutrition Reviews, 67(4), 188205. doi:10.1111/J.1753-4887.2009.00189.x

Ang, J. F. (1991). Water retention capacity and viscosity effect of powdered cellulose. Journal of Food Science, 56(6), 1682-1684.

Ang, J. F., \& Miller, W. B. (1991). Multiple functions of powdered cellulose as a food ingredient. Cereal Foods World, 36(7), 558-564.

Appel, L. J., Frohlich, E. D., Hall, J. E., Pearson, T. A., Sacco, R. L., Seals, D. R., Sacks, F. M., Smith, S. C., Vafiadis, D. K., \& Van Horn, L. V. (2011). The importance of populationwide sodium reduction as a means to prevent cardiovascular disease and stroke: A call to action from the American Heart Association. Circulation, 123, 1138-1143.

Arterburn, L. M., Oken, H. A., Hoffman, J. P., Bailey-Hall, E., Chung, G., Rom, D., Hamersley, J., \& McCarthy, D. (2007). Bioequivalence of docosahexaenoic acid from different algal oils in capsules and in a DHA-fortified food. Lipids, 42(11), 1011-1024.

Arterburn, L. M., Oken, H. A., Hall, E. B., Hamersley, J., Kuratko, C. N., \& Hoffman, J. P. (2008). Algal-oil capsules and cooked salmon: nutritionally equivalent sources of docosahexaenoic acid. Journal of the American Dietetic Association, 108, 1204-1209. 
Benjakul, S., Visessanguan, W., \& Kwalumtharn, Y. (2004). The effect of whitening agents on the gel-forming ability and whiteness of surimi. International Journal of Food Science and Technology, 39(7), 773-781.

Bodner, J. M., \& Sieg, J. (2009). Fiber. In R. Tarté (ed.), Ingredients in meat products: Properties, functionality and applications (pp. 83-108). Springer Science + Business Media, LLC. doi:10.1007/978-0-387-71327-4_4. Retrieved January 25, 2012, from http://powderedcellulose.com/wp-content/themes/agency-sweetener-supplypc/images/fiber-properties-functionality-applications.pdf.

Bourne, M. C. (1978). Texture analysis profile. Food Technology, 37(7), 62-65.

Brownlee, I. A., Dettmar, P. W., Strugala, V., \& Pearson, J. P. (2006). The interaction of dietary fibres with the colon. Current Nutrition and Food Science, 2, 243-264.

Buyck, J. F., Blacher, J., Kesse-Guyot, E., Castetbon, K., Galan, P., Safar, M. E., Hercberg, S., \& Czernichow, S. (2009). Differential associations of dietary sodium and potassium intake with blood pressure: A focus on pulse pressure. Journal of Hypertension, 27, 1158-1164.

Calder, P. C., \& Yaqoob, P. (2009). Omega-3 polyunsaturated fatty acids and human health outcomes. BioFactors, 53(3), 266-272.

Campo, L., \& Tovar, C. (2008). Influence of the starch content in the viscoelastic properties of surimi gels. Journal of Food Engineering, 84, 140-147.

Candela, C. G., López, L. M. B., \& Kohen, V. L. (2011). Importance of a balanced omega 6/omega 3 ratio for the maintenance of health. Nutritional implications. Nutrición Hospitalaria, 26(2), 323-329.

Cardoso, C., Mendes, R., Pedro, S., \& Nunes, M. L. (2008). Quality changes during storage of fish sausages containing dietary fiber. Journal of Aquatic Food Product Technology, 17(1), 73-95.

Cardoso, C., Mendes, R., Vaz-Pires, P., \& Nunes, M. L. (2009). Effect of dietary fibre and MTGase on the quality of mackerel surimi gels. Journal of the Science of Food and Agriculture, 89, 1648-1658. doi:10.1002/jsfa.3636

Chen, Y. C., Nguyen, J., Semmens, K., Beamer, S., \& Jaczynski, J. (2006). Ehancement of omega-3 fatty acid content in rainbow trout (Oncorhynchus mykiss) fillets. Journal of Food Science, 71(7), C383-C389.

China Salt Substitute Study Collaborative Group. (2007). Salt substitution: A low-cost strategy for blood pressure control among rural Chinese. A randomized control trial. Journal of Hypertension, 25(10), 2011-2018. 
Clough, P. (2008). Marketing omega-3 products as nutraceuticals. International symposium on fatty acids - opportunities for health education and investment, 19(3), 233-234.

Cotugna, N., \& Wolpert, S. (2011). Sodium recommendations for special populations and the resulting implications. Journal of Community Health, 36, 874-882.

Dickinson, E., \& Chen, J. (1999). Heat-set whey protein emulsion gels: role of active and interactive filler particles. Journal of Dispersion Science and Technology, 20(1\&2), 197213.

Dietary Guidelines Advisory Committee. (2010). Report of the dietary guidelines advisory committee on the dietary guidelines for Americans, 2010, to the secretary of Agriculture and the Secretary of Health and Human Services. Washington, DC: Government printing office. Retrieved from http://www.cnpp.usda.gov/Publications/DietaryGuidelines/2010/ PolicyDoc/PolicyDoc.pdf

Ding, Y., Liu, Y., Yang, H., Liu, R., Rong, J., Zhao, S., \& Xiong, S. (2011). Effects of $\mathrm{CaCl}_{2}$ on chemical interactions and gel properties of surimi gels from two species of carps. European Food Research and Technology, 233, 569-576.

Domingo, J. L. (2007). Omega-3 fatty acids and the benefits of fish consumption: Is all that glitters gold? Environment International, 33, 993-998.

Gehring, C. K., Gigliotti, J. C., Moritz, J. S., Tou, J. C., \& Jaczynski, J. (2011). Functional and nutritional characteristics of proteins and lipids recovered by isoelectric processing of fish by-products and low-value fish: A review. Food Chemistry, 124, 422-431.

Geleijnse, J. M., Witteman, J. C. M., Bak, A. A. A., den Breeijen, J. H, \& Grobbee, D. E. (1994). Reduction in blood pressure with a low sodium, high potassium, high magnesium salt in older subjects with mild to moderate hypertension. British Medical Journal, 309(6952), 436-440.

Gimeno, O., Astiasarán, I., \& Bello, J. (1999). Influence of partial replacement of NaCl with KCl and $\mathrm{CaCl}_{2}$ on texture and color of dry fermented sausages. Journal of Agricultural and Food Chemistry, 47, 873-877.

Gogus, U., \& Smith, C. (2010). n-3 omega fatty acids: a review of current knowledge. International Journal of Food Science \& Technology, 45, 417-436.

Gou, P., Guerrero, L., Gelabert, J., \& Arnau, J. (1996). Potassium chloride, potassium lactate and glycine as sodium chloride substitutes in fermented sausages and in dry-cured pork loin. Meat Science, 42(1), 37-48.

Guenneugues, P., \& Morrissey, M. T. (2005). Surimi resources. In J. W. Park (Ed.), Surimi and surimi seafood $2^{\text {nd }}$ ed. (pp. 3-32), Boca Raton, FL: Taylor and Francis Group. 
Hall, G. M, \& Ahmad, N. H. (1997). Surimi and fish-mince products. In G. M. Hall (Ed.), Fish processing technology, $2^{\text {nd }}$ ed. (pp. 74-92). New York: Blackie Academic and Professional.

Hall, G. M. (2011). Surimi and fish mince products. In G. M. Hall (Ed.), Fish processing sustainability and new opportunities (pp. 98-111). Oxford: Wiley-Blackwell.

Hamann, D. D., \& MacDonald, G. A. (1992). Rheology and texture properties of surimi and surimi-based foods. In T. C. Lanier \& C. M. Lee (Eds.), Surimi technology (pp. 123-166), New York, NY: Marcel Dekker, Inc.

Hastings, R. J., Keay, J. N., \& Young, K. W. (1990). The properties of surimi and kamaboko gels from nine British species of fish. International Journal of Food Science and Technology, 25, 281-294.

Horita, C. N., Morgano, M. A., Celeghini, R. M. S., \& Pollonio, M. A. R. (2011). Physicochemical and sensory properties of reduced-fat mortadella prepared with blends of calcium, magnesium and potassium chloride as partial substitutes for sodium chloride. Meat Science, 89, 426-433.

Houston, M. C. (2011). The importance of potassium in managing hypertension. Current Hypertension Reports, 13, 309-317.

Institute of Medicine. (2005) Dietary reference intakes for energy, carbohydrate, fiber, fat, fatty acids, cholesterol, protein, and amino acids (macronutrients). National Academy Press, Washington, DC.

Juturu, V. (2008). Omega-3 fatty acids and the cardiometabolic syndrome. Journal of the Cardiometabolic Syndrome, 3, 244-253.

Karppanen, H., \& Mervaala, E. (2006). Sodium intake and hypertension. Progress in Cardiovascular diseases, 49(2), 59-75.

Karthikeyan, M., Dileep, A. O., \& Shamasundar, B. A. (2006). Effect of water washing on the functional and rheological properties of proteins from threadfin bream (Nemipterus japonicus) meat. International Journal of Food Science and Technology, 41, 1002-1010.

Kassis, N. M., Beamer, S. K., Matak, K. E., Tou, J. C., \& Jaczynski, J. (2010). Nutritional composition of novel nutraceutical egg products developed with omega-3-rich oils. Food Science and Technology, 43, 1204-1212.

Kim, Y. S., \& Park, J. W. (2008). Negative roles of salt in gelation properties of fish protein isolate. Journal of Food Science, 73(8), C585-C588. 
Kim, B. Y., Park, J. W., \& Yoon, W. B. (2005). Rheology and texture properties of surimi gels. In J.W. Park (Ed.), Surimi and surimi seafood $2^{\text {nd }}$ ed. (pp. 491-582), Boca Raton, FL: Taylor and Francis Group.

Klesk, K., Yongsawatdigul, J., Park, J. W., Viratchakul, S., \& Virulhakul, P. (2000). Gel forming ability of tropical tilapia surimi as compared with Alaska pollock and pacific whiting surimi. Journal of Aquatic Food Product Technology, 9(3), 91-104.

Koshiyama, I., Hamano, M., \& Fukushima, D. (1980-1981). A heat denaturation study of the 11s globulin in soybean seeds. Food Chemistry, 6, 309-322.

Kris-Etherton, P. M., Harris, W. S., Appel, L. J., \& AHA Nutrition Committee. (2002). Fish consumption, fish oil, omega-3 fatty acids, and cardiovascular disease. Circulation, 106, 2747-2757.

Lanier, T. C. (1986). Functional properties of surimi. Food Technology, 40(3), 107-114, 124.

Lanier, T. C. (1992). Measurement of surimi composition and functional properties. In T. C. Lanier \& C. M. Lee (Eds.), Surimi technology (pp. 123-166), New York, NY: Marcel Dekker, Inc.

Larkin, S. L., Sylvia, G. (1999). Firm-level hedonic analysis of U.S. produced surimi: Implications for processors and resource managers. Marine Resource Economics, 14, 179-198.

Lauro, G. J., Inami, O., \& Johnson, C. (2005). Color measurement and colorants for surimi seafood. In J. W. Park (Ed.), Surimi and surimi seafood $2^{\text {nd }}$ ed. (pp. 749-801), Boca Raton, FL: Taylor and Francis Group.

Lee, Y. S., Zhekov, Z. G., Owens, C. M., Kim, M., \& Meullenet, J. F. (2011). Effects of partial and complete replacement of sodium chloride with potassium chloride on the texture, flavor, and water-holding capacity of marinated broiler breast fillets. Journal of Texture Studies, 43, 124-132.

Lennie, T. A., Song, E. K., Wu, H. R., Chung, M. L., Dunbar, S. B., Pressler, S. J., \& Moser, D. K. (2011). Three gram sodium intake is associated with longer event-free survival only in patients with advanced heart failure. Journal of Cardiac Failure, 17(4), 325-330.

Lian, P. Z., Lee, C. M., \& Chung, K. H. (2002). Textural and physical properties of acid-induced and potassium-substituted low-sodium surimi gels. Journal of Food Science, 67(1), 109112.

Luo, Y. K., Kuwahara, R., Kaneniwa, M., Murata, Y., \& Kokoyama, M. (2001). Comparison of gel properties of surimi from Alaska Pollock and three freshwater fish species: Effects of thermal processing and protein concentration. Journal of Food Science, 66(3), 548-554. 
Mansfield, B. (2003). Spatial globalization: A "geography of quality" in the seafood industry. Economic Geography, 79(1), 1-16.

McManus, A., Merga, M., Newton, W. (2011). Omega-3 fatty acids. What consumers need to know. Appetite, 57, 80-83.

Martínez-Alvarez, O., Borderías, A. J., \& Gómez-Guillén, M. C. (2005). Sodium replacement in the cod (Gadus morhua) muscle salting process. Food Chemistry, 93, 125-133.

Matsui, H., Shimosawa, T., Uetake, Y., Wang, H., Ogura, S., Kaneko, T., Liu, J., Ando, K., \& Fujita, T. (2006). Protective effect of potassium against hypertensive cardiac dysfunction: Association with reactive oxygen species reduction. Hypertension, 48, 225-231.

Montasser, M. E., Shimmin, L. C., Gu, D., Chen, J., Gu, C., Kelly, T. N., Jaquish, C. E., Rice, T., Rao, D. C., Cao, J., Chen, J., Liu, D. P., Whelton, P., He, J., \& Hixson, J. E. (2010). Blood pressure response to potassium supplementation is associated with genetic variation in endothelin 1 and interactions with $\mathrm{E}$ selectin in rural Chinese. Journal of Hypertension, 28, 748-755.

Montero, P., Hurtado, J. L., \& Pérez-Mateos, M. (2000). Microstructural behaviour and gelling characteristics of myosystem protein gels interacting with hydrocolloids. Food Hydrocolloids, 14, 455-461.

Montero, P., \& Pérez-Mateos, M. (2001). Mince gels with hydrocolloids and salts: Composition/function relationships and discrimination of functionality by multivariate analysis. European Food Research and Technology, 213, 338-342.

Murray, E. D., Arntfield, S. D., \& Ismond, M. A. H. (1985). The influence of processing parameters on food protein functionality II. Factors affecting thermal properties as analyzed by differential scanning calorimetry. Canadian Institute of Food Science and Technology Journal, 18(2), 158-162.

Nair, S. S. D., Leitch, J. W., Falconder, J., \& Garg, M. L. (1997). Prevention of cardiac arrhythmia by dietary (n-3) polyunsaturated fatty acids and their mechanism of action. Journal of Nutrition, 127, 383-393.

Narayan, B., Miyashita, K., \& Hosakawa, M. (2006). Physiological effects of eicosapentaenoic acid (EPA) and docosahexaenoic acid (DHA) - a review. Food Reviews International, 22, 291-307.

Narcisco-Gaytán, C., Shin, D., Sams, A. R., Keeton, J. T., Miller, R. K., Smith, S. B., \& Sánchez-Plata, M. X. (2011). Lipid oxidation stability of omega-3- and conjugated linolenic acid-enriched sous vide chicken meat. Poultry Science, 90, 473-480. 
Nitsan, Z., Mokady, S., \& Sukenik, A. (1999). Enrichment of poultry products with $\omega 3$ fatty acids by dietary supplementation with the alga Nannochloropsis and mantur oil. Journal of Agricultural and Food Chemistry, 47, 5127-5132.

Niwa, E. (1992). Chemistry of surimi gelation. In T. C. Lanier \& C. M. Lee (Eds.), Surimi Technology (pp. 429-500), New York, NY: Marcel Dekker, Inc.

Niwa, E., \& Nakajima, G. (1975). Differences in protein structure between elastic kamaboko and brittle one. Nippon Suisan Gakkaishi, 41, 579.

Park, J. W. (1995). Surimi gel colors as affected by moisture content and physical conditions. Journal of Food Science, 60(1), 15-18.

Park, J. W. (2005). Surimi seafood: Products, market, and manufacturing. In J. W. Park (Ed.), Surimi and surimi seafood, $2^{\text {nd }}$ ed. (pp. 375-433), Boca Raton, FL: Taylor and Francis Group.

Park, Y., Kelleher S. D., McClements, D. J., \& Decker, E. A. (2004). Incorporation and stabilization of omega-3 fatty acids in surimi made from cod, Gadus morhua. Journal of Agricultural and Food Chemistry, 52, 597-601.

Park, J. W., \& Lanier, T. C. (1989). Scanning calorimetric behavior of tilapia myosin and actin due to processing of muscle and protein purification. Journal of Food Science, 54, 49-51.

Park, J. W., \& Lin, T. M. J. (2005). Surimi: Manufacturing and evaluation. In J. W. Park (Ed.), Surimi and surimi seafood, $2^{\text {nd }}$ ed. (pp. 33-106), Boca Raton, FL: Taylor and Francis Group.

Park, J. W., Lin, T. M., \& Yongsawatdigul, J. (1997). New developments in manufacturing of surimi and surimi seafood. Food Reviews International, 13(4), 577-610.

Pérez-Mateos, M., Boyd, L. C., \& Lanier, T. C. (2004). Stability of omega-3 fatty acids in fortified surimi seafoods during chilled storage. Journal of Agricultural and Food Chemistry, 55, 7944-7949.

Pietrowski, B. N., Tahergorabi, R., Matak, K. E., Tou, J. C., \& Jaczynski, J. (2011). Chemical properties of surimi seafood nutrified with $\omega-3$ rich oils. Food Chemistry, 129, 912-919.

Pietrowski, B. N., Tahergorabi, R., Jaczynski, J. (2012). Dynamic rheology ant thermal transitions of surimi seafood enhanced with $\omega$-3-rich oils. Food Hydrocolloids, 27, 384389.

Pigott, G. M. (1986). Surimi: The "high tech" raw materials from minced fish. Food Reviews International, 2(2), 213-246.

Prosky, L. (2000) When is dietary fiber considered a functional food? BioFactors, 12, 289-297. 
Psota, P. L., Gebauer, S. K., \& Kris-Etherton, P. (2006). Dietary omega-3 fatty acid intake and cardiovascular risk. American Journal of Cardiology, 98 (suppl), 3i-18i.

Raninen, K., Lappi, J., Mykkänen, H., \& Poutanen, K. (2010). Dietary fiber type reflects physiological functionality: Comparison of grain fiber, inulin, and polydextrose. Nutrition Reviews, 69(1), 9-21. doi:10.1111/J.1753-4887.2010.00358.x

Ratnayake, W. M., \& Galli, C. (2009). Fat and fatty acid terminology, methods of analysis and fat digestion and metabolism: A background review paper. Annals of Nutrition and Metabolism, 55, 8-43.

Reed, Z. H., \& Park, J. W. (2008). Qualification and quantification of fish protein in prepared surimi crabstick. Journal of Food Science, 73(5), c329-c334.

Ruxton, C. H. S., Reed, S. C., Simpson, M. J. A., \& Millington, K. J. (2007). The health benefits of omega-3 polyunsaturated fatty acids: A review of the evidence. Journal of Human Nutrition and Dietetics, 20, 275-285.

Sánchez-Alonso, I., Haji-Maleki, R., \& Borderias, A. J. (2007). Wheat fiber as a functional ingredient in restructured fish products. Food Chemistry, 100, 1037-1043. doi:10.1016/j.foodchem.2005.09.090

Sánchez-Gonzalez, I., Carmona, P., Moreno, P., Borderías, J., Sánchez-Alonso, I., RodríguezCasado, A., \& Careche, M. (2008). Protein and water structural changes in fish surimi during gelation as revealed by isotropic H/D exchange and Raman spectroscopy. Food Chemistry, 106, 56-64.

Sánchez-González, I., Rodríguez-Casado, A., Careche, M., \& Carmona, P. (2009). Raman analysis of surimi gelation by addition of wheat dietary fibre. Food Chemistry, 112, 162168.

Shie, J. S., \& Park, J. W. (1999). Physical characteristics of surimi seafood as affected by thermal processing conditions. Journal of Food Science, 64(2), 287-290.

Simopoulos, A. P. (2003). Importance of the ratio of omega-6/omega-3 essential fatty acids: Evolutionary aspects. World Review of Nutrition and Dietetics, 92, 1-22.

Siró, I., Kápolna, E., Kápolna, B., \& Lugasi, A. (2008). Functional food. Product development, marketing and consumer acceptance - a review. Appetite, 51, 456-467.

Smith, C. E., \& Tucker, K. L. (2011). Health benefits of cereal fibre: A review of clinical trials. Nutrition Research Reviews, 24, 118-131. doi:10.1017/S0954422411000023

Tahergorabi, R., Beamer, S. K., Matak, K. E., \& Jaczynski, J. Salt substitution in surimi seafood and its effects on instrumental quality attributes. $L W T$, submitted for publication. 
Tahergorabi, R., \& Jaczynski, J. (2012). Physiochemical changes in surimi with salt substitute. Food Chemistry, 132, 1281-1286.

Taylor, R. S., Ashton, K. E., Moxham, T., Hooper, L., \& Ebrahim, S. (2011). Reduced dietary salt for the prevention of cardiovascular disease: A meta-analysis of randomized controlled trials (Cochrane review). American Journal of Hypertension, 24(8), 843-853.

Tolasa, S., Lee, C. M., Cakli, S. (2010). Physical and oxidative stabilization of omega-3 fatty acids in surimi gels. Journal of Food Science, 75(3), C305-C310.

Tou, J. C., Jaczynski, J., \& Chen, Y. C. (2007). Krill for human consumption: nutritional value and potential health benefits. Nutrition Reviews, 65(2), 63-77.

Van Mierlo, L. A. J., Greyling, A., Zock, P. L., Kok, F. J., \& Geleijnse, J. M. (2010). Suboptimal potassium intake and potential impact on population blood pressure. Archives of Internal Medicine, 170(16), 1501-1502.

Weickert, M. O., \& Pfeiffer, A. F. H. (2008). Metabolic effects of dietary fiber consumption and prevention of diabetes. Journal of Nutrition, 138, 439-442.

Wesseling, S., Koeners, M. P., \& Joles, J. A. (2011). Salt sensitivity of blood pressure: Developmental and sex-related effects. American Journal of Clinical Nutrition, 94(suppl), 1928S-1932S.

Wright, D. J., Leach, I. B. \& Wilding, P. (1977). Differential scanning calorimetric studies of muscle and its constituent proteins. Journal of the Science of Food and Agriculture, 28, 557-564.

Wu, M. C., Akahane, T., Lanier, T. C., \& Hamann, D. D. (1985). Thermal transitions of actomyosin and surimi prepared from Atlantic croaker as studied by differential scanning calorimetry. Journal of Food Science, 50, 10-13.

Wu, M., Youling, L., Xiong, Y. L., Chen, J., Tang, X., Zhou, G. (2009). Rheological and microstructural properties of porcine myofibrillar protein - lipid emulsion composite gels. Journal of Food Science, 74(4), e207-e217.

Xiong, Y. L. (1992). Thermally induced interactions and gelation of combined myofibrillar protein from white and red broiler muscles. Journal of Food Science, 57(3), 581-585.

Yoon, W. B., Gunasekaran, S., \& Park, J. W. (2004). Characterization of thermorheological behavior of Alaska Pollock and pacific whiting surimi. Journal of Food Science, 69(7), E338-E343. 
Yoon, K. S., \& Lee, C. M. (1990). Effect of powdered cellulose on the texture and freeze-thaw stability of surimi-based shellfish analog products. Journal of Food Science, 55(1), 8791.

Yoon, K., Lee, C. M., \& Chung, K. H. (1987, November). Effect of powdered cellulose on the texture and water binding properties of surimi-based products. $1^{\text {st }}$ Joint Conference of Tropical and Subtropical Fisheries Technology and Atlantic Fisheries Technology, Orlando, FL. Retrieved from http://fshn.ifas.ufl.edu/seafood/sst/AnnPdf/12th_516.pdf

Zhao, G., Etherton, T. D., Martin, K. R., West, S. G., Gillies, P. J., \& Kris-Etherton, P. M. (2004). Dietary $\alpha$-linolenic acid reduces inflammatory and lipid cardiovascular factors in hypercholesterolemic men and women. The Journal of Nutrition, 134, 2991-2997. 


\section{CHAPTER III: PYSICOCHEMICAL PROPERTIES OF SURIMI NUTRIFIED WITH DIETARY FIBER}

\section{Introduction}

Most American diets are deficient in dietary fiber. The Institute of Medicine recommends fiber intake to be 25-38 grams of fiber per day; however the average intake is only about 15 grams each day (Dietary Guidelines Advisory Committee, 2010). Dietary fiber is defined as "remnants of the edible part of the plant and analogous carbohydrate that are resistant to digestion and absorption in the human small intestine with complete or partial fermentation in the human large intestine. It includes polysaccharides, oligosaccharides, lignin and associated plant substances...that promote beneficial physiological effects" (Bodner \& Sieg, 2009; Prosky, 2000). It has been shown that a high intake of dietary fiber is protective against coronary heart disease, diabetes, obesity, and intestinal disorders (Anderson et al., 2009).

Although most beneficial health effects associated with fiber are attributed to soluble fiber, insoluble fiber has been shown to have a significant impact on health, especially in recent years. Insoluble fiber is generally associated with intestinal health due to its effect of increasing fecal bulk and stool frequency, decreasing transit time, and diluting carcinogenic compounds, thereby preventing constipation and possibly reducing the risk of colorectal cancer (Brownlee, Dettmar, Strugala, \& Pearson, 2006; Raninen, Lappi, Mykkänen, \& Poutanen, 2010). Insoluble fiber specifically has also been implicated in being protective against cardiovascular disease (Smith \& Tucker, 2011). Insoluble fiber intake more than soluble fiber intake is associated with a reduced risk of type 2 diabetes mellitus and improved insulin sensitivity (Smith \& Tucker, 
2011; Weickert \& Pfeiffer, 2008). Insoluble fiber may also reduce the risk of obesity possibly by replacing energy dense foods and increasing satiety (Smith \& Tucker, 2011).

In addition to these physiological effects, insoluble fiber also has technological effects that are of benefit to the food science industry. Powdered cellulose specifically is white in color and has a bland taste (Bodner \& Sieg, 2009). It is also chemically inert. Specific fiber lengths of powdered cellulose have distinct effects, with longer fibers (>110 micron) having the ability to bind more water or oil than shorter fiber lengths due to the porous matrix of long fiber length powdered cellulose (Ang, 1991). Although thickening properties are not generally seen with insoluble fiber, cellulose with a fiber length of 110 microns has been shown to have some thickening properties and therefore may have additional functional benefits when compared to other insoluble fibers (Ang, 1991). These characteristics show powdered cellulose may have possible potential for incorporation into food products.

Already, powdered cellulose has been successfully incorporated in baked goods and some processed meat products as a non-caloric bulking agent. Cellulose has improved the volume and stability of cake products and decreased the fat content of fried baked goods while maintaining moisture (Ang \& Miller, 1991). It has also been applied to sausages to reduce fat while retaining textural properties (Bengtsson, Montelius, \& Tornberg, 2011). In these uses, fiber has been shown to have beneficial effects on the properties of the products.

Although insoluble fiber has been well researched in baked goods, its application in surimi seafood has not been thoroughly studied and it is not traditionally added to surimi. Many previous studies incorporating fiber into surimi have utilized soluble fibers such as carrageenan, chicory root inulin, garrofin, guar, and xanthan (Cardoso, Mendes, \& Nunes, 2007; Cardoso, Mendes, Vaz-Pires, \& Nunes, 2009; Sánchez-Alonso, Haji-Maleki, \& Borderias, 2007a). These 
soluble fibers have shown some detrimental effects on textural properties of surimi gels, including loss of elasticity and gel strength combined with hardening of gels (Cardoso et al., 2007). In some cases a softening of surimi gels is seen with soluble fiber addition (Cardoso et al., 2009). These effects are especially noticeable when compared to insoluble fiber addition, which tend to improve hardness, springiness, and chewiness (Cardoso et al., 2009; SánchezAlonso et al., 2007a).

The bland flavor and white color of powdered cellulose make it an optimal choice for addition to surimi, for which whiteness is an essential characteristic; however, the effects of powdered cellulose on gelation and textural properties have not been thoroughly researched. Many previous studies have used inner pea fiber and wheat dietary fiber (Cardoso et al., 2009; Sánchez-Alonso et al., 2007a; Sánchez-Alonso, Solas, \& Borderías, 2007b). Also, research with insoluble fiber has produced conflicting results. Cardoso et al. (2009) found that inner pea fiber addition to chub and Atlantic mackerel increased hardness, springiness, and chewiness and improved elastic and viscous modules. Sánchez-Alonso et al. (2007a) also found that wheat fiber addition to hake and horse mackerel improved whiteness and harness of surimi gels. However, Sánchez-Alonso et al. (2007b) observed a loss of hardness and gel strength as well as a decrease in whiteness with wheat fiber addition to giant squid surimi. One study also observed the effects of powdered cellulose with fiber lengths of 11 to 55 microns on surimi gels and found that more than $2 \%$ fiber addition resulted in significantly lower firmness, chewiness, and rubberiness (Yoon, Lee, \& Chung, 1987).

These varied results may be caused by the variation in marine species. The type or brand of insoluble fiber as well as the fiber length used have different effects in application to surimi gels. In addition, in the design of many of the previously mentioned studies, protein composition 
of the surimi gels was displaced by added fiber, making protein a variable contributing to the results. Surimi gels with lower percent composition of protein will have poorer textural properties compared to gels with a higher composition of protein (Park, 2005). Thus the effects of powdered cellulose fiber on physicochemical properties of surimi seafood have not been thoroughly studied. The objectives of this study are to determine the effects of dietary fiber on 1) color and textural properties and 2) endothermic transitions and gelation properties of surimi gels formulated with a constant protein component.

\section{Materials and Methods}

\section{Surimi}

Frozen Alaska Pollock surimi grade A was obtained from Trident Seafoods Corp. (Seattle, WA). Surimi contained cryoprotectants ( $4 \mathrm{~g} / 100 \mathrm{~g}$ of sorbitol and $4 \mathrm{~g} / 100 \mathrm{~g}$ of sucrose), $0.15 \mathrm{~g} / 100 \mathrm{~g}$ of sodium tripolyphosphate, and $0.15 \mathrm{~g} / 100 \mathrm{~g}$ of tetrasodium pyrophosphate. Frozen surimi blocks (10 kg each) were shipped overnight in heavily insulated industrial strength boxes filled with ice. Upon arrival surimi blocks were cut into approximately $800 \mathrm{~g}$ units, vacuum-packaged, and stored at $-80^{\circ} \mathrm{C}$ until needed. The moisture content of surimi was determined as $76.04 \mathrm{~g} / 100 \mathrm{~g}$ (AOAC, 1995).

\section{Preparation of surimi paste}

Surimi pastes were made using the procedure described by Jaczynski and Park (2003, 2004). Briefly, frozen surimi was thawed in the refrigerator $\left(4^{\circ} \mathrm{C}\right)$ for 1 day. Surimi was chopped in a universal food processor (Model UMC5, Stephan Machinery Corp., Columbus, $\mathrm{OH}$ ) at low speed for $1 \mathrm{~min}$. A surimi paste was obtained by adding $2 \mathrm{~g} / 100 \mathrm{~g}$ of $\mathrm{NaCl}$ and 
chopping at low speed for $0.5 \mathrm{~min}$. Final moisture content was adjusted to $84 \mathrm{~g} / 100 \mathrm{~g}$ by adding chilled water $\left(4^{\circ} \mathrm{C}\right)$ to the paste along with $2.0 \mathrm{~g} / 100 \mathrm{~g}$ crab flavor (F-11019, Activ International, Mitry-Mory Cedex, France). The crab flavor was a water-soluble liquid mixed with a powder. Fiber and silicon dioxide were added to the surimi paste in several combinations (described below) for a final concentration of $8 \mathrm{~g} / 100 \mathrm{~g}$. One treatment without added fiber (with $8 \mathrm{~g} / 100 \mathrm{~g}$ silicon dioxide) was a control. To mix all of the ingredients with surimi paste, chopping was applied at low speed for 1 min. Additional chopping was performed at high speed under vacuum ( 0.5 bar) for the last $3 \mathrm{~min}$. The paste temperature was controlled between $1-4^{\circ} \mathrm{C}$ during chopping. Surimi pastes were prepared in $1 \mathrm{~kg}$ batches with final formulations as listed in Table 1.

The fiber added during the preparation of the surimi paste was Solka Floc® Powdered Cellulose 900 FCC, obtained from the International Fiber Corporation (North Tonawanda, NY). Solka Floc ${ }^{\circledR}$ Powdered Cellulose 900 FCC was used due to the high water retention of the fiber (9.5 g/g fiber). All ingredients remained constant except for fiber and silicon dioxide. Treatments included $0 \%$ fiber ( $0 \%$ powdered cellulose, $8 \%$ silicon dioxide - control), $2 \%$ fiber ( $2 \%$ powdered cellulose, $6 \%$ silicon dioxide), $4 \%$ fiber ( $4 \%$ powdered cellulose, $4 \%$ silicon dioxide), $6 \%$ fiber ( $6 \%$ powdered cellulose, $2 \%$ silicon dioxide), and $8 \%$ fiber ( $8 \%$ powdered cellulose, $0 \%$ silicon dioxide). Pastes prepared in this manner were used to develop heat-set surimi gels for evaluation of color (tristimulus color values) and texture (texture profile analysis, Kramer shear, and torsion test).

\section{Preparation of surimi gels}

Surimi paste was stuffed into (A) stainless steel tubes $($ length $=17.5 \mathrm{~cm}$, internal diameter $=1.9 \mathrm{~cm}$ ) with screw end caps for determination of color and texture properties using 
tristimulus color values ( $\left.\mathrm{L}^{*} \mathrm{a}^{*} \mathrm{~b}^{*}\right)$, texture profile analysis (TPA) and Kramer shear test; and (B) hour-glass pre-molded stainless steel torsion tubes $($ length $=17.5 \mathrm{~cm}$, end diameter $=1.9 \mathrm{~cm}$, midsection diameter $=1.0 \mathrm{~cm}$ ) with screw and caps for determination of texture properties using the torsion shear stress and shear strain. The tubes were heated in a water bath set at $90^{\circ} \mathrm{C}$ for 15 min (Taskaya, Chen, Beamer, \& Jaczynski, 2009). Following heating, tubes were chilled in ice slush and surimi gels were removed for analysis.

\section{Color properties of heat-set surimi gels}

The gel samples were equilibrated to room temperature for $2 \mathrm{~h}$ prior to the color measurement. The color properties of heat-set surimi gels were determined using a Minolta Chroma Meter CR-300 colorimeter (Minolta Camera Co. Ltd., Osaka, Japan). At least ten cylindrical gels $($ height $=2.54 \mathrm{~cm}$, diameter $=1.90 \mathrm{~cm})$ per treatment were used for color measurements. The values for the CIE (Commission Internationale d'Eclairage of France) color system using $\mathrm{L}^{*} \mathrm{a} \mathrm{b}^{*}$ tristimulus color values were determined. Whiteness of gels was

calculated by the following equation (Kristinsson et al., 2005; National Fisheries Institute, 1991):

$$
\text { Whiteness }=100-\left[\left(100-\mathrm{L}^{*}\right)^{2}+\mathrm{a}^{*^{2}}+\mathrm{b}^{*^{2}}\right]^{1 / 2}
$$

\section{Texture properties of heat-set surimi gels}

Three different methods were employed to determine texture: the torsion test, Kramer shear test, and texture profile analysis (TPA). Although these measurements are commonly employed for determination of textural properties, each method provides slightly different information. The torsion test is considered a fundamental test for texture, while the Kramer shear test and TPA are empirical tests (Kim et al., 2005). The most comprehensive understanding of textural properties is provided by a combination of the fundamental methods 
and empirical tests; therefore, these three different methods were employed in the present study.

The gel samples were equilibrated to room temperature for $2 \mathrm{~h}$ prior to the texture measurement.

Torsion test of heat-set surimi gels was performed according to Chen \& Jaczynski (2007a; 2007b) and Jaczynski \& Park (2003b). At least six hour-glass cylindrical gels per treatment were glued to plastic discs and subjected to torsional shear using a Hamman Gelometer (Gel Consultant, Raleigh, NC) set at $2.5 \mathrm{rpm}$. Shear stress and shear strain at mechanical fracture were measured to determine gel strength and gel cohesiveness, respectively.

For the Kramer shear test, at least ten cylindrical gels $($ height $=8.0 \mathrm{~cm}$, diameter $=1.9$ $\mathrm{cm}$ ) per treatment were tested using a texture analyzer (Model TA-HDi, Texture Technologies Corp., Scarsdale, NY) with a Kramer cell attachment (Tahergorabi et al., 2011). The Kramer shear cell consisted of five 3.0-mm thick and 70-mm wide shear blades passing through a cell with a corresponding number of slots. Individual gel samples were weighed and placed under the blades in the Kramer cell. Shear force was measured at a $127 \mathrm{~mm} / \mathrm{min}$ crosshead speed and expressed as maximum peak force ( $\mathrm{g}$ peak force per $\mathrm{g}$ of gel sample).

Texture profile analysis (TPA) of the gels was performed according to Cheret et al. (2005). At least ten cylindrical gels (height $=2.54 \mathrm{~cm}$, diameter $=1.90 \mathrm{~cm}$ ) per treatment were used for the TPA measurement. Gel samples were subjected to two-cycle compression at 50\% compression using the texture analyzer with a 70-mm TPA compression plate attachment moving at a speed of $127 \mathrm{~mm} / \mathrm{min}$. From the resulting force-time curves, hardness, springiness, cohesiveness, gumminess, chewiness, and resilience were determined.

\section{Differential scanning calorimetry (DSC)}

Surimi paste was tested to determine the net heat energy (enthalpy, $\Delta \mathrm{H}$ ) as well as the onset $\left(\mathrm{T}_{\text {onset }}\right)$ and maximum $\left(\mathrm{T}_{\max }\right)$ temperatures for endothermic transitions of the proteins using 
differential scanning calorimeter (DSC Infinity Series F5010, Instrument Specialists, Inc., Spring Grove, IL). Approximately $20 \mathrm{mg}$ of a paste sample was hermetically sealed in an aluminum pan and scanned between 20 and $90^{\circ} \mathrm{C}$ at a heating rate of $10^{\circ} \mathrm{C} / \mathrm{min}$ (Park \& Lanier, 1989; Yongsawatdigul et al., 2004). Careful attention was paid to ensure good contact between the paste sample and the bottom of the aluminum pan. Temperature calibrations were performed prior to measurements according to the manufacturer and an empty pan was used as reference. At least five thermograms per treatment were generated to determine $\Delta \mathrm{H}, \mathrm{T}_{\text {onset }}$, and $\mathrm{T}_{\max }$.

\section{Oscillatory dynamic rheology}

The non-destructive, gelation properties of the surimi pastes were determined using a cone and plate attached to an oscillatory dynamic rheometer (Bohlin CVOR 200, Malvern Instruments Ltd., Worcestershire, UK). Once the sample was pressed by lowering the measuring geometry plate, excess sample was removed with a stainless steel spatula. The gap between measuring geometry and peliter plates was adjusted to $150 \mu \mathrm{m}$. The storage modulus (G') was measured with a temperature increasing from 25 to $95^{\circ} \mathrm{C}$ at the heating rate of $1{ }^{\circ} \mathrm{C} / \mathrm{min}(\mathrm{Chen} \&$ Jaczynski 2007a; 2007b). Tests were conducted at $1 \%$ strain and $0.1 \mathrm{~Hz}$ frequency. A plastic cover supplied from the company was used to prevent moisture evaporation during measurement. An average of 3 rheograms per treatment was used to determine G'.

\section{Statistical Analysis}

One batch of each treatment was created. In each batch at least ten measurements for determination color $\left(L^{*} a^{*} b^{*}\right)$ were performed, six for torsion test, ten for Kramer test, and ten for TPA. Data were subjected to one-way analysis of variance (ANOVA). A significant difference was determined at the 0.05 probability level and differences between treatments were tested using the Least Significant Difference (LSD) test (Freud and Wilson, 1997). All statistical 
analyses of data were performed using SAS (2002). The data are reported as mean values \pm standard deviation (SD).

\section{Results and Discussion}

\section{Color properties of heat-set surimi gels}

Figure 1 shows the tristimulus color values $\left(\mathrm{L}^{*} \mathrm{a}^{*} \mathrm{~b}^{*}\right)$ and a plot of the whiteness values. $\mathrm{L}^{*}$ is a scale, $0-100$, of blackness and whiteness with 0 being more black and 100 being more white. The value $\mathrm{a}^{*}$ correlates with redness (positive values) and greenness (negative values), and $b^{*}$ is a measure of yellowness (positive values) and blueness (negative values). Whiteness was calculating using $\mathrm{L}^{*}, \mathrm{a}^{*}$, and $\mathrm{b}^{*}$ as previously described. Overall whiteness decreased with the addition of fiber. This is mainly seen in the $6 \%$ and $8 \%$ treatments as they are significantly less white $(\mathrm{P}<0.05)$ than the $2 \%$ and $4 \%$ treatments. This decrease in whiteness correlates with a decrease in $\mathrm{L}^{*}$ values with increasing fiber $(\mathrm{P}<0.05)$; however, this decrease is only seen with more than $4 \%$ fiber added to the product. The $\mathrm{a}^{*}$ and $\mathrm{b}^{*}$ measures showed a similar trend. These values showed a significant decrease with each incremental increase in fiber $(\mathrm{P}<0.05)\left(\mathrm{a}^{*}\right.$ : $0.3 \pm 0.0$ for control vs. $-2.8 \pm 0.1$ for $8 \%$ fiber; $b^{*}: 9.5 \pm 0.7$ for control vs. $5.4 \pm 0.2$ for $8 \%$ fiber). This indicates a shift away from neutral for $\mathrm{a}^{*}$ toward a greener product, and in the case of $\mathrm{b}^{*}$, a shift toward a less yellow product. Although whiteness decreased with these samples, these values are still acceptable of high quality surimi gels.

Other studies have also observed the effects of fiber on color values. Sánchez-Alonso et al. (2007a) used wheat fiber as an additive in hake and horse mackerel. They found a significant increase $(\mathrm{P}<0.05)$ in whiteness in proportion to the amount of fiber added $(0 \%, 3 \%$, or $6 \%)$ in both raw and cooked samples. Cardoso et al. (2009) compared treatments of mackerel with inner 
pea fiber to mackerel with chicory root inulin and found no significant effect on color values or whiteness in treatments with $0 \%, 2 \%$ and $4 \%$ fiber. In another study, Sánchez-Alonso et al. (2007b) incorporated wheat dietary fiber into giant squid surimi and found a slight decrease in whiteness from $83.5 \%$ with $0 \%$ fiber to $79.6 \%$ with $6 \%$ fiber. This is comparable to the present study where a decrease in whiteness was also seen; however, in the present study the $4 \%$ fiber treatment had the highest whiteness value (even over the $0 \%$ fiber treatment) at $84.08 \%$ and this value decrease with the addition of fiber to $81.53 \%$ with $8 \%$ fiber. Sánchez-Alonso et al. (2007b) observed a similar decrease in lightness $\left(\mathrm{L}^{*}\right)$ and a significant increase in yellowness $\left(+b^{*}\right)$. The present study also observed a slight decrease in lightness. In contrast, the yellowness was seen to decrease proportional to added fiber.

There are several possible explanations for the effects seen in these studies. It is probable that both the fiber type and the species of fish used impacted the tristimulus color values. Fish species may have the largest impact since the flesh of some species is darker than that of others. This may explain the lack of significant color differences with the mackerel, which has darker flesh than Alaska Pollock. In fish with darker flesh, fiber seems to have a whitening effect, whereas fish with white flesh do not benefit from the whitening effect.

\section{Texture properties of heat-set gels}

Torsion test was used to measure shear stress and shear strain at mechanical fracture of surimi gels. These measures correspond to gel strength and cohesiveness, respectively (Kim et al., 2005). Shear stress and shear strain are shown in Figure 2. Treatments with $2 \%$, 4\%, and $6 \%$ fiber showed significantly higher $(\mathrm{P}<0.05)$ shear stress than the control and $8 \%$ fiber treatments, indicating a greater gel strength with $2 \%$ to $6 \%$ fiber addition. Although these treatments all had similar shear stress, shear strain was highest for the $2 \%$ fiber treatment 
$(\mathrm{P}<0.05)$ indicating that $2 \%$ fiber formed the most cohesive gel. The $4 \%$ and $6 \%$ fiber treatments had similar, yet lower $(\mathrm{P}<0.05)$ shear strain values. The control and $8 \%$ fiber treatments had the lowest shear strain values $(\mathrm{P}<0.05)$. These results indicate that a fiber addition of $2 \%$ to $6 \%$ will produce gels with greater gel strength and cohesiveness.

The Kramer shear test is another measure of gel strength. Treatments with $6 \%$ and $8 \%$ fiber demonstrated the highest Kramer force $(\mathrm{P}<0.05)$ (Figure 3). This is contradictory to the torsion test which showed $8 \%$ fiber having the lowest shear stress and thus gel strength, showing that multiple instruments are necessary to evaluate the various components of texture. Both $2 \%$ fiber and 4\% fiber showed a higher Kramer force than the control $(\mathrm{P}<0.05)$, but were lower than the $6 \%$ and $8 \%$ treatments.

Texture Profile Analysis (TPA) (Table 2) measures various textural parameters: hardness, the peak height on the first compression that measures a food's resistance during a bite; springiness, the ratio of product height on the second compression to the original compression distance that measures the ability of the product to retain its shape and size after one bite; cohesiveness, the ratio of the second compression area to the first compression area that measures the resistance of the product during chewing; gumminess, the product of hardness and chewiness that measures strength required in chewing; chewiness, the product of gumminess and springiness that measures the energy used in chewing; and resilience, a measure of how well a product regains its original position, (Cardoso, Mendes, Pedro, \& Nunes., 2008). There was no difference in springiness among the treatments. Cohesiveness results reflected shear stress and shear strain values, with $2 \%$ and $4 \%$ fiber having the highest values $(\mathrm{P}<0.05)$ and the control and 8\% fiber having the lowest values $(\mathrm{P}<0.05)$. Hardness (Figure 3 ), gumminess and chewiness showed similar trends, increasing incrementally with the addition of fiber. $6 \%$ and $8 \%$ fiber had 
the greatest gumminess and chewiness $(\mathrm{P}<0.05)$, and $8 \%$ fiber had the greatest hardness $(\mathrm{P}<0.05)$. Resilience, however, showed the opposite trend among the treatments with resilience decreasing as percent fiber increased. Resilience was greatest for $2 \%$ fiber $(\mathrm{P}<0.05)$.

In general, the results of the torsion test, Kramer shear test, and TPA were supportive of each other. Similar results were found among all tests. The control treatment showed properties of a weak, soft gel, whereas the $8 \%$ fiber treatment formed a gel with great hardness, chewiness and gumminess, yet was also a weaker gel than the $2 \%, 4 \%$, and $6 \%$ treatments. These treatments showed greater gel strength and cohesiveness, with $6 \%$ fiber having the greater hardness.

Previous studies of fiber addition to surimi report mixed results. Some studies report a decrease in chewiness, cohesiveness, springiness, hardness, gel strength, and elasticity (Cardoso et al., 2007; Cardoso et al., 2008; Sánchez-Alonso et al., 2007b; Yoon et al., 1987). Others report increased chewiness, springiness, hardness, elasticity, and gel strength (Cardoso et al., 2007; 2008; 2009; Sánchez-Alonso et al., 2007a). These results vary depending on the type of fiber used and their level of incorporation in surimi. Yoon et al. (1987) reported a decrease in firmness, chewiness, and rubberiness when fiber was incorporated above $2 \%$ in surimi gels. Similarly, Sánchez-Alonso et al. (2007b) reported a decrease in chewiness, gel strength, hardness, and cohesiveness with wheat dietary fiber incorporated at $3 \%$ and $6 \%$ levels. However, in another study, Sánchez-Alonso et al. (2007a) found hardness to increase when water was not added to maintain constant moisture. Cardoso et al. $(2007,2009)$ found chicory root inulin to reduce hardness and increase elasticity of surimi gels. When inner pea fiber was used instead, increased hardness, springiness, and chewiness was seen (Cardoso et al., 2009). 
The mechanisms for these findings may be related to a loss of gel strength seen related to decreased protein concentration in proportion to the increased fiber addition. Surimi with lower protein content is known to produce less firm gels, which would affect the textural properties of the gels. In the present study, protein concentration remained constant. This may explain the increased hardness, chewiness, gumminess, springiness, Kramer shear force, and shear stress and strain seen in this study. In addition, it is possible that fiber incorporation may disrupt the existing protein matrix (Cardoso et al., 2007; Sánchez-Alonso et al., 2007b). High fiber incorporation of $8 \%$ in the present study did result in significantly lower shear stress and shear strain values, which may be explained by disruption of the protein matrix.

\section{Differential scanning calorimetry (DSC)}

Irreversible denaturation of protein is a necessary step in the process of heat-induced surimi protein gelation. Because surimi has been washed of sarcoplasmic proteins, the protein components present in the surimi used in this study are myofibrillar proteins, composed of actin and myosin. These proteins denature at different temperatures, with the myosin undergoing thermal denaturation at a lower temperature than actin. Therefore, the first peak in the DSC thermograms (Figure 4) corresponds to myosin denaturation and the second peak corresponds to actin denaturation (Wright, Leach, \& Wilding, 1977).

The objective of evaluating DSC in this study was to measure thermal denaturation of actin and myosin under the influence of powdered cellulose fiber. Surimi pastes were used for the DSC tests. Results showed that the changes in $\mathrm{T}_{\max }$ of myosin and actin were relatively unchanged among the treatments, with Peak 1 occurring around $30-35^{\circ} \mathrm{C}$ and Peak 2 occurring around $70-75^{\circ} \mathrm{C}$ for all treatments. From these results it is seen that powdered cellulose fiber does not affect denaturation of actin or myosin. This implies that fiber does not interact with 
thermal gelation of proteins in the surimi gels. Powdered cellulose fiber has been reported to be a chemically inert product, and therefore does not interfere with gelation or denaturation (Sánchez-Alonso, et al., 2007a; Yoon et al., 1987).

\section{Oscillatory dynamic rheology}

In addition to DSC, dynamic rheology was used to study heat-induced gelation of myofibrillar proteins. Rheology is useful in determining textural characteristics of gels as well as chemical characteristics that contribute to gelation (Hamann \& MacDonald, 1992). Viscoelasticity is one measure of dynamic rheology and is indicated by the elastic modulus, $\mathrm{G}^{\prime}$. $\mathrm{G}^{\prime}$ is a measure of the viscous vs. elastic nature of a sample. When $\mathrm{G}^{\prime}$ is equal to zero the sample is entirely viscous in nature. As a sample becomes more elastic, this value increases. This process occurs in steps: 1) initiation step characterized by the unfolding of protein molecules, and 2) aggregation step which results in gel formation via hydrogen bonds, electrostatic bonds, and hydrophobic interactions, usually occurring above $55^{\circ} \mathrm{C}$ (Yoon, Gunasekaran, \& Park, 2004). Dynamic rheology is used in this study to determine the effect of fiber on gelation curves.

In the present study, the graphical portrayal of elastic modulus for each treatment followed the same approximate trend, with one large peak and plateau between 80 and $90^{\circ} \mathrm{C}$. In addition, all treatments showed an initial increase in elastic modulus at around $55^{\circ} \mathrm{C}$ indicating the formation of hydrogen bonds, electrostatic bonds, and hydrophobic interactions as mentioned by Yoon et al. (2004). There were differences between the treatments, however. In general there was an increase in final $\mathrm{G}^{\prime}$ at $90^{\circ} \mathrm{C}$ as fiber concentration increased (Figure 4). With each addition of fiber (from $0 \%$ to $2 \%$ to $4 \%$, etc.) the final elastic modulus of the sample increased. This trend was seen for all treatments except for the $6 \%$ and $8 \%$ treatments. For these 
treatments, $6 \%$ fiber created a more elastic product than $8 \%$ fiber. This observation is interesting to note since the only variation in the treatments is the fiber concentration, yet as previously mentioned, powdered cellulose fiber has is a chemically inert additive. The fiber must therefore have an effect, independent of protein gelation, which contributes to the elastic nature of the surimi gel.

There are a few factors that may contribute to enhanced gelation with the addition of fiber. One factor may be the dehydration effect of the fiber. Yoon, Gunasekaran, \& Park (2004) noted that proteins with a lower moister and thus having a higher protein concentration more readily began the gelation process. This may also be related to the high rate of increase in elastic modulus after fiber addition since the concentrated proteins more willingly undergo protein unfolding and subsequent formation of disulphide and hydrophobic interactions (Karthikeyan, Dileep, \& Shamasundar, 2006).

Although the treatments in this study had a constant concentration of protein (thus removing protein concentration as a variable), powdered cellulose fiber has a large water holding capacity, thereby removing moisture from the protein portion of the surimi sol and concentrating the myofibrillar proteins. Sánchez-González et al. (2009) used wheat dietary fiber as an additive in Alaska Pollock surimi and found that the fiber did absorb moisture from the gel, increasing the moisture in the fiber portion of the gel. They also noted an increase in $\beta$-sheet formation with increased fiber concentration ( $6 \%$ fiber) which may have been caused by the dehydration effect of the fiber on the protein, leading to increased protein aggregation and formation of $\beta$-sheets as opposed to $\alpha$-helices. This is beneficial to gel strength as increased $\beta$-sheet formation is directly correlated with higher elasticity and possibly indicates a more regular arrangement of the protein network (Niwa \& Nakajima, 1975; Sánchez-González et al., 2009). It could also be 
hypothesized that the powdered cellulose may form its own network that complements the protein network (Chen., 2006). The decrease in elastic modulus seen with $8 \%$ fiber may be due to over-incorporation of fiber causing some disruption in the protein matrix. Overall, these high elastic modulus values indicate that surimi with fiber addition is able to form a highly ordered network leading to increased gel strength as evidenced by the textural effects discussed earlier (Karthikeyan et al., 2006).

\section{Conclusion}

This study demonstrated that powdered cellulose fiber can be a beneficial additive in surimi seafood. Although fiber addition resulted in slightly lower color values, these values are still acceptable of premium grade surimi. In addition, fiber improved textural properties such as hardness, cohesiveness, chewiness, and gel strength. Some decline in gel strength was seen in $8 \%$ fiber and was further evidenced in rheological data. This suggests that there may be some disruption of the protein matrix with a high concentration of fiber. Lower concentrations of fiber showed a large increase in elastic modulus, indicating fiber may support the existing protein matrix to create a stronger gel. These results are promising for the future implications of manufacturing and marketing a surimi product with added fiber and possible health benefits. Sensory evaluation is recommended to assess consumer acceptance of the product.

\section{References}

Anderson, J. W., Baird, P., Davis, R. H., Ferreri, S., Knudtson, M., Koraym, A., Waters, V., \& Williams, C. L. (2009). Health benefits of dietary fiber. Nutrition Reviews, 67(4), 188205. doi:10.1111/J.1753-4887.2009.00189.x 
Ang, J. F. (1991). Water retention capacity and viscosity effect of powdered cellulose. Journal of Food Science, 56(6), 1682-1684.

Ang, J. F., \& Miller, W. B. (1991). Multiple functions of powdered cellulose as a food ingredient. Cereal Foods World, 36(7), 558-564.

Association of Official Analytical Chemists. (1995). Official Methods of Analysis. (16th ed). Washington, DC: Association of Official Analytical Chemists.

Bengtsson, H., Montelius, C., Tornberg, E. (2011). Heat-treated and homogenised potato pulp suspensions as additives in low-fat sausages. Meat Science, 88, 75-81. doi:10.1016/j.meatsci.2010.12.005

Bodner, J. M., \& Sieg, J. (2009). Fiber. In R. Tarté (ed.), Ingredients in meat products: Properties, functionality and applications (pp. 83-108). Springer Science + Business Media, LLC. doi:10.1007/978-0-387-71327-4_4. Retrieved January 25, 2012, from http://powderedcellulose.com/wp-content/themes/agency-sweetener-supplypc/images/fiber-properties-functionality-applications.pdf.

Brownlee, I. A., Dettmar, P. W., Strugala, V., \& Pearson, J. P. (2006). The interaction of dietary fibres with the colon. Current Nutrition and Food Science, 2, 243-264.

Cardoso, C., Mendes, R., \& Nunes, M. L. (2007). Effect of transglutaminase and carrageenan on restructured fish products containing dietary fibres. International Journal of Food Science and Technology, 42, 1257-1264. doi:10.1111/j.1365-2621.2006.01231.x

Cardoso, C., Mendes, R., Pedro, S., \& Nunes, M. L. (2008). Quality changes during storage of fish sausages containing dietary fiber. Journal of Aquatic Food Product Technology, 17(1), 73-95.

Cardoso, C., Mendes, R., Vaz-Pires, P., \& Nunes, M. L. (2009). Effect of dietary fibre and MTGase on the quality of mackerel surimi gels. Journal of the Science of Food and Agriculture, 89, 1648-1658. doi:10.1002/jsfa.3636

Chen, H. H. (2006). Thermal gelation behaviors of surimi protein mixed with hydroxypropylmethylcellulose. Fisheries Science, 72, 679-685.

Chen, Y. C., \& Jaczynski, J. (2007a). Gelation of protein recovered from Antarctic krill (Euphausia superb) by isoelectric solubilization/precipitation as affected by function additives. Journal of Agricultural and Food Chemistry, 55, 1814-1822.

Chen, Y. C., \& Jaczynski, J. (2007b). Protein recovery from rainbow trout (Oncorhynchus mykiss) processing by-products via isoelectric solubilization/precipitation and its gelation properties as affected by functional additives. Journal of Agricultural and Food Chemistry, 55, 9079-9088. 
Cheret, R., Chapleau, N., Delbarre-Ladrat, C., Verrez-Bagnis, V., \& Lamballerie, M. D. (2005). Effects of high pressure on texture and microstructure of sea bass (Dicentrarchus labrax L. ) fillets. Journal of Food Science, 70, E477-E483.

Dietary Guidelines Advisory Committee. (2010). Report of the dietary guidelines advisory committee on the dietary guidelines for Americans, 2010, to the secretary of Agriculture and the Secretary of Health and Human Services. Washington, DC: Government printing office. Retrieved from http://www.cnpp.usda.gov/Publications/DietaryGuidelines/2010/PolicyDoc/PolicyDoc.pd $\mathrm{f}$

Freud, R. J., \& Wilson, W. J. (1997). Design of experiments. San Diego (CA): Academic Press. p. 464.

Hamann, D. D., \& MacDonald, G. A. (1992). Rheology and textural properties of surimi and surimi-based foods. In T. C. Lanier \& C. M. Lee (Eds.), Surimi Technology (pp. 429500), New York, NY: Marcel Dekker, Inc.

Jaczynski, J., \& Park, J. W. (2003). Microbial inactivation and electron penetration in surimi seafood during electron beam processing. Journal of Food Science, 68(5), 1788-1792.

Jaczynski, J., \& Park, J. W. (2004). Physiochemical changes in Alaska Pollock surimi and surimi gel as affected by electron beam. Journal of Food Science, 69(1), 53-57.

Karthikeyan, M., Dileep, A. O., \& Shamasundar, B. A. (2006). Effect of water washing on the functional and rheological properties of proteins from threadfin bream (Nemipterus japonicas) meat. International Journal of Food Science and Technology, 41, 1002-1010.

Kim, B. Y., Park, J. W., \& Yoon, W. B. (2005). Rheology and texture properties of surimi gels. In J.W. Park (Ed.), Surimi and surimi seafood $2^{\text {nd }}$ ed. (pp. 491-582), Boca Raton, FL: Taylor and Francis Group.

Kristinsson, H. G., Theodore, A. E., Demir, N., \& Ingadottir, B. (2005). A comparative study between acid- and alkali-aided processing and surimi processing for the recovery of proteins from channel catfish muscle. Journal of Food Science, 70, C298-C306.

National Fisheries Institute. (1991). A manual of standard methods for measuring and specifying the properties of surimi. Washington (D.C.): National Fisheries Institute.

Niwa, E., \& Nakajima, G. (1975). Differences in protein structure between elastic kamaboko and brittle one. Nippon Suisan Gakkaishi, 41, 579.

Park, J. W., \& Lanier, T. C. (1989). Scanning calorimetric behavior of tilapia myosin and actin due to processing of muscle and protein purification. Journal of Food Science, 54, 49-51.

Prosky, L. (2000) When is dietary fiber considered a functional food? BioFactors, 12, 289-297. 
Raninen, K., Lappi, J., Mykkänen, H., \& Poutanen, K. (2010). Dietary fiber type reflects physiological functionality: Comparison of grain fiber, inulin, and polydextrose. Nutrition Reviews, 69(1), 9-21. doi:10.1111/J.1753-4887.2010.00358.x

Sánchez-Alonso, I., Haji-Maleki, R., \& Borderias, A. J. (2007a). Wheat fiber as a functional ingredient in restructured fish products. Food Chemistry, 100, 1037-1043. doi:10.1016/j.foodchem.2005.09.090

Sánchez-Alonso, I., Solas, M. T., \& Borderías, A. J. (2007b) Technological implications of addition of wheat dietary fibre to giant squid (Dosidicus gigas) surimi gels. Journal of Food Engineering, 81, 404-411. doi:10.1016/j.jfoodeng.2006.11.015

Sánchez-González, I., Rodríguez-Casado, A., Careche, M., \& Carmona, P. (2009). Raman analysis of surimi gelation by addition of wheat dietary fibre. Food Chemistry, 112, 162168.

SAS Institute. (2002). SAS/STAT guide for personal computers, version 8.1. Cary (NC): SAS Institute.

Smith, C. E., \& Tucker, K. L. (2011). Health benefits of cereal fibre: A review of clinical trials. Nutrition Research Reviews, 24, 118-131. doi:10.1017/S0954422411000023

Tahergorabi, R., Beamer, S. K., Matak, K. E., \& Jaczynski, J. (2011). Effect of isoelectric solubilization/precipitation and titanium dioxide on whitening and texture of proteins recovered from dark chicken-meat processing by-products. LWT-Food Science and Technology, 44(4), 896-903.

Taskaya, L., Chen, Y. C., \& Jaczynski, J. (2009a). Functional properties of proteins recovered from whole gutted silver carp (Hypophthalmichthys molitrix) by isoelectric solubilization / precipitation. LWT - Food Science and Technology, 42(6), 1082-1089.

Weickert, M. O., \& Pfeiffer, A. F. H. (2008). Metabolic effects of dietary fiber consumption and prevention of diabetes. Journal of Nutrition, 138, 439-442.

Wright, D. J., Leach, I. B. \& Wilding, P. (1977). Differential scanning calorimetric studies of muscle and its constituent proteins. Journal of the Science of Food and Agriculture, 28, 557-564.

Yongsawatdigul, J., \& Park, J. W. (2004). Effects of alkali and acid solubilization on gelation characteristics of rockfish muscle proteins. Journal of Food Science, 69, 499-505.

Yoon, K., Lee, C. M., \& Chung, K. H. (1987, November). Effect of powdered cellulose on the texture and water binding properties of surimi-based products. $1^{\text {st }}$ Joint Conference of Tropical and Subtropical Fisheries Technology and Atlantic Fisheries Technology, Orlando, FL. Retrieved from http://fshn.ifas.ufl.edu/seafood/sst/AnnPdf/12th_516.pdf 
Yoon, W. B., Gunasekaran, S., \& Park, J. W. (2004). Characterization of thermorheological behavior of Alaska pollock and pacific whiting surimi. Journal of Food Science, 69(7), E338-E343. 


\section{CHAPTER IV: INTERACTIONS OF DIETARY FIBER AND OMEGA-3-RICH OILS WITH PROTEIN IN SURIMI GELS}

\section{Introduction}

Heart disease is one of the leading causes of death in the United States. As of 2006, mortality from cardiovascular disease (CVD) was $34.3 \%$, translating to 1 of every 2.9 deaths (Lloyd-Jones et al., 2010). Similarly, mortality from coronary heart disease (CHD) is 1 of every 6 deaths in the United States (Lloyd-Jones et al., 2010). In response to these high rates of heart disease, the American Heart Association (AHA) released dietary recommendations, with major points including limiting foods high in cholesterol and saturated fat, substituting saturated fats with unsaturated fats, increasing fiber intake, and reducing salt (sodium chloride) intake (Krauss et al., 2000).

Fiber has been implicated in preventing heart disease; however, most American diets are deficient in dietary fiber. The Institute of Medicine recommends fiber intake to be 25-38 grams of fiber per day; however the average intake is only about 15 grams each day (Dietary Guidelines Advisory Committee, 2010). Dietary fiber is defined as "remnants of the edible part of the plant and analogous carbohydrate that are resistant to digestion and absorption in the human small intestine with complete or partial fermentation in the human large intestine. It includes polysaccharides, oligosaccharides, lignin and associated plant substances...that promote beneficial physiological effects" (Bodner \& Sieg, 2009; Prosky, 2000). It has been shown that a high intake of dietary fiber is protective against coronary heart disease, diabetes, obesity, and intestinal disorders (Anderson et al., 2009). 
Populations with fat intake of $>30 \%$ total energy had low mortality rates from CVD possibly associated with an observed high intake of fish oils (Psota, Gebauer, \& Kris-Etherton, 2006). Further studies have associated omega-3 polyunsaturated fatty acid (PUFA) intake with improvement of various cardiovascular measures. $\alpha$-linolenic acid (ALA, 18:3n3) has been found to decrease levels of C-reactive protein (CRP), a measure of inflammation associated with cardiovascular disease, and thereby reduce risk of heart disease (Zhao, Etherton, Martin, West, Gillies, \& Kris-Etherton, 2004). Eicosapentaenoic acid (EPA, 20:5n3) and docosahexaenoic acid (DHA, 22:6n3) intake have shown positive effects on cardiovascular measure by decreasing triglycerides, total cholesterol, and LDL cholesterol, and increasing HDL cholesterol (Juturu, 2008; Nair, Leitch, Falconer, \& Garg, 1997; Narayan, Miyashita, \& Hosakawa, 2006). They have also been found to decrease hypertension and prevent arrhythmia (Narayan et al., 2006). Studies show adequate dietary EPA and DHA may reduce CVD mortality by 30-60\% (Psota et al., 2006). Because of these cardioprotective effects, the AHA, World Health Organization, and Dietary Guidelines Advisory Committee Report recommend consuming two servings of fatty fish or fish high in omega-3 PUFAs, EPA and DHA, twice per week (Dietary Guidelines Advisory Committee, 2010; Krauss et al., 2000; World Health Organization, 2003). A more in depth review of cardioprotective benefits of omega-3 PUFAs is discussed elsewhere (Mozaffarian, \& Wu, 2011; Psota et al., 2006).

Omega-3 PUFAs can be derived from plants and marine sources. Plant sources such as walnuts, seeds, flaxseed, soybean, and canola oil are generally abundant in ALA, although algal oils have been found to be a good source of DHA (Arterburn et al., 2008; Calder \& Yaqoob, 2009; Gogus \& Smith, 2010). Marine sources, especially cold water fish, are abundant in EPA and DHA, which are the physiologically active forms of omega-3 PUFAs (Narayan et al., 2006). 
Currently, dietary intakes of ALA, EPA, and DHA among western adults are 0.5-2 g/day (ALA) and as low as $<0.1 \mathrm{~g} /$ day (EPA and DHA) in individuals who do not consume fish, whereas the recommended intakes are 1.1 to $1.6 \mathrm{~g} /$ day (ALA) for females and males, respectively, and 0.3$0.4 \mathrm{~g} / \mathrm{day}$ of EPA and DHA, although some sources recommend $0.5 \mathrm{~g} / \mathrm{d}$ or more (Calder \& Yaqoob, 2009; IOM, 2005; Juturu, 2008; Kris-Etherton, Grieger, \& Etherton, 2009). Although the human metabolism is capable of converting ALA to EPA and DHA, these conversion rates are inefficient with 5-10\% of ALA being converted to EPA and only 2-5\% to DHA (Anderson \& Ma, 2009; Psota et al., 2006). This low EPA/DHA level necessitates an increased intake of omega-3 PUFAs in the form of EPA and DHA to observe the stated health benefits. Some have suggested a possible deficiency in omega-3 PUFAs may contribute to deaths associated with heart disease and that supplementation or change in diet to include increased omega-3 PUFAs could help prevent the progression of this condition (Gogus \& Smith, 2010).

In addition to fiber and omega-3 PUFAs, sodium has also been implicated in cardiovascular disease. High sodium intake is associated with hypertension, or high blood pressure (BP), which can attribute to the development of cardiovascular disease. High sodium intake is also attributed to the development of fibrosis in the heart, kidneys, and arteries (Appel et al., 2011). The Dietary Guidelines Advisory Committee (2010) recommends a sodium intake of less than $2300 \mathrm{mg}$ per day for the general population and an intake of less than $1500 \mathrm{mg}$ per day for those aged 51 years or older, or African American ethnicity, or afflicted with hypertension, diabetes, or chronic kidney disease. Despite these recommendations, sodium intake has continued to rise, possibly due to the high sodium content of processed foods. Using salt substitutes in manufacturing food products may help reduce sodium intake. Potassium 
chloride $(\mathrm{KCl})$ is commonly used as a salt substitute due to the cardioprotective effects of potassium, including reducing BP and mean arterial pressure (Buyck et al., 2009).

The market for functional foods is becoming increasingly popular worldwide. Functional foods are those that contain added, technologically developed ingredients with specific health benefits (Siró, Kápolna, Kápolna, \& Lugasi, 2008). In regards to omega-3 PUFAs, the high cost of fish and potential for contamination with compounds such as mercury may drive consumers to choose enriched foods over fish sources to increase omega-3 PUFA consumption (Candela, López, \& Kohen, 2011). Surimi is myofibrillar fish protein that has been washed of lipids and other impurities. It is a logical vehicle for functional additives as surimi is naturally low in fat, of good nutritional quality, and consists of highly functional myofibrillar proteins. In a way, the addition of omega-3 PUFAs into surimi would mimic natural fish products (Park, Kelleher, McClements, \& Decker, 2004).

Surimi seafood is not currently fortified with fiber or omega-3 oils, nor is salt substitute $(\mathrm{KCl})$ traditionally used in the formulation of surimi. Although there is little research on the combined effect of fiber, omega-3 oils, and $\mathrm{KCl}$ on the functional properties of surimi seafood, studies have looked at the distinct effects of fiber, omega-3-rich oil, and $\mathrm{KCl}$ addition. Fiber incorporation in surimi shows mixed results and seem to be dependent on the source of fiber used. Many previous studies have utilized soluble fibers such as carrageenan, chicory root inulin, garrofin, guar, and xanthan (Cardoso, Mendes, \& Nunes, 2007; Cardoso, Mendes, VazPires, \& Nunes, 2009; Sánchez-Alonso, Haji-Maleki, \& Borderias, 2007a). These soluble fibers have shown some detrimental effects on textural properties of surimi gels, including loss of elasticity and gel strength combined with hardening of gels (Cardoso et al., 2007; 2009). Research with insoluble fiber, on the other hand, has produced conflicting results. Sánchez- 
Alonso et al. (2007b) observed a loss of hardness and gel strength with wheat fiber addition to giant squid surimi. Another study observed the effects of powdered cellulose with fiber lengths of 11 to 55 microns on surimi gels and found that more than $2 \%$ fiber addition resulted in significantly lower firmness, chewiness, and rubberiness (Yoon, Lee, \& Chung, 1987). In contrast, Cardoso et al. (2009) found that inner pea fiber addition to chub and Atlantic mackerel increased hardness, springiness, and chewiness and improved elastic and viscous modules.

When looking at surimi with omega-3-rich oil added in the form of fish oil concentrate, menhaden oil, or marine oil, Peréz-Mateos et al. (2004) observed increased shear stress, breaking force, and hardness with omega-3 addition when compared to control. Another study found that surimi addition of algal oil (high in DHA) as an emulsified oil had no effect on gel strength, whereas addition as bulk oil significantly decreased gel strength $(\mathrm{P}<0.05)$ when compared to the control that contained no oil (Park et al., 2004). A study using flaxseed, algae, menhaden, krill, and a blend of oils incorporated in surimi found no significant difference in shear stress or strain between the samples and the control and texture profile analysis measures showed no significant difference when compared to control except in the case of krill oil, which was significantly $(\mathrm{P}<0.05)$ lower than the control (Pietrowski, Tahergorabi, Matak, Tou, \& Jaczynski, 2011). In a follow-up study Pietrowski et al. (2012) found that incorporating the aforementioned omega-3rich oils increased the elastic modulus (as measured by $\mathrm{G}^{\prime}$ ) of the surimi gel, indicating possible contribution of the oils to the protein matrix. These studies show that incorporation of omega-3rich oils in surimi can produce quality products.

When used as a substitute for $\mathrm{NaCl}$ in Alaska Pollock surimi, $\mathrm{KCl}$ has been found to produce an acceptable product with acceptable color and textural character traits (Tahergorabi et al., submitted for publication). Using $\mathrm{KCl}$ as a salt substitute, however, did result in softer gels 
with decreased hardness (Gimeno, Astiasarán, \& Bello, 1999; Montero \& Pérez-Mateos, 2001; Tahergorabi et al., submitted for publication). In formulations of surimi, dry-cured pork loin, and mortadella that used only partial substitutions of $\mathrm{KCl}$ for $\mathrm{NaCl}$, gel firmness was not affected (Gou, Guerrero, Gelabert, \& Arnau, 1996; Horita et al., 2011; Lian et al., 2002). Although some differences were seen in texture, surimi gelation patterns and viscoelasticity were unchanged when $\mathrm{KCl}$ was used in place of $\mathrm{NaCl}$ (Lian et al., 2002; Tahergorabi \& Jaczynski, 2012). Salt substitution has also been reported to have little effect on the color of resulting gels (Tahergorabi et al., submitted for publication).

Although previous research has reviewed the distinct effects of the incorporation of fiber, omega-3 oils, or $\mathrm{KCl}$ on textural quality and gelation of surimi seafood products, no known study has evaluated the effect of the combined addition of fiber and omega- 3 oils, with $\mathrm{KCl}$ used as a substitute for $\mathrm{NaCl}$. This would render a nutraceutical product that addresses the dietary recommendations posed by the American Heart Association. The objective of this study was to analyze the effects of added dietary fiber and omega-3 oil, with $\mathrm{KCl}$ used as a salt substitute, and their effect on physicochemical properties of surimi.

\section{Materials and Methods}

\section{Surimi}

Frozen Alaska Pollock surimi grade A was obtained from Trident Seafoods Corp.

(Seattle, WA). Surimi contained cryoprotectants ( $4 \mathrm{~g} / 100 \mathrm{~g}$ of sorbitol and $4 \mathrm{~g} / 100 \mathrm{~g}$ of sucrose), $0.15 \mathrm{~g} / 100 \mathrm{~g}$ of sodium tripolyphosphate, and $0.15 \mathrm{~g} / 100 \mathrm{~g}$ of tetrasodium pyrophosphate.

Frozen surimi blocks (10 kg each) were shipped overnight in heavily insulated industrial strength boxes filled with ice. Upon arrival surimi blocks were cut into approximately $800 \mathrm{~g}$ units, 
vacuum-packaged, and stored at $-80^{\circ} \mathrm{C}$ until needed. The moisture content of surimi was determined as $76.04 \mathrm{~g} / 100 \mathrm{~g}$ (AOAC, 1995).

\section{Preparation of surimi paste}

Surimi pastes were made using the procedure described by Jaczynski and Park (2003, 2004). Briefly, frozen surimi was thawed in the refrigerator $\left(4^{\circ} \mathrm{C}\right)$ for 1 day. Surimi was chopped in a universal food processor (Model UMC5, Stephan Machinery Corp., Columbus, $\mathrm{OH}$ ) at low speed for $1 \mathrm{~min}$. A surimi paste was obtained by adding $2.8 \mathrm{~g} / 100 \mathrm{~g}$ of $\mathrm{KCl}$ and chopping at low speed for $0.5 \mathrm{~min} . \mathrm{KCl}$ concentration was calculated as described in Tahergorabi et al. (2012). Final moisture content was adjusted to $79 \mathrm{~g} / 100 \mathrm{~g}$ by adding chilled water $\left(4^{\circ} \mathrm{C}\right)$ to the paste. Either fiber or silicon dioxide was added to the surimi paste for a final concentration of $6 \mathrm{~g} / 100 \mathrm{~g}$. Omega-3-rich oils (see below) were added at $10 \mathrm{~g} / 100 \mathrm{~g}$ by replacing water (1:1) added to the surimi paste (Park, 2005; Pérez-Mateos et al., 2004; 2006). The oil was homogenized with water to dilute the color before addition to surimi. Final combined oil and water concentration was $37.2 \mathrm{~g} / 100 \mathrm{~g}$ in all treatments. One treatment without added fiber or omega-3-rich oil, with $6 \mathrm{~g} / 100 \mathrm{~g}$ silicon dioxide was a control. To mix all of the ingredients with surimi paste, chopping was applied at low speed for 1 min. Additional chopping was performed at high speed under vacuum ( 0.5 bar $)$ for the last 3 minutes. The paste temperature was controlled between $1-4^{\circ} \mathrm{C}$ during chopping. Surimi pastes were prepared in 1 $\mathrm{kg}$ batches with final formulations as listed in Table $\mathbf{3 .}$

The fiber added during the preparation of the surimi paste was Solka Floc® Powdered Cellulose 900 FCC, obtained from the International Fiber Corporation (North Tonawanda, NY). Solka Floc ${ }^{\circ}$ Powdered Cellulose 900 FCC was used due to the high water retention of the fiber (9.5 g/g fiber). Silicon dioxide was added as inert filler in place of fiber at a concentration of 6 
g/100 g. The following omega-3-rich oils were added to surimi paste: flaxseed oil, obtained from Jedwards International, Inc. (Quincy, MA); algae oil (DHAS), obtained from Martek Biosciences (Columbia, MD); and menhaden oil (Omega Pure 8042TE), obtained from Omega Pure (Reedsville, VA). These oils were combined in a blend (Flaxseed:Algae:Menhaden 8:1:1) and added to surimi paste at a concentration of $10 \mathrm{~g} / 100 \mathrm{~g}$.

Treatments consisted of 1) control with $0 \%$ oil and $6 \%$ silicone dioxide (in place of fiber), 2) fiber treatment with $6 \%$ fiber added (no silicon dioxide), 3) oil treatment with $10 \%$ omega-3-rich oil blend and 6\% silicon dioxide (in place of fiber), and 4) fiber/oil treatment with $6 \%$ fiber (no silicone dioxide), and 10\% omega-3-rich oil blend. Pastes prepared in this manner were used to develop heat-set surimi gels for evaluation of color (tristimulus color values) and texture (texture profile analysis, Kramer shear, and torsion test), as well as for DSC and dynamic rheology tests.

\section{Preparation of surimi gels}

Surimi paste was stuffed into (A) stainless steel tubes (length $=17.5 \mathrm{~cm}$, internal diameter $=1.9 \mathrm{~cm}$ ) with screw end caps for determination of color and texture properties with tristimulus color values ( $\left.\mathrm{L}^{*} \mathrm{a}^{*} \mathrm{~b}^{*}\right)$, texture profile analysis (TPA) and Kramer shear test; and (B) hour-glass pre-molded stainless steel torsion tubes $($ length $=17.5 \mathrm{~cm}$, end diameter $=1.9 \mathrm{~cm}$, midsection diameter $=1.0 \mathrm{~cm}$ ) with screw and caps for determination of texture properties with the torsion test. The tubes were heated in a water bath set at $90^{\circ} \mathrm{C}$ for $15 \mathrm{~min}$ (Taskaya, Chen, Beamer, \& Jaczynski, 2009). Following heating, tubes were chilled in ice slush and surimi gels were removed for analysis. 


\section{Color properties of heat-set surimi gels}

The gel samples were equilibrated to room temperature for $2 \mathrm{~h}$ prior to the color measurement. The color properties of heat-set surimi gels were determined using a Minolta Chroma Meter CR-300 colorimeter (Minolta Camera Co. Ltd., Osaka, Japan). At least fifteen cylindrical gels $($ height $=2.54 \mathrm{~cm}$, diameter $=1.90 \mathrm{~cm})$ per treatment were used for color measurements. The values for the CIE (Commission Internationale d'Eclairage of France) color system using $\mathrm{L}^{*} \mathrm{a} * \mathrm{~b} *$ tristimulus color values were determined. Whiteness of gels was calculated by the following equation (Kristinsson et al., 2005; National Fisheries Institute, 1991):

$$
\text { Whiteness }=100-\left[\left(100-L^{*}\right)^{2}+a^{*^{2}}+b^{*^{2}}\right]^{1 / 2}
$$

\section{Texture properties of heat-set surimi gels}

Three different methods were employed to determine texture: the torsion test, Kramer shear test, and texture profile analysis (TPA). Although these measurements are commonly employed for determination of textural properties, each method provides slightly different information. The torsion test is considered a fundamental test for texture, while the Kramer shear test and TPA are empirical tests (Kim et al., 2005). The most comprehensive understanding of textural properties is provided by a combination of the fundamental methods and empirical tests; therefore, these three different methods were employed in the present study. The gel samples were equilibrated to room temperature for $2 \mathrm{~h}$ prior to the texture measurement.

Torsion test of heat-set surimi gels was performed according to Chen \& Jaczynski (2007a; 2007b) and Jaczynski \& Park (2003). At least five hour-glass cylindrical gels per treatment were glued to plastic discs and subjected to torsional shear using a Hamman Gelometer 
(Gel Consultant, Raleigh, NC) set at $2.5 \mathrm{rpm}$. Shear stress and shear strain at mechanical fracture were measured to determine gel strength and gel cohesiveness, respectively.

For the Kramer shear test, at least eight cylindrical gels $($ height $=8.0 \mathrm{~cm}$, diameter $=1.9$ $\mathrm{cm}$ ) per treatment were tested using a texture analyzer (Model TA-HDi, Texture Technologies Corp., Scarsdale, NY) with a Kramer cell attachment (Tahergorabi et al., 2011). The Kramer shear cell consisted of five 3.0-mm thick and 70-mm wide shear blades passing through a cell with a corresponding number of slots. Individual gel samples were weighed and placed under the blades in the Kramer cell. Shear force was measured at a $127 \mathrm{~mm} / \mathrm{min}$ crosshead speed and expressed as maximum peak force (g peak force per $g$ of gel sample).

Texture profile analysis (TPA) of the gels was performed according to Cheret et al. (2005). At least fifteen cylindrical gels $($ height $=2.54 \mathrm{~cm}$, diameter $=1.90 \mathrm{~cm})$ per treatment were used for the TPA measurement. Gel samples were subjected to two-cycle compression at $50 \%$ compression using the texture analyzer with a 70-mm TPA compression plate attachment moving at a speed of $127 \mathrm{~mm} / \mathrm{min}$. From the resulting force-time curves, hardness, springiness, cohesiveness, gumminess, chewiness, and resilience were determined.

\section{Differential scanning calorimetry (DSC)}

Surimi paste was tested to determine the net heat energy (enthalpy, $\Delta \mathrm{H}$ ) as well as the onset $\left(\mathrm{T}_{\text {onset }}\right)$ and maximum $\left(\mathrm{T}_{\max }\right)$ temperatures for endothermic transitions of the proteins using differential scanning calorimeter (DSC Infinity Series F5010, Instrument Specialists, Inc., Spring Grove, IL). Approximately $20 \mathrm{mg}$ of a paste sample was hermetically sealed in an aluminum pan and scanned between 20 and $90^{\circ} \mathrm{C}$ at a heating rate of $10^{\circ} \mathrm{C} / \mathrm{min}$ (Park \& Lanier, 1989; Yongsawatdigul et al., 2004). Careful attention was paid to ensure good contact between the paste sample and the bottom of the aluminum pan. Temperature calibrations were performed 
prior to measurements according to the manufacturer and an empty pan was used as reference. At least five thermograms per treatment were generated to determine $\Delta \mathrm{H}, \mathrm{T}_{\text {onset }}$, and $\mathrm{T}_{\max }$.

\section{Oscillatory dynamic rheology}

The non-destructive, gelation properties of the surimi pastes were determined using a cone and plate attached to an oscillatory dynamic rheometer (Bohlin CVOR 200, Malvern Instruments Ltd., Worcestershire, UK). Once the sample was pressed by lowering the measuring geometry plate, excess sample was removed with a stainless steel spatula. The gap between measuring geometry and peliter plates was adjusted to $150 \mu \mathrm{m}$. The storage modulus (G') was measured with a temperature increasing from 25 to $95^{\circ} \mathrm{C}$ at the heating rate of $1{ }^{\circ} \mathrm{C} / \mathrm{min}(\mathrm{Chen} \&$ Jaczynski 2007a; 2007b). Tests were conducted at $1 \%$ strain and $0.1 \mathrm{~Hz}$ frequency. A plastic cover supplied from the company was used to prevent moisture evaporation during measurement. An average of 3 rheograms per treatment was used to determine G'.

\section{Statistical analysis}

One batch of each treatment was created. In each batch at least ten measurements for determination color $\left(\mathrm{L}^{*} \mathrm{a}^{*} \mathrm{~b}^{*}\right)$ were performed, six for torsion test, ten for Kramer test, and ten for TPA. Data were subjected to one-way analysis of variance (ANOVA). A significant difference was determined at the 0.05 probability level and differences between treatments were tested using the Least Significant Difference (LSD) test (Freud and Wilson, 1997). All statistical analyses of data were performed using SAS (2002). The data are reported as mean values \pm standard deviation (SD). 


\section{Results and Discussion}

\section{Color properties of heat-set surimi gels}

Figure 5 shows the tristimulus color values $\left(\mathrm{L}^{*} \mathrm{a}^{*} \mathrm{~b}^{*}\right)$ and a graphical depiction of whiteness values. $L^{*}$ is a scale, $0-100$, of blackness and whiteness with 0 being more black and 100 being more white. The value $\mathrm{a}^{*}$ correlates with redness (positive values) and greenness (negative values), and $\mathrm{b}^{*}$ is a measure of yellowness (positive values) and blueness (negative values). Whiteness was calculating using $\mathrm{L}^{*}, \mathrm{a}^{*}$, and $\mathrm{b}^{*}$ as previously described.

In this study, lightness $\left(\mathrm{L}^{*}\right)$ increased with the addition of oil $(\mathrm{P}<0.05)$. Although $\mathrm{L}^{*}$ was significantly $(\mathrm{P}<0.05)$ lower for the fiber treatment compared to the control, the fiber/oil treatment showed the highest lightness values $(\mathrm{P}<0.05)$ among all treatments. Sánchez-Alonso et al. (2007b) observed a similar decrease in lightness ( $\left.\mathrm{L}^{*}\right)$ with the addition of wheat dietary fiber to giant squid surimi, although the decrease in lightness was accompanied by an increase in yellowness $\left(+b^{*}\right)$ that was not observed in this study. Oil addition to surimi caused an increase in lightness that Pérez-Mateos et al. (2004) explained was due to an increased dispersion of light caused by the presence of emulsified oil droplets. Pietrowski et al. (2011) saw a similar increase in lightness compared to the control with the addition of corn, flaxseed, algae, and menhaden oil to surimi.

Addition of fiber to surimi, both in the fiber and fiber/oil treatments, resulted in more negative $a^{*}$ values, indicating a slightly greater green hue in these treatments. The oil treatment was also significantly $(\mathrm{P}<0.05)$ more green than the control; however, the fiber/oil treatment displayed the lowest $(\mathrm{P}<0.05) \mathrm{a}^{*}$ values. These results differ from those of Pietrowski et al. (2011) who used a similar oil blend (Flaxseed:Algae:Krill 8:1:1) and found a significant increase in redness $\left(+\mathrm{a}^{*}\right)$ from $-3.41 \pm 0.07$ in the control to $23.24 \pm 0.4$ with the oil blend. Krill has a 
natural red color due to the presence of the antioxidant and carotenoid astaxanthin, which explains the red color seen in the study by Pietrowski et al. (2011) (Gigliotti, Davenport, Beamer, Tou, \& Jaczynski, 2011; Tou, Jaczynski, \& Chen, 2007). In the present study, menhaden was substituted for krill oil in the blend to avoid the coloration seen with krill oil.

Fiber improved the $\mathrm{b}^{*}$ (yellowness) value over the control $(\mathrm{P}<0.05)$ by decreasing $+\mathrm{b}^{*}$. Although fiber decreased the whiteness when added alone to surimi, the fiber/oil treatment increased the yellowness $\left(+b^{*}\right)$ value $(\mathrm{P}<0.05)$ more than the addition of oil alone (oil treatment $19.89 \pm 0.18$, fiber/oil treatment $23.32 \pm 0.15)$. A similar increase in yellowness $\left(+b^{*}\right)$ was seen in the addition of algal oil to cod surimi (Park et al., 2004). Pietrowski et al. (2011) observed the largest increase in yellowness with algae and krill oils. The coloration present with the current blend of Flaxseed:Algae:Menhaden oils (8:1:1) can be explained by the high carotenoid content of algae oil, which produced the yellow-orange coloration seen in treatments with oil (Moretti et al., 2006; Nitsan, Mokady, \& Sukenik, 1999; Pietrowski et al., 2011). Evidently, the effect of homogenization was not great enough to overcome the strong yellow pigmentation of these carotenoids. It is interesting to note that fiber in the presence of oil resulted in an increase in yellowness compared to the oil treatment when fiber alone decreased the yellowness in comparison to the control. It is possible the presence of fiber may enhance the coloring already present in the surimi gel.

Overall whiteness decreased with the treatments compared to the control. The decrease seen with fiber was most likely due to low $\mathrm{L}^{*}$ and $\mathrm{a}^{*}$ values compared to the control. The oil treatment, although lightness increased, had a large increase in $b^{*}$ resulting in a lower whiteness value. The fiber/oil treatment showed the lowest $(\mathrm{P}<0.05)$ whiteness. This treatment showed the 
most greenness and yellowness compared to other treatments. As previously mentioned, the strong yellow pigmentation was likely due to the natural presence of carotenoids in algae oil.

A previous study by Sánchez-Alonso et al. (2007a) used wheat fiber as an additive in hake and horse mackerel. They found a significant increase $(\mathrm{P}<0.05)$ in whiteness in proportion to the amount of fiber added $(0 \%, 3 \%$, or $6 \%)$ in both raw and cooked samples. In another study, Sánchez-Alonso et al. (2007b) incorporated wheat dietary fiber into giant squid surimi and found a slight decrease in whiteness from $83.5 \%$ with $0 \%$ fiber to $79.6 \%$ with $6 \%$ fiber. The differences in whiteness with fiber addition are most likely due to the type of fiber and quality of surimi used in the study. Fiber may have a whitening effect on low quality surimi, whereas it may detract from the whiteness of high quality surimi.

\section{Texture properties of heat-set surimi gels}

Torsion test was used to measure shear stress and shear strain at mechanical fracture of surimi gels. These measures correspond to gel strength and cohesiveness, respectively (Kim et al., 2005). Shear stress and shear strain are shown in Figure 7. Shear stress was significantly higher $(\mathrm{P}<0.05)$ than the control for the fiber, oil, and fiber/oil treatments. Shear strain showed an increase with the addition of fiber and oil separately, however, the fiber/oil treatment was not significantly different from the control.

The Kramer shear test is another measure of gel strength and is shown in Figure 7.

Kramer shear force increased compared to the control with the separate addition of fiber and oil. In the fiber/oil treatment, samples showed significantly $(\mathrm{P}<0.05)$ greater shear force than the control, fiber, and oil treatments.

Texture Profile Analysis (TPA) measures various textural parameters: hardness, the peak height on the first compression that measures a food's resistance during a bite; springiness, the 
ratio of product height on the second compression to the original compression distance that measures the ability of the product to retain its shape and size after one bite; cohesiveness, the ratio of the second compression area to the first compression area that measures the resistance of the product during chewing; gumminess, the product of hardness and chewiness that measures strength required in chewing; chewiness, the product of gumminess and springiness that measures the energy used in chewing; and resilience, a measure of how well a product regains its original position, (Cardoso, Mendes, Pedro, \& Nunes, 2008). See Table 4 and Figure 7 for TPA and hardness, respectively. This data shows that oil addition or fiber/oil addition resulted in treatments with the greatest $(\mathrm{P}<0.05)$ springiness, cohesiveness, chewiness, and resilience. Fiber treatments both alone and with oil showed a decrease in springiness, cohesiveness, and resilience. However the fiber/oil treatment had significantly greater gumminess and chewiness than both the fiber treatment and the control. Hardness (shown in Figure 7) followed a trend similar to Kramer shear force with the fiber/oil treatment having the greatest $(\mathrm{P}<0.05)$ hardness compared to the control, fiber, and oil treatments.

Previous studies of fiber incorporation in surimi show mixed results, with some reporting a decrease in gel strength and hardness, and others reporting an increase in these measures (Cardoso et al., 2007; 2008; 2009; Sánchez-Alonso et al., 2007a; 2007b; Yoon, Lee, \& Chung, 1987). These results likely vary due to the differences in fiber types used and amount of addition to surimi. In a study by Sánchez-Alonso et al. (2007a), researchers observed an increase in hardness with $3 \%$ wheat dietary fiber addition when water was not added to maintain constant moisture. In the present study, water (or water plus oil) addition was constant among all treatments and additional water was not added to fiber treatments to balance the water-absorbing capacity of fiber. This may have contributed to the hardness seen with fiber treatments. An 
unassociated increase in hardness and gel strength was also seen with the oil treatments. In another study, an increase in hardness and breaking force was seen with $2.5 \%$ oil addition to surimi when compared to a control with no added oil (Pérez-Mateos, Gómez-Guillién, Hurtado, Solas, \& Montero, 2002). Pérez-Mateos et al. (2004) observed a similar increase in shear stress (which correlates with gel strength) with menhaden oil and marine oil addition to surimi. These researchers attributed the increase in gel strength to the substitution of oil for the same amount of water used in that study. Another theory is that oil may occupy the void spaces of the protein matrix, restraining the protein matrix against movement and possibly interacting with the matrix to increase gel strength (Dickinson \& Chen, 1999; Wu et al., 2009; Yost \& Kinsella, 1992).

\section{Differential scanning calorimetry (DSC)}

DSC allows for continuous non-destructive monitoring of changes occurring during heating (Wu, Akahane, Lanier, \& Hamann, 1985). Irreversible denaturation of protein is a necessary step in the process of heat-induced surimi protein gelation. Because surimi has been washed of sarcoplasmic proteins, the protein components present in the surimi used in this study are myofibrillar proteins, composed of actin and myosin. These proteins denature at different temperatures, with the myosin undergoing thermal denaturation at a lower temperature than actin. Therefore, the first peak in the DSC thermograms (Figure 8) corresponds to myosin denaturation and the second peak corresponds to actin denaturation (Wright, Leach, \& Wilding, 1977). Enthalpy, or $\Delta H$, is the heat change required thermal denaturation. $\Delta H$ represents exothermic reactions, including those associated with disruption of hydrophobic interactions, and endothermic reactions due to the disruption of hydrogen bonds (Murray, Arntfield, \& Ismond, 1985). It is determined by measuring the area under the DSC transition curve. 
The objective of evaluating DSC in this study was to measure thermal denaturation of actin and myosin under the influence of powdered cellulose fiber, an omega-3-rich oil blend, and both fiber and oil together. Surimi pastes were used for the DSC tests. All treatments showed peak one, associated with myosin denaturation, to occur between 25 and $55^{\circ} \mathrm{C}$ and peak two, associated with actin denaturation, to occur between 62 and $77^{\circ} \mathrm{C}$. Actin denaturation occurred at slightly lower temperatures in treatments with oil (oil and fiber/oil) than in the fiber and control treatments. $\Delta \mathrm{H}$ for myosin denaturation (not calculated) is much greater than that of actin denaturation for all treatments, indicating a greater amount of energy required for denaturation of myosin. Myosin denaturation also showed a much broader peak, which suggests that thermal denaturation did not occur at one temperature, but over a wide temperature range (Park \& Lanier, 1989). The DSC thermograms show that protein denaturation is not disrupted with the addition of fiber or oil to surimi pastes. This is important since protein denaturation is an essential step in protein network formation as it leads to the molecular associations that form the gel network (Park \& Lanier, 1989).

\section{Oscillatory dynamic rheology}

Dynamic rheology was used to study heat-induced gelation of myofibrillar proteins.

Rheology is useful in determining textural characteristics of gels as well as chemical characteristics that contribute to gelation (Hamann \& MacDonald, 1992). Viscoelasticity is one measure of dynamic rheology and is indicated by the elastic modulus, $G^{\prime}$. $G^{\prime}$ is a measure of the viscous vs. elastic nature of a sample. When $\mathrm{G}^{\prime}$ is equal to zero the sample is entirely viscous in nature. As a sample becomes more elastic, the value increases. This process occurs in steps: 1) initiation step characterized by the unfolding of protein molecules, and 2) aggregation step which results in gel formation via hydrogen bonds, electrostatic bonds, and hydrophobic interactions, 
usually occurring above $55^{\circ} \mathrm{C}$ (Yoon, Gunasekaran, \& Park, 2004). Dynamic rheology is used in this study to determine the effect of individual additives (fiber or oil) and the combination of these additives (fiber with oil) on gelation curves.

In the present study, all treatments had the same general effect on elastic modulus $\left(\mathrm{G}^{\prime}\right)$, with an increase beginning around $45^{\circ} \mathrm{C}$ and continuing until about 85 to $90^{\circ} \mathrm{C}$ (see Figure 9). In a study by Yoon et al. (2004), the minimum temperature of increase in viscoelasticity corresponds to the beginning of intermolecular disulphide covalent bonding, with the maximum temperature at approximately $74^{\circ} \mathrm{C}$ indicating completion of most covalent bonding in Alaska Pollock and Pacific Whiting surimi. The rate and amount of increase in elastic modulus varied with each treatment in the current study. Although both the fiber treatment and the oil treatment resulted in increased elastic modulus over the control (fiber more so than oil), the fiber/oil treatment had a much larger final elastic modulus at $90^{\circ} \mathrm{C}$ as well as a greater rate of increase in elastic modulus between $55^{\circ} \mathrm{C}$ and $90^{\circ} \mathrm{C}$. This large increase in elastic modulus is greater than the summation of the elastic modulus for the separate fiber and oil treatments, possibly suggesting an interaction between fiber, oil, and myofibrillar protein of surimi that resulted in increased viscoelasticity.

Previous studies have shown both fiber and oil to have distinct effects on myofibrillar protein gelation and network formation that result in increased viscoelasticity. The effects seen with fiber may be attributed to moisture distribution in the surimi gels. Powdered cellulose in the sample used has a water holding capacity of $9.5 \mathrm{~g}$ water/g fiber. This draws some moisture away from the protein portion of the surimi sol resulting in more concentrated myofibrillar proteins. In support of this theory, Sánchez-González et al. (2009) used wheat dietary fiber as an additive in Alaska Pollock surimi and found that the fiber absorbed moisture from the gel, 
increasing the moisture in the fiber portion of the gel. They also noted an increase in $\beta$-sheet formation with increased fiber concentration ( $6 \%$ fiber) which may have been caused by the dehydration effect of the fiber on the protein, leading to increased protein aggregation and formation of $\beta$-sheets as opposed to $\alpha$-helices. This is beneficial to gel strength as increased $\beta$ sheet formation is directly correlated with higher elasticity and possibly indicates a more regular arrangement of the protein network (Niwa \& Nakajima, 1975; Sánchez-González et al., 2009).

A similar increase in viscoelasticity with oil addition to Alaska Pollock surimi was observed in another study (Pietrowski et al., 2012). The unsaturated nature of omega-3 fatty acids may contribute this beneficial effect as Wu et al. (2009) observed that unsaturated fatty acids are more structurally flexible than saturated fatty acids and are able to interact more strongly with proteins at the oil/water interface. Yost \& Kinsella (1992) also observed that unsaturated fats occupied the outer surface of the butterfat droplet and associated with dialyzed whey protein isolate more than saturated fat, which were found in the center of the fat droplets. Wu et al. (2009) observed a distinct membrane around fat globules in porcine myofibrillar protein and reported that the membrane was most likely comprised of proteins, suggesting that fat globules can behave as interactive fillers. Dickinson \& Chen (1999) described active fillers as compounds that have a strong interaction with the gel matrix, mechanically reinforcing the protein network and increasing gel strength. They also observed that oil droplets behave strongly as active filler in whey protein emulsion gels via integration into the gel matrix through chemical and physical interactions both with protein on different oil droplets and between protein of the gel matrix and protein monolayers at the droplet surface. Yost \& Kinsella (1992) similarly observed that the majority of fat globules were covered with protein aggregates and that clumps or strands of protein aggregates projected from fat droplets and linked them to the protein 
matrix. They found pre-emulsified fat droplets to behave as active fillers that increase gel strength since smaller fat droplets increase the area available for protein adsorption and integration into the gel microstructure upon heating (Yost \& Kinsella, 1992).

Although no studies have assessed the viscoelastic fiber-oil interaction in surimi, the nature of these additives lends to possible theories. Powdered cellulose is porous in nature, allowing it to retain both water and oil (Ang, 1991; 1993). Although the oil retention capacity of powdered cellulose is less than that for water, Ang \& Miller (1991) found that powdered cellulose of 110 microns in length (the length used in this study) could retain up to $8 \mathrm{~g}$ oil/g powdered cellulose. This explains how fiber may associate with oil in surimi gels and thereby be incorporated into the protein matrix. In addition, there is a possibility that fiber-fat complexes may form at elevated temperatures, such as during frying (Ang, 1993). The temperatures in this study are much lower than potential frying temperatures; however, the minimum temperature required for fiber-fat complex formation is not known. The addition of oil in place of water may also have a further dehydrating effect on surimi gels. The adsorption and association of protein with oil droplets may decrease the volume of oil that can associate with fiber. Also, as less water is used in the formulation of treatments with added oil, fiber may be able to bind a higher percent of total water used resulting in a lower moisture content of the myofibrillar protein portion of surimi gels. This dehydration would cause a decrease in protein-water interaction, resulting in increased $\beta$-sheet formation and a subsequent increase in elasticity possible more regular arrangement of the protein network (Niwa \& Nakajima, 1975; Sánchez-Gonzalez et al., 2008; 2009). The combined effect of greater $\beta$-sheet formation and enhanced structural stability due to the oil-protein network may explain the elevated viscoelasticity seen in this study. 


\section{Conclusion}

Powdered cellulose fiber and omega-3-rich oils improve both textural and rheological characteristic of surimi gels. With the combined addition of these additives, a large increase was seen in viscoelasticity that was not seen with fiber and oil when added separately. This indicates greater protein network formation and suggests a possible interaction among fiber, oil, and myofibrillar proteins. This increase in viscoelasticity was reflected in textural properties of heatset gels, such as hardness and Kramer shear force. Although color properties were negatively affected with the addition of oil, mainly by increased yellowness $\left(+b^{*}\right)$, this may be overcome by addition of whitening agents or possibly by further homogenizing or emulsifying the oil with water or another substance to disperse the color pigments. Overall, this study suggests that fiber and oil may be used together as additives in surimi seafood to create a product with improved textural properties. These results are promising for possible future manufacturing and marketing of surimi seafood with added heart-health benefits, especially when taking into consideration the increased popularity of functional/nutraceutical foods. Although results are promising, sensory evaluation is recommended to assess consumer acceptance of the product.

\section{References}

Anderson, B. M., \& Ma, D. W. L. (2009). Are all n-3 polyunsaturated fatty acids created equal? Lipids in Health and Disease, 8, 33.

Anderson, J. W., Baird, P., Davis, R. H., Ferreri, S., Knudtson, M., Koraym, A., Waters, V., \& Williams, C. L. (2009). Health benefits of dietary fiber. Nutrition Reviews, 67(4), 188205. doi:10.1111/J.1753-4887.2009.00189.x

Ang, J. F. (1991). Water retention capacity and viscosity effect of powdered cellulose. Journal of Food Science, 56(6), 1682-1684. 
Ang, J. F., (1993). Reduction of fat in fried batter coatings with powdered cellulose. Journal of the American Oil Chemists' Society, 70(6), 619-622.

Ang, J. F., \& Miller, W. B. (1991). Multiple functions of powdered cellulose as a food ingredient. Cereal Foods World, 36(7), 558-564.

Appel, L. J., Frohlich, E. D., Hall, J. E., Pearson, T. A., Sacco, R. L., Seals, D. R., Sacks, F. M., Smith, S. C., Vafiadis, D. K., \& Van Horn, L. V. (2011). The importance of populationwide sodium reduction as a means to prevent cardiovascular disease and stroke: A call to action from the American Heart Association. Circulation, 123, 1138-1143.

Arterburn, L. M., Oken, H. A., Hall, E. B., Hamersley, J., Kuratko, C. N., \& Hoffman, J. P. (2008). Algal-oil capsules and cooked salmon: nutritionally equivalent sources of docosahexaenoic acid. Journal of the American Dietetic Association, 108, 1204-1209.

Association of Official Analytical Chemists. (1995). Official Methods of Analysis. (16th ed). Washington, DC: Association of Official Analytical Chemists.

Bodner, J. M., \& Sieg, J. (2009). Fiber. In R. Tarté (ed.), Ingredients in meat products: Properties, functionality and applications (pp. 83-108). Springer Science + Business Media, LLC. doi:10.1007/978-0-387-71327-4_4. Retrieved January 25, 2012, from http://powderedcellulose.com/wp-content/themes/agency-sweetener-supplypc/images/fiber-properties-functionality-applications.pdf.

Buyck, J. F., Blacher, J., Kesse-Guyot, E., Castetbon, K., Galan, P., Safar, M. E., Hercberg, S., \& Czernichow, S. (2009). Differential associations of dietary sodium and potassium intake with blood pressure: A focus on pulse pressure. Journal of Hypertension, 27, 1158-1164.

Calder, P. C., \& Yaqoob, P. (2009). Omega-3 polyunsaturated fatty acids and human health outcomes. BioFactors, 53(3), 266-272.

Candela, C. G., López, L. M. B., \& Kohen, V. L. (2011). Importance of a balanced omega 6/omega 3 ratio for the maintenance of health. Nutritional implications. Nutrición Hospitalaria, 26(2), 323-329.

Cardoso, C., Mendes, R., \& Nunes, M. L. (2007). Effect of transglutaminase and carrageenan on restructured fish products containing dietary fibres. International Journal of Food Science and Technology, 42, 1257-1264. doi:10.1111/j.1365-2621.2006.01231.x

Cardoso, C., Mendes, R., Pedro, S., \& Nunes, M. L. (2008). Quality changes during storage of fish sausages containing dietary fiber. Journal of Aquatic Food Product Technology, 17(1), 73-95.

Cardoso, C., Mendes, R., Vaz-Pires, P., \& Nunes, M. L. (2009). Effect of dietary fibre and MTGase on the quality of mackerel surimi gels. Journal of the Science of Food and Agriculture, 89, 1648-1658. doi:10.1002/jsfa.3636 
Chen, Y. C., \& Jaczynski, J. (2007a). Gelation of protein recovered from Antarctic krill (Euphausia superb) by isoelectric solubilization/precipitation as affected by function additives. Journal of Agricultural and Food Chemistry, 55, 1814-1822.

Chen, Y. C., \& Jaczynski, J. (2007b). Protein recovery from rainbow trout (Oncorhynchus mykiss) processing by-products via isoelectric solubilization/precipitation and its gelation properties as affected by functional additives. Journal of Agricultural and Food Chemistry, 55, 9079-9088.

Cheret, R., Chapleau, N., Delbarre-Ladrat, C., Verrez-Bagnis, V., \& Lamballerie, M. D. (2005). Effects of high pressure on texture and microstructure of sea bass (Dicentrarchus labrax L.) fillets. Journal of Food Science, 70, E477-E483.

Dickinson, E., \& Chen, J. (1999). Heat-set whey protein emulsion gels: role of active and interactive filler particles. Journal of Dispersion Science and Technology, 20(1\&2), 197213.

Dietary Guidelines Advisory Committee. (2010). Report of the dietary guidelines advisory committee on the dietary guidelines for Americans, 2010, to the secretary of Agriculture and the Secretary of Health and Human Services. Washington, DC: Government printing office. Retrieved from http://www.cnpp.usda.gov/Publications/DietaryGuidelines/2010/PolicyDoc/PolicyDoc.pd $\mathrm{f}$

Freud, R. J., \& Wilson, W. J. (1997). Design of experiments. San Diego (CA): Academic Press. p. 464.

Gigliotti, J. C., Davenport, M. P., Beamer, S. K., Tou, J. C., \& Jaczynski, J. (2011). Extraction and characterisation of lipids from Antarctic krill (Euphausia superba). Food Chemistry, $125,1028-1036$.

Gogus, U., \& Smith, C. (2010). n-3 omega fatty acids: a review of current knowledge. International Journal of Food Science \& Technology, 45, 417-436.

Hamann, D. D., \& MacDonald, G. A. (1992). Rheology and textural properties of surimi and surimi-based foods. In T. C. Lanier \& C. M. Lee (Eds.), Surimi Technology (pp. 429500), New York, NY: Marcel Dekker, Inc.

Institute of Medicine. (2005) Dietary reference intakes for energy, carbohydrate, fiber, fat, fatty acids, cholesterol, protein, and amino acids (macronutrients). National Academy Press, Washington, DC.

Jaczynski, J., \& Park, J. W. (2003). Microbial inactivation and electron penetration in surimi seafood during electron beam processing. Journal of Food Science, 68(5), 1788-1792. 
Jaczynski, J., \& Park, J. W. (2004). Physiochemical changes in Alaska Pollock surimi and surimi gel as affected by electron beam. Journal of Food Science, 69(1), 53-57.

Juturu, V. (2008). Omega-3 fatty acids and the cardiometabolic syndrome. Journal of the Cardiometabolic Syndrome, 3, 244-253.

Kim, B. Y., Park, J. W., \& Yoon, W. B. (2005). Rheology and texture properties of surimi gels. In J.W. Park (Ed.), Surimi and surimi seafood $2^{\text {nd }} e d$. (pp. 491-582), Boca Raton, FL: Taylor and Francis Group.

Krauss, R. M., Eckel, R. H., Howard, B., Appel, L. J., Daniels, S. R., Deckelbaum, R. J., Erdman, J. W., Kris-Etherton, P., Goldberg, I. J., Kotchen, T. A., Lichtenstein, A. H., Mitch, W. E., Mullis, R., Robinson, K., Wylie-Rosett, J., St. Jeor, S., Suttie, J., Tribble, D. L., Bazzarre, T. L. (2000). AHA dietary guidelines: revision 2000: a statement for healthcare professionals from the nutrition committee of the American Heart Association. Stroke, 31, 2751-2766.

Kris-Etherton, P. M., Grieger, J. A., \& Etherton, T. D. (2009). Dietary reference intakes for DHA and EPA. Prostaglandins, Leukotrienes and Essential Fatty Acids, 81, 99-104.

Kristinsson, H. G., Theodore, A. E., Demir, N., \& Ingadottir, B. (2005). A comparative study between acid- and alkali-aided processing and surimi processing for the recovery of proteins from channel catfish muscle. Journal of Food Science, 70, C298-C306.

Lloyd-Jones, D., Adams, R. J., Brown, T. M., Carnethon, M., Dai, S., De Simone, G., Ferguson, T. B., Ford, E., Furie, K., Gillepsie, C., Go, A., Greenlund, K., Haase, N., Hailpern, S., Ho, P. M., Howard, V., Kissela, B., Kittner, S., Lackland, D., Lisabeth, L., Marelli, A., McDermott, M. M., Meigs, J., Mozaffarian, D., Mussolino, M., Nichol, G., Roger, V. L., Rosamond, W., Sacco, R., Sorlie, P., Stafford, R., Thom, T., Wasserthiel-Smoller, S., Wong, N. D., Wylie-Rosett, J. (2010). Heart disease and stroke statistics - 2010 update: a report from the American heart association. Circulation, 121, e46-e215.

Moretti, V. M., Mentasti, T., Bellagamba, F., Luzzana, U., Caprino, F., Turchini, G. M., Giani, I., \& Valfre, F. (2006). Determination of astaxanthin stereoisomers and colour attributes in flesh of rainbow trout (Oncorhynchus mykiss) as a tool to distinguish the dietary pigment source. Food Additives and Contaminants, 23(11), 1056-1063.

Mozaffarian, D., \& Wu, J. H. Y. (2011). Omega-3 fatty acids and cardiovascular disease. Journal of the American College of Cardiology, 58(20), 2047-2067.

Murray, E. D., Arntfield, S. D., \& Ismond, M. A. H. (1985). The influence of processing parameters on food protein functionality II. Factors affecting thermal properties as analyzed by differential scanning calorimetry. Canadian Institute of Food Science and Technology Journal, 18(2), 158-162. 
Nair, S. S. D., Leitch, J. W., Falconder, J., \& Garg, M. L. (1997). Prevention of cardiac arrhythmia by dietary (n-3) polyunsaturated fatty acids and their mechanism of action. Journal of Nutrition, 127, 383-393.

Narayan, B., Miyashita, K., \& Hosakawa, M. (2006). Physiological effects of eicosapentaenoic acid (EPA) and docosahexaenoic acid (DHA) - a review. Food Reviews International, 22, 291-307.

National Fisheries Institute. (1991). A manual of standard methods for measuring and specifying the properties of surimi. Washington (D.C.): National Fisheries Institute.

Nitsan, Z., Mokady, S., \& Sukenik, A. (1999). Enrichment of poultry products with $\omega 3$ fatty acids by dietary supplementation with the alga Nannochloropsis and mantur oil. Journal of Agricultural and Food Chemistry, 47, 5127-5132.

Niwa, E., \& Nakajima, G. (1975). Differences in protein structure between elastic kamaboko and brittle one. Nippon Suisan Gakkaishi, 41, 579.

Park, J. W. (2005). Ingredient technology for surimi and surimi seafood. In J. W. Park, Surimi and Surimi Seafood, $2^{\text {nd }}$, ed. (p 649-707). Boca Raton (FL): Taylor and Francis Group.

Park, J. W., \& Lanier, T. C. (1989). Scanning calorimetric behavior of tilapia myosin and actin due to processing of muscle and protein purification. Journal of Food Science, 54, 49-51.

Park, Y., Kelleher S. D., McClements, D. J., \& Decker, E. A. (2004). Incorporation and stabilization of omega-3 fatty acids in surimi made from cod, Gadus morhua. Journal of Agricultural and Food Chemistry, 52, 597-601.

Pérez-Mateos, M., Gómez-Guillién, M. C., Hurtado, J. L., Solas, M. T., \& Montero, P. (2002). The effect of rosemary extract and omega-3 unsaturated fatty acids on the properties of gels made from the flesh of mackerel (Scomber scombrus) by high pressure and heat treatments. Food Chemistry, 79, 1-8.

Pérez-Mateos, M., Boyd, L. C., \& Lanier, T. C. (2004). Stability of omega-3 fatty acids in fortified surimi seafoods during chilled storage. Journal of Agricultural and Food Chemistry, 55, 7944-7949.

Pérez-Mateos, M., Lanier, T. C., \& Boyd, L. C. (2006). Effects of rosemary and green tea extracts on frozen surimi gels fortified with omega-3 fatty acids. Journal of the Science of Food and Agriculture, 86, 558-567.

Pietrowski, B. N., Tahergorabi, R., Matak, K. E., Tou, J. C., \& Jaczynski, J. (2011). Chemical properties of surimi seafood nutrified with $\omega-3$ rich oils. Food Chemistry, 129, 912-919. 
Pietrowski, B. N., Tahergorabi, R., Jaczynski, J. (2012). Dynamic rheology ant thermal transitions of surimi seafood enhanced with $\omega$-3-rich oils. Food Hydrocolloids, 27, 384389.

Prosky, L. (2000) When is dietary fiber considered a functional food? BioFactors, 12, 289-297.

Psota, P. L., Gebauer, S. K., \& Kris-Etherton, P. (2006). Dietary omega-3 fatty acid intake and cardiovascular risk. American Journal of Cardiology, 98 (suppl), 3i-18i.

Sánchez-Alonso, I., Haji-Maleki, R., \& Borderias, A. J. (2007a). Wheat fiber as a functional ingredient in restructured fish products. Food Chemistry, 100, 1037-1043. doi:10.1016/j.foodchem.2005.09.090

Sánchez-Alonso, I., Solas, M. T., \& Borderías, A. J. (2007b) Technological implications of addition of wheat dietary fibre to giant squid (Dosidicus gigas) surimi gels. Journal of Food Engineering, 81, 404-411. doi:10.1016/j.jfoodeng.2006.11.015

Sánchez-González, I., Rodríguez-Casado, A., Careche, M., \& Carmona, P. (2009). Raman analysis of surimi gelation by addition of wheat dietary fibre. Food Chemistry, 112, 162168.

Sánchez-Gonzalez, I., Carmona, P., Moreno, P., Borderías, J., Sánchez-Alonso, I., RodríguezCasado, A., \& Careche, M. (2008). Protein and water structural changes in fish surimi during gelation as revealed by isotropic H/D exchange and Raman spectroscopy. Food Chemistry, 106, 56-64.

SAS Institute. (2002). SAS/STAT guide for personal computers, version 8.1. Cary (NC): SAS Institute.

Siró, I., Kápolna, E., Kápolna, B., \& Lugasi, A. (2008). Functional food. Product development, marketing and consumer acceptance - a review. Appetite, 51, 456-467.

Tahergorabi, R., Beamer, S. K., Matak, K. E., \& Jaczynski, J. (2011). Effect of isoelectric solubilization/precipitation and titanium dioxide on whitening and texture of proteins recovered from dark chicken-meat processing by-products. LWT-Food Science and Technology, 44(4), 896-903.

Tahergorabi, R., Jaczynski, J. (2012). Physiochemical changes in surimi with salt substitute. Food Chemistry, 132, 1281-1286.

Taskaya, L., Chen, Y. C., Beamer, S., \& Jaczynski, J. (2009). Texture and colour properties of proteins recovered from whole gutted silver carp (Hypophthalmichthys molitrix) using isoelectric solubilisation / precipitation. Journal of the Science of Food and Agriculture, 89(2), 349-358. 
Tou, J. C., Jaczynski, J., \& Chen, Y. C. (2007). Krill for human consumption: nutritional value and potential health benefits. Nutrition Reviews, 65(2), 63-77.

World Health Organization. (2003). Diet, Nutrition, and the Prevention of Chronic Diseases. Geneva: World Health Organization, 2003. Technical report No. 916.

Wright, D. J., Leach, I. B. \& Wilding, P. (1977). Differential scanning calorimetric studies of muscle and its constituent proteins. Journal of the Science of Food and Agriculture, 28, 557-564.

Wu, M. C., Akahane, T., Lanier, T. C., \& Hamann, D. D. (1985). Thermal transitions of actomyosin and surimi prepared from Atlantic croaker as studied by differential scanning calorimetry. Journal of Food Science, 50, 10-13.

Wu, M., Youling, L., Xiong, Y. L., Chen, J., Tang, X., Zhou, G. (2009). Rheological and microstructural properties of porcine myofibrillar protein - lipid emulsion composite gels. Journal of Food Science, 74(4), e207-e217.

Yongsawatdigul, J., \& Park, J. W. (2004). Effects of alkali and acid solubilization on gelation characteristics of rockfish muscle proteins. Journal of Food Science, 69, 499-505.

Yoon, K., Lee, C. M., \& Chung, K. H. (1987, November). Effect of powdered cellulose on the texture and water binding properties of surimi-based products. $1^{\text {st }}$ Joint Conference of Tropical and Subtropical Fisheries Technology and Atlantic Fisheries Technology, Orlando, FL. Retrieved from http://fshn.ifas.ufl.edu/seafood/sst/AnnPdf/12th_516.pdf

Yoon, W. B., Gunasekaran, S., \& Park, J. W. (2004). Characterization of thermorheological behavior of Alaska Pollock and pacific whiting surimi. Journal of Food Science, 69(7), E338-E343.

Yost, R. A., \& Kinsella, J. E. (1992). Microstructre of whey protein isolate gels containing emulsified butterfat droplets. Journal of Food Science, 57(4), 892-897.

Zhao, G., Etherton, T. D., Martin, K. R., West, S. G., Gillies, P. J., \& Kris-Etherton, P. M. (2004). Dietary $\alpha$-linolenic acid reduces inflammatory and lipid cardiovascular factors in hypercholesterolemic men and women. The Journal of Nutrition, 134, 2991-2997. 


\section{TABLES}

2

3 Table 1. Final surimi batter formulations. Batters with different levels of fiber were formulated to contain $78 \%$ moisture and equal

4 amount of protein, water, salt, and water-based crab flavor by using inert filler, silicon dioxide $\left(\mathrm{SiO}_{2}\right)$. $\mathrm{Batch}_{\mathrm{size}}$ was $1000 \mathrm{~g}$.

5

6

10

11

12

13

14

15

\begin{tabular}{|cccccc|c|}
\hline $\begin{array}{c}\text { Fiber } \\
\text { (g/1000 g) }\end{array}$ & $\begin{array}{c}\text { Filler- } \\
\text { (g/1000 g) }\end{array}$ & $\begin{array}{c}\text { Surimi } \\
\text { (g/1000 g) }\end{array}$ & $\begin{array}{c}\text { Water } \\
(\mathrm{g} / 1000 \mathrm{~g})\end{array}$ & $\begin{array}{c}\text { Salt } \\
(\mathrm{g} / 1000 \mathrm{~g})\end{array}$ & $\begin{array}{c}\text { Crab flavor } \\
(\mathrm{g} / 1000 \mathrm{~g})\end{array}$ & $\begin{array}{c}\text { Batch weight } \\
\text { (g) }\end{array}$ \\
\hline 0.0 (control) & 80.0 & 480.0 & 400.0 & 20.0 & 20.0 & 1000.0 \\
\hline 20.0 & 60.0 & 480.0 & 400.0 & 20.0 & 20.0 & 1000.0 \\
40.0 & 40.0 & 480.0 & 400.0 & 20.0 & 20.0 & 1000.0 \\
60.0 & 20.0 & 480.0 & 400.0 & 20.0 & 20.0 & 1000.0 \\
80.0 & 0.0 & 480.0 & 400.0 & 20.0 & 20.0 & 1000.0 \\
\hline
\end{tabular}


2 Table 2. Effect of fiber on texture profile analysis* (TPA) of surimi gels.

4

5

7

8

10

11

$12 *$ Data are given as mean values \pm standard deviation $(n=3)$. Different letters within the same row indicate significant differences

13 (Fisher's Least Significant Difference, $\mathrm{P}<0.05)$ between mean values. 
2 Table 3. Final surimi batter formulations. Batters were formulated to contain equal amount of protein (i.e., surimi) and salt substitute.

3 Silicon dioxide $\left(\mathrm{SiO}_{2}\right)$ was used as inert filler in place of fiber. Oil replaced water at 1:1 ratio. Batch size was 1000g.

4

5

6

7

\begin{tabular}{|c|c|c|c|c|c|c|c|}
\hline $\begin{array}{l}\text { Treatment } \\
\text { name }\end{array}$ & $\begin{array}{c}\text { Surimi } \\
\text { (g/1000 g) }\end{array}$ & $\begin{array}{c}\text { Water } \\
\text { (g/1000 g) }\end{array}$ & $\begin{array}{l}\text { Salt substitute } \\
\qquad(\mathrm{g} / 1000 \mathrm{~g})\end{array}$ & $\begin{array}{c}\text { Fiber } \\
\text { (g/1000 g) }\end{array}$ & $\begin{array}{c}\text { Oil } \\
\text { (g/1000g) }\end{array}$ & $\begin{array}{c}\text { Filler }-\mathrm{SiO}_{2} \\
\text { (g/1000 g) }\end{array}$ & $\begin{array}{c}\text { Batch weight } \\
\text { (g) }\end{array}$ \\
\hline Control & 540.0 & 372.0 & 28.0 & 0.0 & 0.0 & 60.0 & 1000.0 \\
\hline Fiber & 540.0 & 372.0 & 28.0 & 60.0 & 0.0 & 0.0 & 1000.0 \\
\hline Oil & 540.0 & 272.0 & 28.0 & 0.0 & 100.0 & 60.0 & 1000.0 \\
\hline Fiber + Oil & 540.0 & 272.0 & 28.0 & 60.0 & 100.0 & 0.0 & 1000.0 \\
\hline
\end{tabular}

12 
2 Table 4. Effect of nutraceutical additives on texture profile analysis* (TPA) of surimi gels.

3

\begin{tabular}{|c|c|c|c|c|}
\hline & Control & Fiber & Oil & Fiber + Oil \\
\hline Springiness & $1.55 \pm 0.34 b$ & $1.26 \pm 0.46 \mathrm{c}$ & $2.05 \pm 0.01 \mathrm{a}$ & $1.61 \pm 0.23 \mathrm{~b}$ \\
\hline Cohesiveness & $0.565 \pm 0.035 b$ & $0.543 \pm 0.009 c$ & $0.618 \pm 0.012 \mathrm{a}$ & $0.547 \pm 0.007 \mathrm{c}$ \\
\hline Gumminess & $384 \pm 49 c$ & $530 \pm 46 b$ & $533 \pm 26 b$ & $628 \pm 17 \mathrm{a}$ \\
\hline Chewiness & $594 \pm 142 b$ & $658 \pm 247 b$ & $1091 \pm 53$ a & $986 \pm 149$ a \\
\hline Resilience & $0.294 \pm 0.019 b$ & $0.216 \pm 0.005 c$ & $0.339 \pm 0.006 a$ & $0.223 \pm 0.003 b c$ \\
\hline
\end{tabular}

4

$5 *$ Data are given as mean values \pm standard deviation $(n=3)$. Different letters within the same row indicate significant differences

6 (Fisher's Least Significant Difference, $\mathrm{P}<0.05)$ between mean values.

7

8

9 


\section{FIGURES}

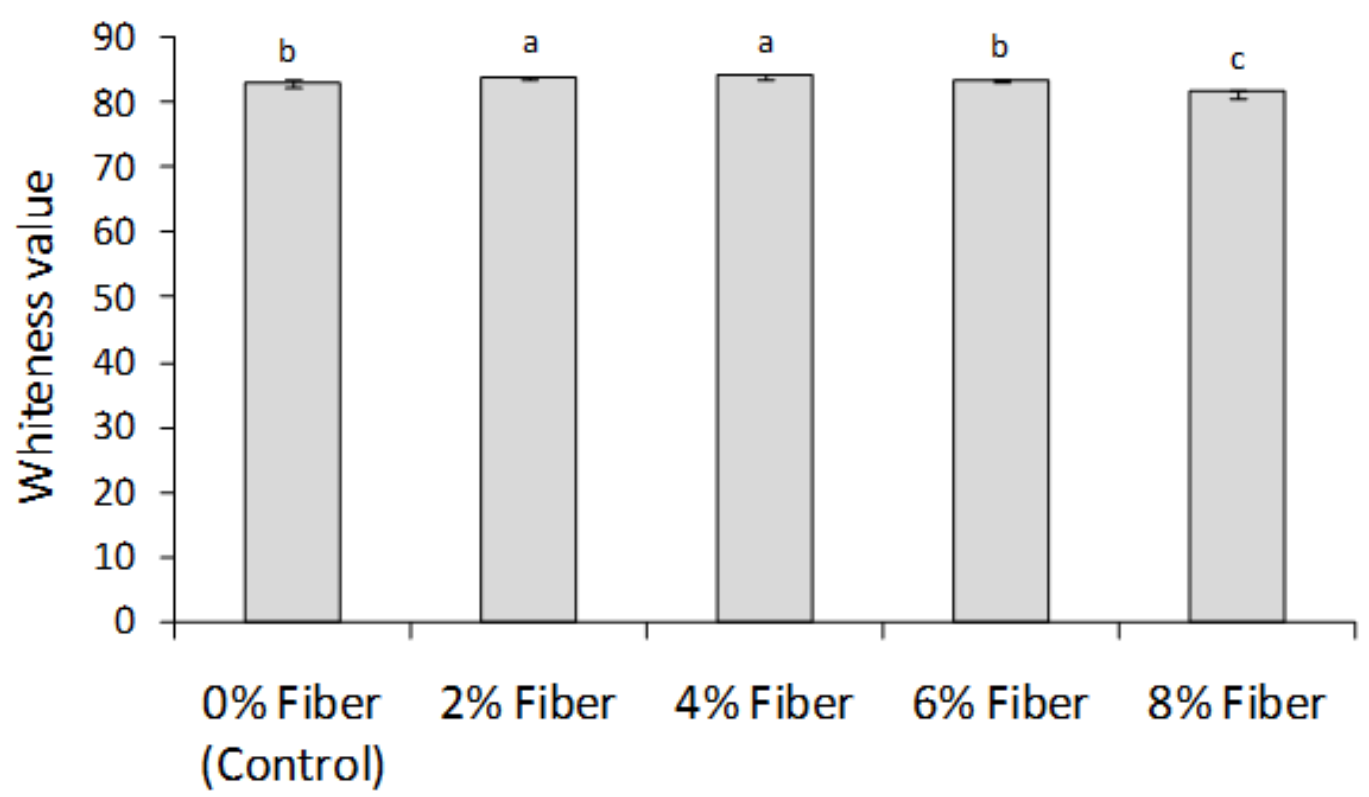

\begin{tabular}{cccccc}
\cline { 2 - 5 } & $\begin{array}{l}\text { 0\% Fiber } \\
\text { (Control) }\end{array}$ & 2\% Fiber & $4 \%$ Fiber & $6 \%$ Fiber & $8 \%$ Fiber \\
\hline$L^{*}$ & $86.0 \pm 0.3 \mathrm{a}$ & $86.3 \pm 0.4 \mathrm{a}$ & $86.1 \pm 0.3 \mathrm{a}$ & $84.9 \pm 0.1 \mathrm{~b}$ & $82.6 \pm 0.7 \mathrm{c}$ \\
$\mathrm{a}$ & $0.3 \pm 0.0 \mathrm{a}$ & $-0.5 \pm 0.1 \mathrm{~b}$ & $-1.1 \pm 0.1 \mathrm{c}$ & $-1.8 \pm 0.0 \mathrm{~d}$ & $-2.8 \pm 0.1 \mathrm{e}$ \\
$\mathrm{b}$ & $9.5 \pm 0.7 \mathrm{a}$ & $8.3 \pm 0.1 \mathrm{~b}$ & $7.6 \pm 0.2 \mathrm{c}$ & $7.0 \pm 0.3 \mathrm{~d}$ & $5.4 \pm 0.2 \mathrm{e}$ \\
\hline
\end{tabular}

2

4

$5 *$ Data are given as mean values \pm standard deviation $(\mathrm{SD}, \mathrm{n}=3)$. Small bars of the top of data

6 bars in the figure (top) indicate SD. Different letters on the top of SD bars indicate significant

7 differences (Fisher's Least Significant Difference, $\mathrm{P}<0.05$ ) between mean values. Different

8 letters within the same row in the table (bottom) indicate significant differences (Fisher's Least

$9 \quad$ Significant Difference, $\mathrm{P}<0.05)$ between mean values. 


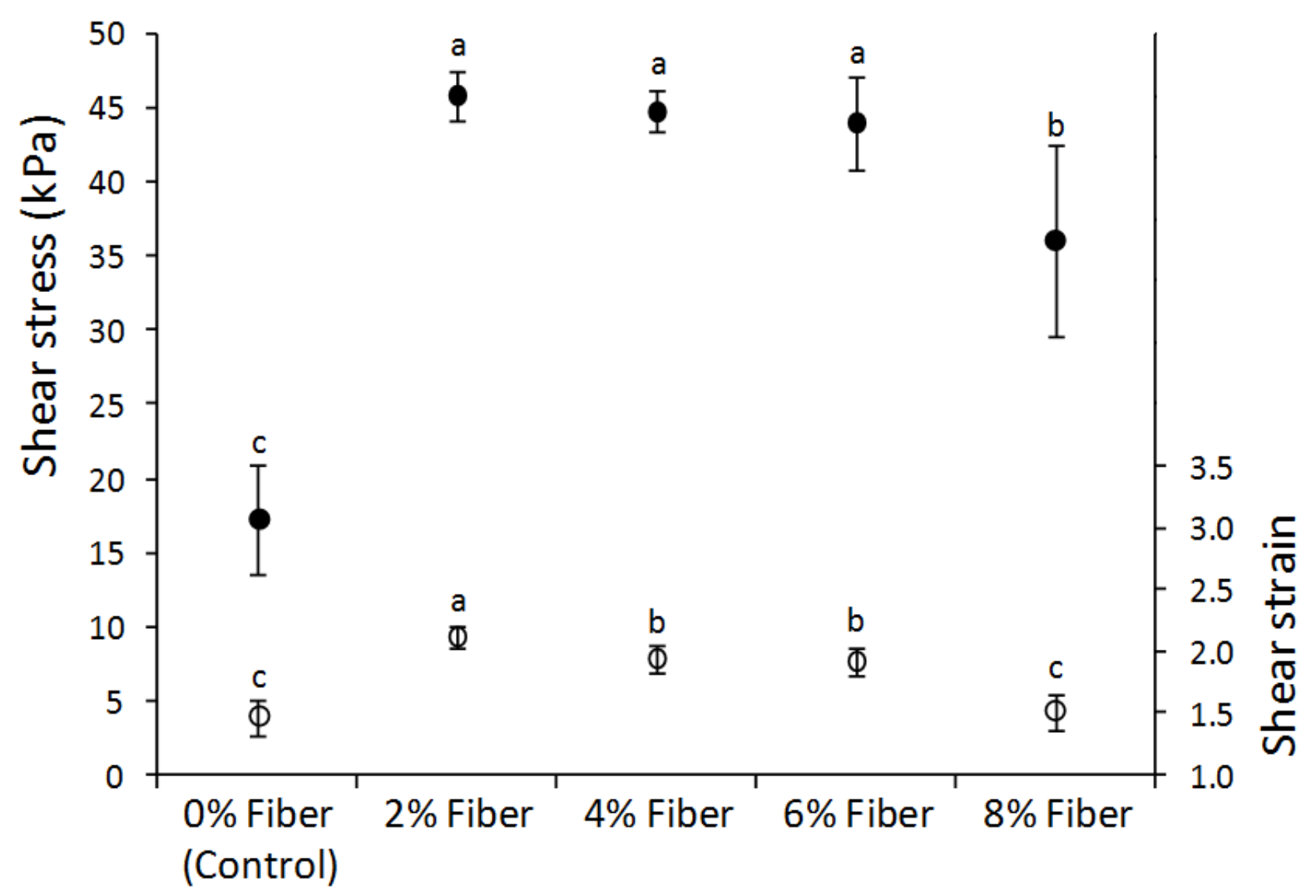

3 Figure 2. Effect of fiber on torsion shear stress and strain* at mechanical fracture of surimi gels $(\bullet-$ shear stress; $\bigcirc-$ shear strain).

4 * Data are given as mean values \pm standard deviation $(\mathrm{SD}, \mathrm{n}=3)$. Bars on data points indicate SD. Different letters on the top of SD

5 bars indicate significant differences (Fisher's Least Significant Difference test, $\mathrm{P}<0.05$ ). 

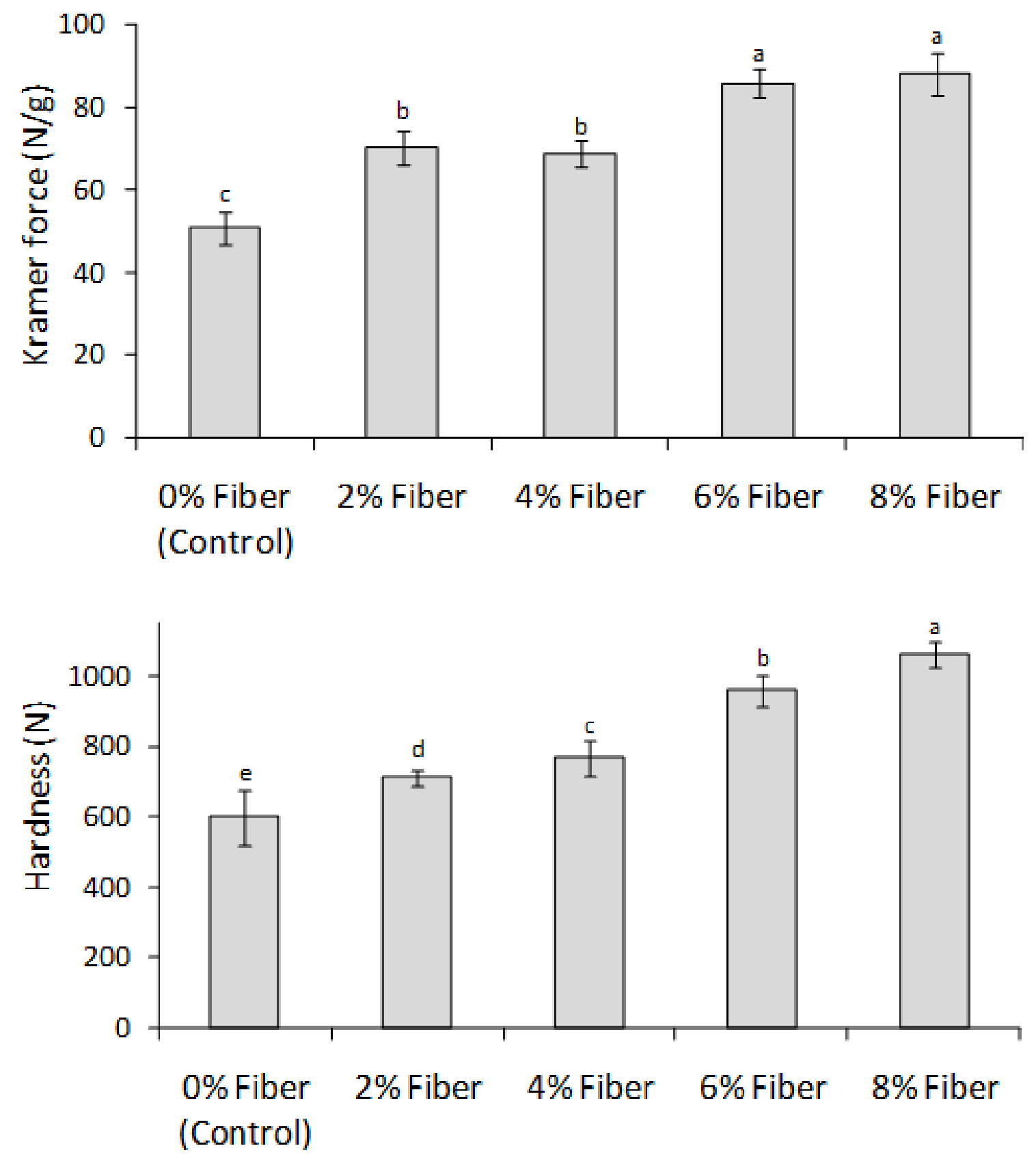

1

2 Figure 3. Effect of fiber on Kramer shear force* (top) and hardness* (bottom) of surimi gels.

$3 *$ Data are given as mean values \pm standard deviation $(\mathrm{SD}, \mathrm{n}=3)$. Small bars of the top of data

4 bars indicate SD. Different letters on the top of SD bars indicate significant differences (Fisher's

5 Least Significant Difference, $\mathrm{P}<0.05)$ between mean values. 

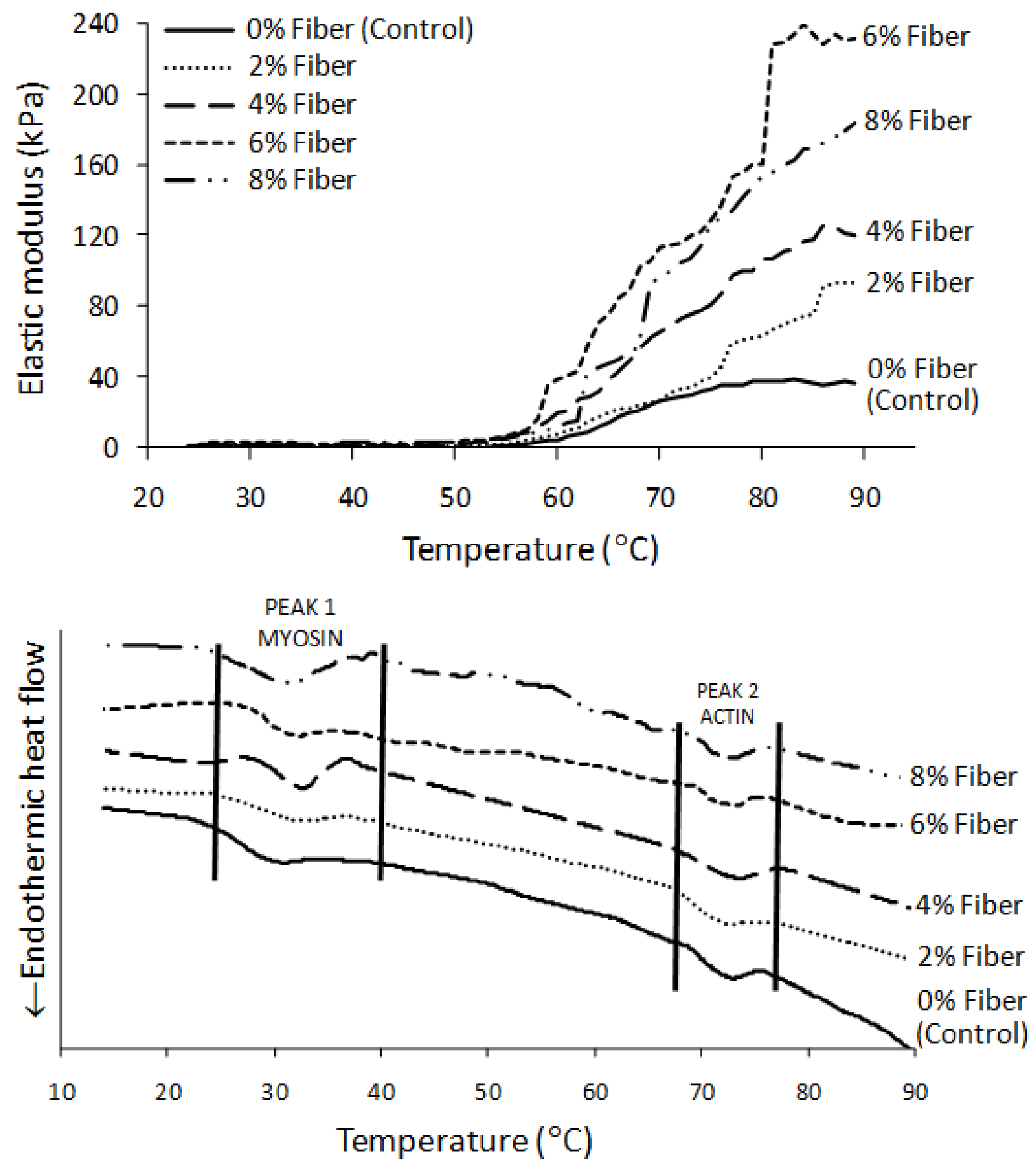

Figure 4. Average $(n=3)$ elastic moduli $\left(G^{\prime}\right.$, top graph) and differential scanning calorimetry (DSC) thermograms (bottom graph) of surimi pastes with different levels of added fiber. 


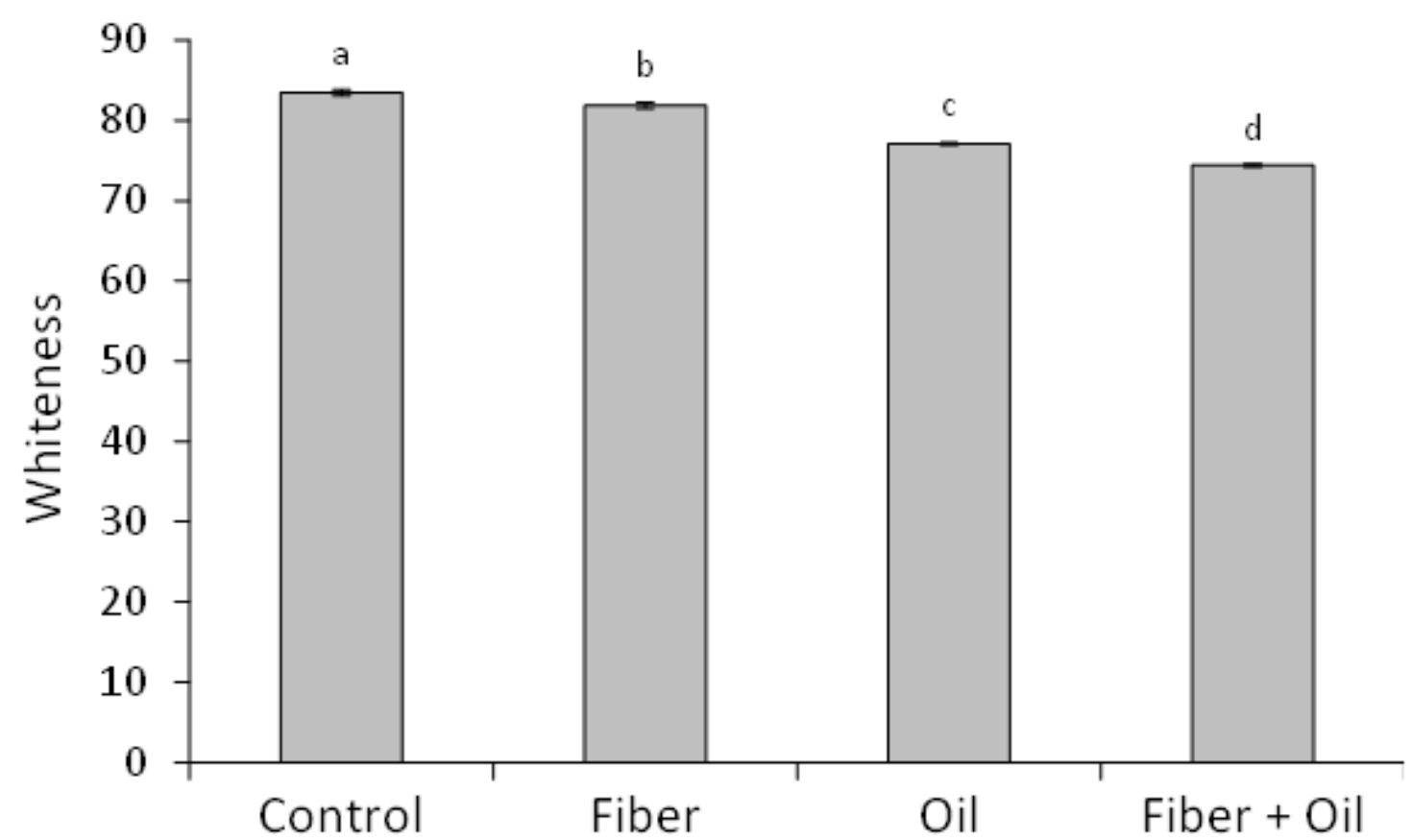

Figure 5. Effect of nutraceutical additives on whiteness values* (top) and color properties* (bottom) of surimi gels.

* Data are given as mean values \pm standard deviation $(\mathrm{SD}, \mathrm{n}=3)$. Small bars of the top of data bars in the figure (top) indicate SD. Different letters on the top of SD bars indicate significant differences (Fisher's Least Significant Difference, $\mathrm{P}<0.05$ ) between mean values. Different letters within the same row in the table (bottom) indicate significant differences (Fisher's Least Significant Difference, $\mathrm{P}<0.05)$ between mean values. 


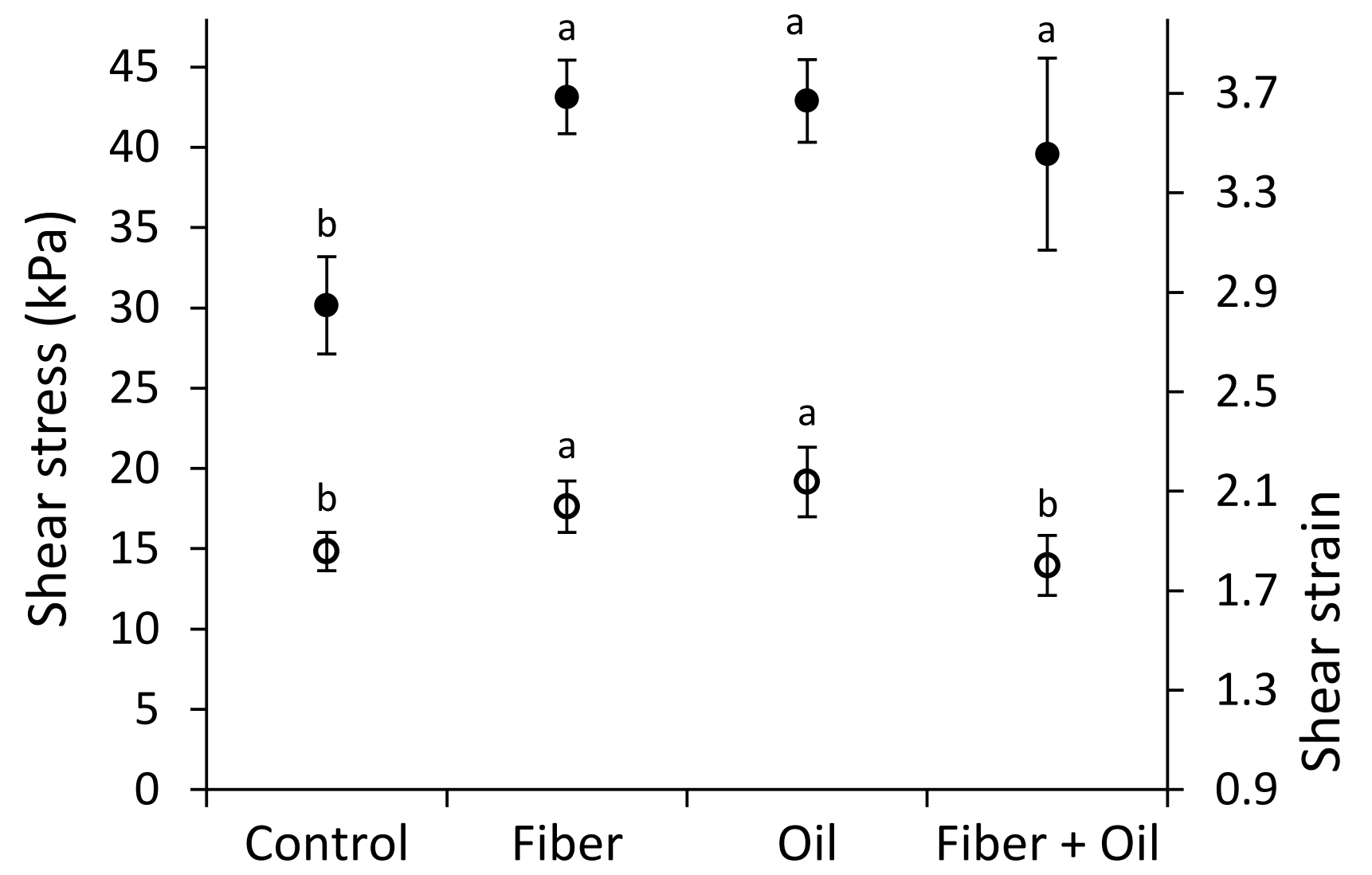

Figure 6. Effect of nutraceutical additives on torsion shear stress and strain* at mechanical fracture of surimi gels $(\bullet-$ shear stress;

$\circ$ - shear strain).

* Data are given as mean values \pm standard deviation $(\mathrm{SD}, \mathrm{n}=3)$. Bars on data points indicate SD. Different letters on the top of SD bars indicate significant differences (Fisher's Least Significant Difference test, $\mathrm{P}<0.05$ ). 

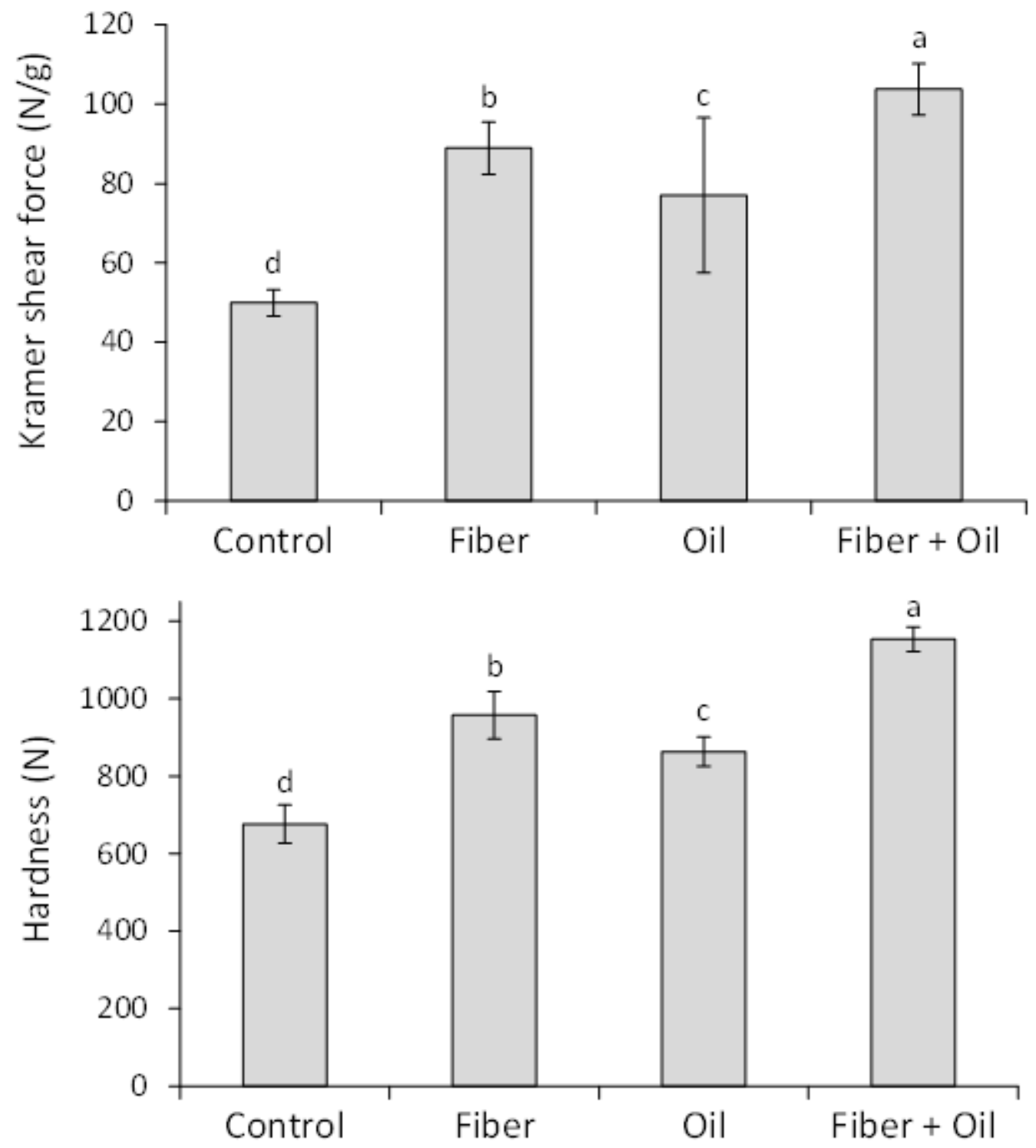

Figure 7. Effect of nutraceutical additives on Kramer shear force* (top) and hardness* (bottom) of surimi gels.

* Data are given as mean values \pm standard deviation $(\mathrm{SD}, \mathrm{n}=3)$. Small bars of the top of data bars indicate SD. Different letters on the top of SD bars indicate significant differences (Fisher's Least Significant Difference, $\mathrm{P}<0.05)$ between mean values. 


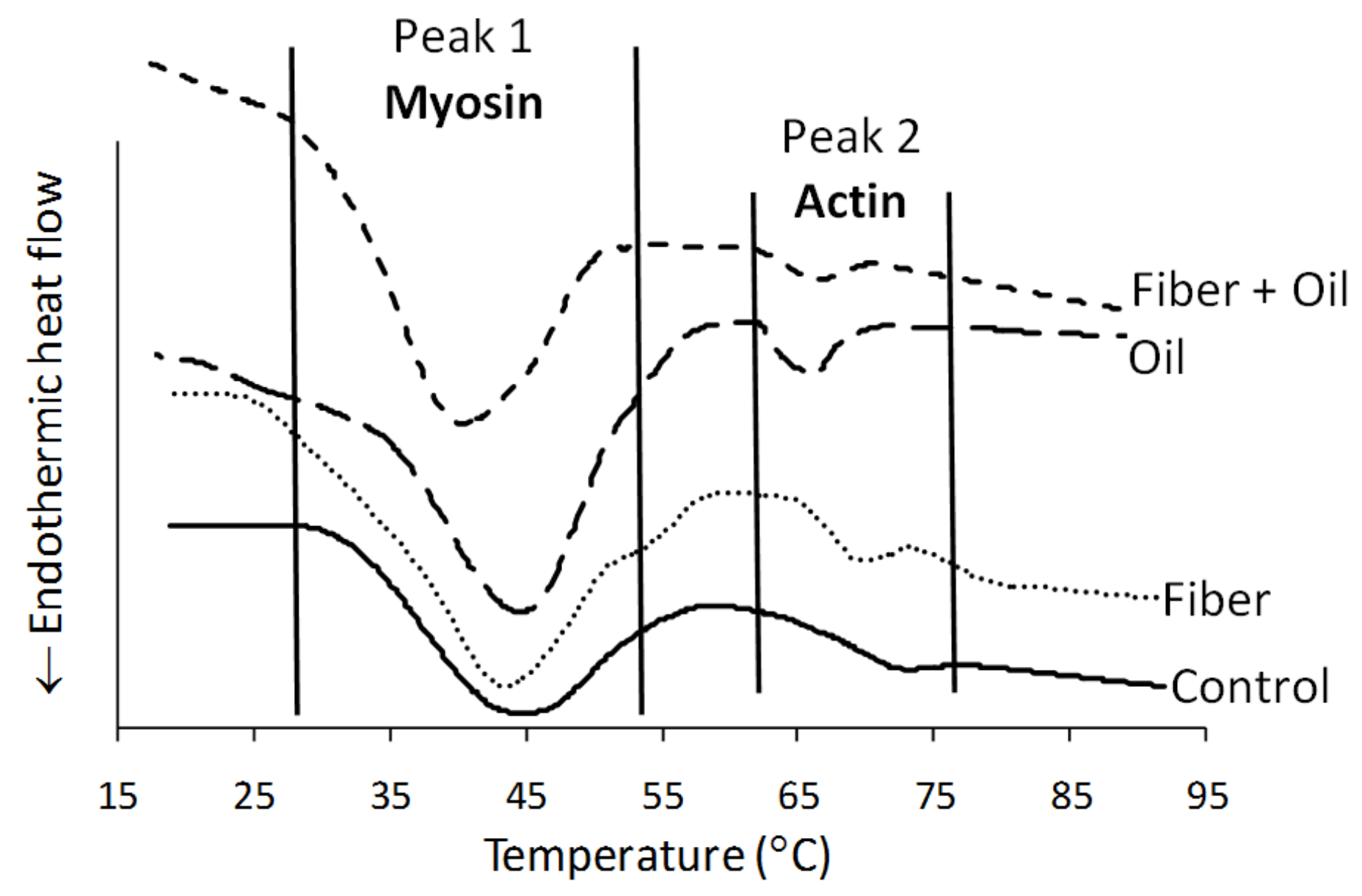

Figure 8. Average $(n=3)$ differential scanning calorimetry (DSC) thermograms of surimi pastes with added nutraceutical additives. 


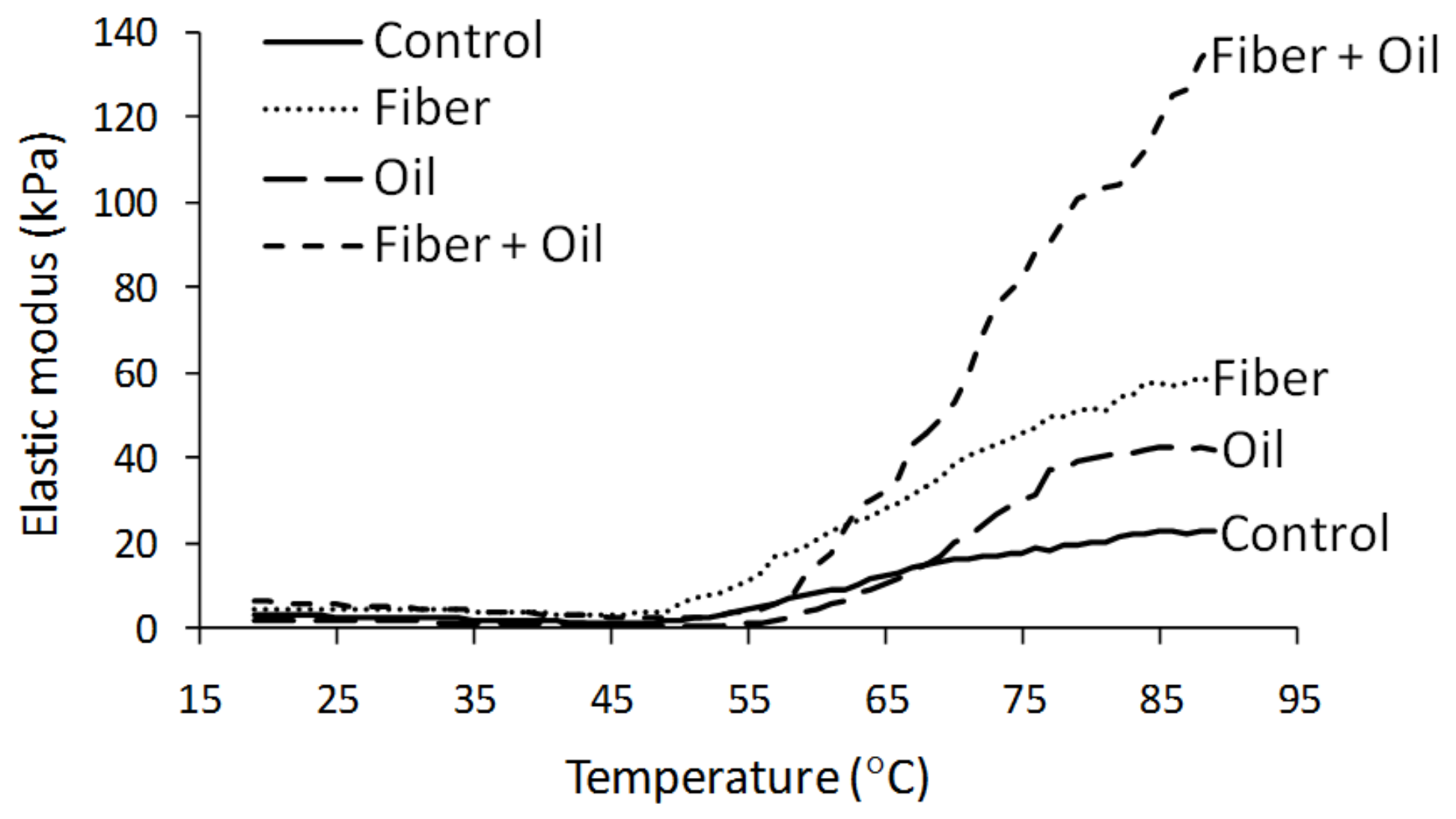

Figure 9. Average $(n=3)$ elastic moduli $\left(G^{\prime}\right)$ of surimi pastes with added nutraceutical additives. 